


\title{
Medicare and the Geography of Financial Health*
}

\author{
Paul Goldsmith-Pinkham ${ }^{\dagger} \quad$ Maxim Pinkovskiy $\quad$ Jacob Wallace ${ }^{\S}$
}

January 15,2020

\begin{abstract}
We use a five percent sample of Americans' credit bureau data to study the effects of public health insurance on the geography of consumer financial health. Exploiting the (nearly) universal eligibility for Medicare at age 65, we find a 30 percent reduction in debt collections with limited effects on other financial outcomes. Medicare reduces the geographic variation in collections by two-thirds at age 65, and halves the geographic correlation between collections and demographics like race and education. Areas that experienced larger gains in financial health at age 65 had higher shares of black residents, people with disabilities, and for-profit hospitals.
\end{abstract}

\footnotetext{
*First version: April 22, 2017. This version: January 15, 2020. The views expressed are those of the authors and do not necessarily reflect those of the Federal Reserve Bank of New York or the Federal Reserve System. We thank Chima Ndumele, Mark Schlesinger, Julia Smith, Isaac Sorkin, Eric Zwick, Trevor Gallen, and seminar members at the Yale SOM Finance Lunch, Association for Public Policy Analysis and Management, Gerzensee European Summer Symposium in Financial Markets, NTA Annual Conference on Taxation, and Salomon Center/BPI Conference on Household Finance, for helpful comments. Joseph Doran, Danno Lemu, Davy Perlman, and Lauren Thomas provided excellent research assistance.

${ }^{\dagger}$ Yale School of Management. Email: paul.goldsmith-pinkham@yale.edu

†Federal Reserve Bank of New York. Email: maxim.pinkovskiy@ny.frb.org

§Yale School of Public Health. Email: jacob.wallace@yale.edu
} 


\section{Introduction}

Why does consumer financial strain vary so much across the United States? In this paper, we examine the role health insurance plays in shaping the geography of financial health. To do this, we use a five percent sample of Americans' credit report data, combined with a regression discontinuity (RD) approach, to estimate the effect of universal health insurance at age 65-when most Americans become eligible for Medicare-separately for each commuting zone in the United States.

We use our place-based estimates of Medicare's causal effects for three purposes. First, we show that Medicare reduces geographic variation in debt collections by two-thirds at age 65. Second, we show that the gains in financial health due to Medicare are greatest in the South (e.g., Mississippi) where, in addition to a greater share of uninsured, the financial health improvements per newly-insured individual are also the highest. We show that these commuting zones experiencing the largest gains at age 65 had larger shares of black residents, people with disabilities, and for-profit hospitals. Third, we construct forecasts of the causal effect of expanding coverage to the near-elderly in each commuting zone in the United States, which we use to evaluate existing policies and can serve as a guide for future expansions.

We start by presenting estimates at the national level, allowing for a transparent discussion of our identification and comparison to prior work. We document a sharp reduction of 8 percent in the uninsurance rate at age 65 , which falls from a pre-65 mean of 11 percent to approximately 3 percent. ${ }^{1}$ Coinciding with the change in health insurance coverage at 65 , we estimate a 30 dollar reduction in collection debts, validating a causal link between health insurance and financial strain. Our estimates imply that Medicare reduces outstanding debts in collection by 120 million dollars each year for its cohort of new enrollees. The reductions in collections debt are concentrated in the right tail, with large reductions (30-40 percent) in the share of individuals with the highest level of debt in collections (e.g., over 10,000 dollars). In contrast with the effects on collections debt, we generally find statistically insignificant effects for other measures of financial strain, including delinquent debt, bankruptcy, and credit score.

Having documented the sharp change in financial health at age 65 at the national level, we

\footnotetext{
${ }^{1}$ In order to qualify for Medicare, an individual or their spouse must have worked and paid Medicare taxes for at least 10 years.
} 
then estimate Medicare's causal effect for each commuting zone in the country. We first use these estimates to quantify how much Medicare reduces the geographic disparities in consumer financial strain. Using the RD design, we construct counterfactual estimates of consumer financial strain at age 65, with and without Medicare, for each commuting zone. We show that Medicare reduces the geographic variation in collections by two-thirds at age 65, and halves the cross-sectional correlation between collections debt and area-level demographics like race and education. These findings highlight an understudied aspect of the Medicare program - that it largely eliminates geographic disparities in access to insurance (geographic variation in uninsurance rates falls by $93.5 \%$ at age 65 ), and thus substantially reduces geographic disparities in some measures of consumer financial strain.

Second, we identify the characteristics of areas that experience the largest improvements in financial health at age 65 . We begin by asking whether the reductions in consumer financial strain are driven by reductions in the uninsurance rate, or changes in the composition of health insurance. $^{2}$ Given that Medicare is a national policy, people living in all locations are eligible to benefit. However, it is reasonable to expect that the impact may vary depending on individual (or local) characteristics. Since we cannot directly observe health insurance status in our credit report data, we focus on the relationship between insurance coverage and financial health at the locality-level. We find that the largest (smallest) reductions in collections debt are concentrated in areas that experienced the largest (smallest) increases in the insurance rate at age 65, suggesting that the gains in financial health are driven by reducing the number of uninsured, rather than changes in the composition of coverage. Our results imply a reduction in collection balances of $\$ 675$ for each individual that gains coverage from Medicare at age 65, which falls within the range of estimates from prior work on the effects of Medicaid coverage (Finkelstein et al., 2012; Hu et al., 2018).

While the main effects of Medicare on financial health are driven by reducing the share of uninsured, the gains at age 65 are not the same for the uninsured in all locations. To examine how the financial health improvements from Medicare for the uninsured vary by area, we estimate CZ-level reductions in collections per newly-insured individual by scaling the change in financial health estimates by the estimated effect of Medicare on insurance rates. This allows us to sepa-

\footnotetext{
${ }^{2}$ For individuals with no insurance prior to Medicare, turning age 65 provides a big increase in risk protection. For individuals with insurance at age 65, the transition to Medicare can lead to a change in premiums, benefits, their provider network, and the set of supply incentives providers face when treating them (Clemens and Gottlieb (2017)).
} 
rately examine the extensive margin - locations with large changes in the number of uninsured — and the intensive margin — locations with large effects per newly-insured individual. ${ }^{3}$ We then examine the demographic and healthcare market characteristics associated with these estimated reductions in financial strain per newly-insured individual at age 65.

We find that the uninsured experience larger gains in financial health due to Medicare eligibility at age 65 in areas with larger shares of black residents, people with disabilities, and for-profit hospitals. This last fact is consistent with observational evidence that for-profit hospitals offer less charity care than not-for-profit hospitals ( e.g., Horwitz, 2005; Schlesinger and Gray, 2006; Valdovinos, Le and Hsia, 2015), and that hospitals in markets with a higher share of for-profits respond to competition by reducing charity care and trying to avoid the uninsured (Frank, Salkever and Mitchell, 1990). ${ }^{4}$ The positive correlation with the share of people with disabilities may reflect these residents' greater healthcare needs. The relationship with the share of black residents is also strikingly consistent with evidence on racial disparities in access to treatment (Nelson, 2002). ${ }^{5}$

Third, we construct forecasts of the causal effect of expanding (nearly) universal health insurance on financial health in each commuting zone. These can be used to guide policymakers and evaluate the targeting of existing policies. Ideally, each forecast would be the unbiased causal estimate for the location from our RD design. However, in many locations, the near-elderly population is small and the estimates are noisy. To reduce noise, we follow Chetty and Hendren (2018) and construct forecasts using a shrinkage estimator that combines our unbiased RD estimates and a predicted effect for each commuting zone based on its demographic and healthcare market characteristics. This predicted effect is estimated using Lasso and a large number of location characteristics (Tibshirani, 1996), and then combined with our unbiased (but noisy) RD estimates to construct the mean-square-error (MSE) minimizing linear forecast. ${ }^{6}$

The largest forecast reductions in collections debt are concentrated in the South. Among the 50

\footnotetext{
${ }^{3}$ While our analysis suggests that the primary mechanism through which Medicare affects financial strain is by reducing the uninsurance rate, it is unlikely that the exclusion restriction holds. As a result, we view this as an informative scaling exercise rather than a well-identified IV.

${ }^{4}$ However, recent work by Capps, Carlton and David (2017) examines whether not-for-profit hospitals increase the provision of charity care more in response to market power than for-profits and find no difference between the two.

${ }^{5}$ Given the relative uniformity of the Medicare health insurance environment (Finkelstein, Gentzkow and Williams, 2016), an alternative interpretation of these correlates is as predictors of the effect of being uninsured on consumer financial strain, rather than simply correlates of heterogeneity in the reduction in collections debt per newly-insured at age 65.

${ }^{6}$ This approach follows several recent papers combining unbiased causal estimates with observational data, including Chetty and Hendren (2018) and Angrist et al. (2017).
} 
most populated commuting zones (based on the near-elderly) in the United States, a coverage expansion to the near-elderly in Raleigh, NC, is forecast to reduce collections balances by 48 dollars per capita, one of the largest forecast improvements among the top $50 \mathrm{CZs}$. In contrast, a coverage expansion to the near-elderly in San Francisco, CA, is only forecast to reduce collections balances by 8 dollars per capita. This is not simply because there are a greater number of uninsured in Raleigh; in fact, the near-elderly uninsurance rates in the two places are similar. ${ }^{7}$ The differences in the forecasts arise primarily due to large differences in the forecast reductions in collections balances per newly-insured individual in the two locations. In Raleigh, NC, the forecast reduction in collections balances was $\$ 761$ per newly-insured individual, 345\% higher than the analogous forecast in San Francisco, CA.

Lastly, we examine how CZ-level forecasts changed due to the passage of the Affordable Care Act in 2010, a national health reform that substantially expanded coverage (e.g., Frean, Gruber and Sommers, 2017). We find that forecasts of the causal effect of expanding coverage on financial health remain large even after the ACA's implementation in 2014. But, they have become more geographically-concentrated in the "Deep South" region that comprises Louisiana, Alabama, Mississippi, Georgia, and South Carolina (as well as parts of Texas and Florida). Our data provide two insights into why this is the case. First, the near-elderly uninsured have become increasingly concentrated in the South. This is a result of the geographically diffuse coverage gains associated with the ACA, which increased existing geographic disparities in coverage. Second, the forecast reductions in collections debt per newly-insured individual are largest in the South (before and after the ACA), compounding the growing disparity in coverage.

While regression discontinuity has been used to study the effects of Medicare, in this paper we are identifying 741 separate treatment effects, one for each commuting zone (CZ) in the country. This requires a stronger assumption than prior work in this literature-namely that other factors (e.g., employment, income, etc.) do not also change at age 65 in any of the CZs. We replicate the same covariate smoothness tests done at the national level for each location, and find no evidence of large changes in other covariates at 65 in any of the CZs.

Our research design has three key limitations. First, our results provide average treatment

\footnotetext{
${ }^{7}$ The near-elderly uninsurance rates in Raleigh, NC and San Francisco, CA during the period 2014-2017 were 6.5 and 5.9 percent, respectively.
} 
effects for individuals near the age 65 eligibility threshold for Medicare. Second, and related, the RD design is well-suited to estimate the short-run effects of Medicare, but will underestimate its effect for financial health measures that respond with a lag to a change in health insurance status. Third, we are limited to the measures of consumer financial strain that are available in credit report data and unable to measure any stress reduction associated with improvements in financial health (Baicker et al., 2013).

This paper makes three primary contributions. First, we contribute to a small, but growing, literature that examines the financial risk protection provided by Medicare to elderly Americans (Finkelstein and McKnight, 2008; Engelhardt and Gruber, 2011; Barcellos and Jacobson, 2015; Caswell and Goddeeris, 2019) and a broader literature on the risk protection provided by health insurance, which includes studies that examine the effects of Medicaid expansions (Gross and Notowidigdo, 2011; Allen et al., 2017; Brevoort, Grodzicki and Hackmann, 2017; Hu et al., 2018; Allen et al., 2019), the Oregon Health Insurance Experiment (Finkelstein et al., 2012), and the Massachusetts health reform (Mazumder and Miller, 2016). ${ }^{8}$ We contribute to this literature in two ways. First, we examine the effect of Medicare at age 65 on a broad set of financial health outcomes from administrative credit report data. These results expand the outcomes of Caswell and Goddeeris (2019) beyond just debt collections, and highlight that financial health benefits of Medicare are concentrated in debt collections, with limited effects for other consumer credit outcomes. Second, we exploit our place-based estimates of Medicare's causal effect to explore the effects of Medicare on the extensive margin (changes in insurance rates) and intensive margin (changes in financial health per newly-insured individual).

Second, our work contributes to a growing literature on the geography of health and economic opportunity. Prior work has documented the important role that geography plays in economic opportunity (Chetty et al., 2014), healthcare utilization and spending (Finkelstein, Gentzkow and Williams, 2016; Cooper et al., 2018), and mortality (Finkelstein, Gentzkow and Williams, 2019). Recent work has also documented the fact that financial strain is highly concentrated geographically (Keys, Mahoney and Yang, 2019), but evidence from movers analyses has yielded inconclusive results about the effects of geography on consumer financial strain (Miller and Soo, 2018; Keys,

\footnotetext{
${ }^{8}$ Collectively, the studies document reductions in the reported difficulty of paying medical bills, debt past due, debt in collections, payday borrowing, evictions, and consumer bankruptcy, as well as improvements in consumer credit scores associated with gains in health insurance coverage.
} 
Mahoney and Yang, 2019). We contribute to this literature by using nearly universal eligibility for Medicare to examine the role health insurance plays in shaping the geography of financial health. We find that Medicare reduces the geographic variation in collections by two-thirds at age 65, and halves the geographic correlation between collections debt and demographics like race and education.

Third, we use our place-based estimates to investigate the incidence of Medicare. At $\$ 750$ billion in annual spending (and growing), Medicare's incidence as one of the largest public programs is of first-order policy importance. McClellan and Skinner (2006) find that the distributional consequences of Medicare are roughly neutral while Bhattacharya and Lakdawalla (2006) find that Medicare is highly progressive. We show that the gains in financial health due to Medicare are greatest in the South (and particularly the Deep South) where, in addition to there being a greater number of the uninsured, the financial health improvements per newly-insured person are the greatest.

The paper proceeds as follows. Section 2 describes the data we use in the paper. Section 3 outlines the regression discontinuity design and describes our national level RD results. Section 4 presents location-specific RD results and examines how Medicare reshapes geographic disparities in financial health. Section 5 presents the characteristics of areas that experienced the largest improvements in financial health due to Medicare. Section 6 presents forecasts of the effects of a (nearly) universal coverage expansion to the near-elderly (e.g., lowering the Medicare eligibility age) and discusses how the ACA has changed the forecast. Section 7 concludes.

\section{Study data}

\subsection{Financial outcomes data}

The main dataset used in our analysis is the Federal Reserve Bank of New York's Equifax Consumer Credit Panel (CCP). The CCP is a five percent random sample of all individuals in the U.S. with credit reports. ${ }^{9}$ Like other credit report data, the CCP data are derived from public records, collections agencies, and trade lines data from lending institutions. The data include a comprehensive set of consumer credit outcomes, including information on credit scores (originating from

\footnotetext{
${ }^{9}$ Lee and Van der Klaauw (2010) show that the CCP is reasonably representative of the U.S. population with the possible exception of very young adults, suggesting that sample representativeness should not be a concern in our application.
} 
Equifax Risk Score 3.0), unsecured credit lines, auto loans, and mortgages. The data also include year of birth and precise geographic location at the census block level. No other demographic information is available at the individual level. The CCP data are available quarterly from 1999 to the present. See Avery et al. (2003) and Lee and Van der Klaauw (2010) for additional details.

A major virtue of the CCP is its large sample size, which allows us to measure financial outcomes at granular geographic levels with precision. This is key to our RD estimation strategy across geographies, where we estimate the effect of Medicare separately for each of the 741 commuting zones in the country (as well as the 50 states). For our analyses, we use the data in localityby-age-by-year cells, weighted by the underlying population in each cell. Since we only observe birth year, and the data is quarterly, age is measured with noise. For example, all individuals with birth year 1940 are measured as age 65 in 2005q1, while in reality some of these individuals will turn 65 later in the year. We address this using a "donut" RD procedure which we discuss in more detail in Section 3.

The financial health variables that we focus on from the CCP are the size and number of accounts sent to collection agencies (usually, these are accounts that have been delinquent for over 90 days), the size and number of accounts that are delinquent, the Equifax Risk Score, as well as additional financial health outcomes (e.g., bankruptcy). Refer to Appendix Table A1 for the definitions of each of the financial health outcomes we use from the CCP.

\subsection{Demographic and health insurance data}

For demographic and health insurance information, we draw on the American Community Survey (Ruggles et al., 2019). An advantage of the American Community Survey (ACS) is that the data are available at the Public Use Microdata Area (PUMA)-by-age-by-year level for our study period (2008-2017). The ACS data can also be aggregated at the state level. Unlike the CCP, the ACS data is not also available at more granular levels such as the county-by-age-by-year level. As a result, all analyses use samples constructed from the PUMA and state datasets, linked to the Commuting Zone- and state-level to permit comparison of the two sets of outcomes. ${ }^{10}$

Demographic data. We construct demographic variables from the ACS at the PUMA-by-ageby-year level to test for covariate smoothness in validating our RD design and to examine the

\footnotetext{
${ }^{10}$ Our cross-walk from PUMA to Commuting Zones uses David Dorn's crosswalks, available here: https : / / www . ddorn. net/data.htm.
} 
correlates of geographic heterogeneity in our treatment effects. From the ACS, we measure the homeownership rate, family size, sex, marital status, race, educational attainment, employment status, usual hours worked per week, total personal income, social security income, poverty status, and disability rate.

Health insurance data. The ACS also allows us to construct health insurance variables from the ACS at the PUMA-by-age-by-year level to test for changes in health insurance at age 65 and to examine the correlates of geographic heterogeneity in our treatment effects. From the ACS, we measure the share of individuals in each cell with any health insurance coverage, private health insurance coverage, health insurance through employer/union, health insurance purchased directly, health insurance through Medicaid, health insurance through VA, health insurance through Indian Health Services. From this data, we also constructed an indicator for whether an individual had multiple sources of coverage and used that to measure the share of individuals in each cell with more than one source of coverage.

\subsection{Additional area-level characteristics data}

In addition to the CCP and ACS data, we constructed additional characteristics at the PUMA-level. These characteristics are drawn from several places, including the Healthcare Cost Report Information System (HCRIS) and the Dartmouth Atlas. From the HCRIS data, we construct PUMAlevel measures of the share of hospital patient days at for-profit hospitals, teaching hospitals, and public hospitals. We also measure the average hospital occupancy rate at the PUMA-level and the hospital beds per capita. In addition, for the period 2010-2017 we measure PUMA-level reported charity care costs per patient day and payments recovered by hospitals from charity care patients by patient day. From the Darthmouth Atlas data, we measure the PUMA-level risk-adjusted Medicare spending per enrollee (Dartmouth Institute, 2019).

\section{The Effect of Medicare on Financial Health}

In this section, we describe our main empirical methodology for estimating the overall effect of Medicare. We then report the effect on different health insurance outcomes, and on our various financial health outcomes. Finally, we report results of several robustness tests. 


\subsection{Empirical strategy}

Estimating the causal effect of health insurance on financial outcomes is difficult, because uninsured individuals tend to also have high rates of poverty and other factors correlated with financial distress. Consider a model that relates financial health outcomes, such as debt collections, to health insurance status for individual $i$ :

$$
y_{i}=\alpha+\beta \text { HealthInsurance }{ }_{i}+\epsilon_{i}
$$

where $y_{i}$ is the average dollar value of debt in collections, Insurance ${ }_{i}$ is the share of individuals with health insurance, and $\epsilon_{i}$ is noise.

In Figure 1, we consider the naive version of this relationship at the state-level for adults between the ages of 55-64. In each panel, we plot the relationship between different financial health measures as the $y$ variable and the uninsurance rate as the explanatory variable. Estimates of Equation 1 using the data in Figure 1 imply a $\beta$ of almost $-1,400$ dollars for debt collections, -0.24 percentage points for bankruptcy, -0.18 percentage points for the share of debt past due, and 311 points for credit scores. This implies, for example, that health insurance coverage decreases the amount of debt collections by 1,400 dollars on average. However, this estimate is likely to be biased, as health insurance coverage status is correlated with unobservable determinants of the outcome; formally, $E\left[\epsilon_{i}\right.$ Insurance $\left._{i}\right] \neq 0$. For example, states with high uninsurance rates likely have high rates of poverty, which are also associated with financial strain.

To address this omitted variable bias, we indirectly estimate the causal impact of health insurance status on financial health using a regression discontinuity (RD) design that takes advantage of the sharp change in eligibility for Medicare coverage at age 65. We compare individuals just above and below the age 65 eligibility threshold under the assumption that individuals around the discontinuity are similar on observable and unobservable characteristics. Under this assumption, any discontinuities in financial health around age 65 can be attributed to the change in coverage as individuals age onto Medicare. ${ }^{11}$ This research design has been used to study the impact of

\footnotetext{
${ }^{11}$ Since there are individuals at age 64 with and without coverage, and with different benefit designs and plan structures, the treatment we're studying is a weighted average of the effect of the transition to Medicare for those who were previously uninsured and those with different forms of coverage at age 64. Later, we exploit geographic variation in the distribution of the uninsurance rate to explore how our effects vary based on the impact of Medicare on uninsurance.
} 
Medicare on healthcare use, spending, mortality, and a limited set of financial health measures (e.g. Card, Dobkin and Maestas (2008, 2009); Wallace and Song (2016); Barcellos and Jacobson (2015); Caswell and Goddeeris (2019)).

Our main regression discontinuity analyses involve estimating equations of the form:

$$
y_{i, l, t}(\text { age })=\underbrace{\gamma \times 1(\text { age }>65)}_{\text {Medicare }}+\underbrace{f(\text { age }) \times 1(\text { age } \leq 65)+g(\text { age }) \times 1(\text { age }>65)}_{\text {local linear effect of age }}+\epsilon_{i, l, t}(\text { age }) .
$$

where $y_{i, l, t}($ age $)$ is a measure of financial health for individuals $i$ in location $l$ in time period $t$ of a given age. To control for the effect of age on financial health, $f$ (age) and $g$ (age) are smooth functions representing the age profile of $y_{i, l, t}$ for those below the age of 65 and those above the age of 65 , respectively. The coefficient of interest is $\gamma$, which measures the change in financial strain at age 65. The $\epsilon_{i, l, t}$ term captures other omitted factors that may drive differences in financial health across locations, time and age. We estimate the effects using data collapsed to location-age or location-age-year cells, but weighted using underlying population values in each cell to reflect individual level responses to the Medicare policy.

A benefit of the regression discontinuity design is that we can easily visualize the treatment effect using graphical methods. For each of our main results, we present the averages of $y_{i l t}($ age $)$ for each value of age. Additionally, we use our estimated functions, $\hat{f}($ age $)$ and $\hat{g}($ age $)$ to predict the estimated value of $y$ at age 65, both with and without Medicare. This effectively presents the two average counterfactual cases necessary for estimation of $\gamma$ : outcomes for individuals are not eligible for Medicare and those who are, holding age fixed.

The exact estimation of Equation 2 is complicated by two features of our data: first, our running variable, age, is measured in discrete year increments in our sample; second, because we only observe birth year in the CCP data, we measure age with noise. ${ }^{12}$ The discreteness of the data causes difficulties in both the estimation of $f(\cdot), g(\cdot)$ and $\gamma$, as well as inference about these parameters. Additionally, the error in our measurement of age 65 forces us to omit age 65 in our estimation procedure, and use a "donut" RD. ${ }^{13}$ To account for both issues, we follow the "honest"

\footnotetext{
${ }^{12}$ To see this, consider an individual born in 1954. In 2019, they can be either age 64 or 65 . As a result, our data will combine both Medicare-treated and non-treated individuals at age 65.

${ }^{13}$ This approach is common in many RD settings where the treatment timing is noisily measured (see for e.g., Barreca et al. (2011)).
} 
confidence intervals approach outlined in Kolesár and Rothe (2018), and Armstrong and Kolesár $(2018 b, a)$. This method requires an additional tuning parameter, $K$, which imposes an upper bound on the absolute value of the second derivative of the conditional expectation function. Intuitively, this method places a bound on how quickly the functions $f(\cdot)$ and $g(\cdot)$ can change. ${ }^{14}$ Similar to robustness exercises with bandwidths in previous RD methods, we present additional robustness tests which vary the value of $K$. In all cases for our estimation, we report four numbers: our point estimate, the estimated standard error, and the bias-adjusted confidence interval.

The key identifying assumption for our approach is that non-Medicare characteristics that affect outcomes do not jump discontinuously at age 65. For example, many individuals tend to retire in their early to mid-60s, which spurs substantial changes to income and work patterns, and may also affect their choices on where and with whom to live. While prior studies that use this identification strategy have not found evidence of discontinuous changes in other covariates at age 65, we re-examine this question using a rich set of outcomes from the American Community Survey.

We report our formal estimates of potential discontinuities at age 65 in Panel A of Table 1. In the first column, we report the average value of the outcome at age 65, without Medicare. This is based on our estimate of $f$ (age) at age $=65$. In the second column, we report the RD estimate over the full sample, including both the standard error of the estimate in parentheses and our bias-adjusted 95\% confidence interval. In the third and fourth column, we repeat the exercise, splitting the sample into states with above and below-median near-elderly uninsurance rates, as measured in the ACS in 2012. For all six outcomes, we cannot reject the null that the effect size is zero. In Appendix Figure A1, we report the graphical versions for each of these estimates. We can see that for several of the outcomes, including employment, hours worked per week and social security income, there is a strong age trend between age 60 and 70, but no obvious discrete jump in outcomes at age 65. The exception is for social security income, but the difference is not statistically significant, and the jump does not stand out from the sharply rising trend in social security income during the mid-60s. In contrast, there is little movement in overall income during

\footnotetext{
${ }^{14}$ To choose our value of $K$ for our main estimates, we follow an approach similar to the approach advocated in Imbens and Wager (2019). We take a large window to the left of the RD cutoff and fit a quadratic function of age to the data. We take the coefficient on the quadratic term (the second derivative), take the absolute value, and multiply it by four. We take this as our estimate of $K$.
} 
this period. ${ }^{15}$ Intuitively, while the early to mid-60s are a time of transition for many individuals, the precise age of 65 is no longer a focal point for retirement decisions, which smooths out the timing of other lifestyle changes in a way that does not confound them with Medicare eligibility.

\subsection{Medicare eligibility and health insurance coverage}

We first examine the effects of Medicare eligibility on various forms of health insurance coverage. In Panel B of Table 1, we report the regression discontinuity estimates of the effect of Medicare eligibility on various measures of health insurance status. In Column 1, we report the estimated mean of individuals at age 65, without Medicare, as estimated using $\hat{f}(65)$ from Equation 2 . In Column 2, we report the overall estimate using the full sample. In Columns 3 and 4, we split our sample of states by the near-elderly (age 55 to 64) uninsurance rate in 2013. In Column 3, we report the average effect for states in the bottom half of near-elderly uninsurance, and in Column 4 we report the effect for states in the top half.

The effect of Medicare eligibility on the share of individuals with any form of coverage at age 65 is large. The share of individuals with health insurance increases by 7.9 percentage points, relative to an overall insurance rate of almost 91 percent prior to Medicare. Unsurprisingly, the effect of Medicare eligibility on the share with individuals with health insurance coverage is almost twice as high in Column 4 (9.8 percentage points) compared to Column 3 (5.8 percentage points). In addition, the effect on the share of individuals with multiple forms of insurance coverage is substantial. We estimate an increase of 47.3 percent overall, with small differences between states with high and low near-elderly uninsurance rates - an increase of 50.8 and 43.9 percent, respectively. The effect is driven, as expected, through a takeup in insurance through Medicare of 72.6 percent; these effects are similar across our sample split. Finally, we find a small one percent increase in the share of individuals with Medicaid, but we cannot reject that the effect of Medicare eligibility on Medicaid at age 65 is zero, as the 95 percent confidence interval includes 0 . All other insurance estimates are large and statistically significant at the 5\% level in the main sample.

Figure 2 presents the graphical versions of these estimates, with the average value of each outcome plotted by age. In Panels A, B and C, we see the large and significant jump in the share of individuals with health insurance, multiple forms of coverage, and coverage by Medicare. In

\footnotetext{
${ }^{15}$ We report additional covariate smoothness tests in Appendix Table A2, and similarly find no statistically significant effects at age 65 .
} 
Panel D, we see a small jump in the share with Medicaid, but the discontinuity is small compared to the mean of the outcome prior to eligibility for Medicare, perhaps explaining why the estimated effect is noisier. Pre-trends in age do not appear to explain the estimates in any of the panels. ${ }^{16}$

\subsection{Medicare eligibility and financial health}

We next estimate the effect of Medicare eligibility at age 65 on financial health. We report estimates for a number of financial health outcomes in Table 2, following the same format as Table 1.

We first consider debts in collection in Panel A. In the overall sample, we estimate a drop in the amount of debts in collection of 28.55 dollars, which is roughly 30 percent of the debt collections level at age 65 without Medicare (the pre-treatment mean). This effect is statistically significant at the five percent level, with a $95 \%$ confidence interval of -17.96 to -39.14 . We estimate a similarly significant effect on the number of collections, with the average number of collections falling by about 0.02 , or roughly 15 percent of the control mean of 0.14 . However, while we estimate a drop on the extensive margin of collections of 0.5 percent ( 7 percent of the control mean), the $95 \%$ confidence interval includes zero, and we are unable to reject a zero effect. This suggests that while there is a large decline on the intensive margin in the amount and number of collections, those individuals with collections who are treated continue to have debt in collections. ${ }^{17}$

Panels B and C of Table 2 report the effects of Medicare eligibility on debts in delinquency and additional financial outcomes. While the estimated effect of Medicare on debts in delinquency is negative, the effects are not statistically distinguishable from zero. Total debt delinquency drops by 221 dollars, roughly 7 percent of the control mean; credit card delinquency drops 14 dollars, or 4.2 percent of the control mean; and mortgage delinquency drops 191 dollars, or 8.8 percent of the control mean. We can rule out drops larger than 656 dollars on total debt delinquency, 49 dollars on credit card debt delinquency, and 561 dollars on mortgage debt delinquency. ${ }^{18}$

\footnotetext{
${ }^{16}$ In Appendix Table A3, we consider the effect of Medicare eligibility on a number of additional health insurance outcomes. We find that that Medicare has a large negative effect on the share of individuals with private insurance and insurance through their employer, and a positive increase in the share of individuals with direct purchase insurance. This is consistent with individuals moving away from employer insurance, and supplementing their Medicare insurance with additional private insurance (such as Medigap coverage).

${ }^{17}$ The effects on debts in collection vary with states' level of near-elderly uninsurance, a fact we explore in more detail in subsequent sections. In the half of states with below-median uninsurance rates, we find smaller effects of Medicare, with total debts in collection falling by 16 dollars. In contrast, Medicare causes total debt in collection to fall by 40 dollars in states with above-median near-elderly uninsurance rates. The size of the drop in the number of debts and the extensive margin also varies positively with the level of near-elderly uninsurance, although only the effect on number of collections in states with below median near-elderly uninsurance is statistically significant.

${ }^{18}$ Those most susceptible to debt delinquency are also restricted in their supply of credit, which means measuring
} 
Panel C of Table 2 reports the effects of Medicare eligibility on three additional financial outcomes: the Equifax Risk Score 3.0 (the CCP's version of credit scores), foreclosure rates, and bankruptcy rates. We find no economically or statistically significant effects on the Equifax Risk Score measure - we can rule out an increase greater than 3.9 points with $95 \%$ confidence. We find similarly insignificant effects in other measures: the decline in foreclosure rates is 0.005 percentage points ( 9 percent of the control mean) and the decline in bankruptcy rates is 0.004 percentage points (4 percent of the control mean). For bankruptcy rates, we can rule out declines of 0.014 percentage points with $95 \%$ confidence.

Figure 3 plots the average value across age in years for four measures of financial strain: (i) debt collection balance; (ii) probability of bankruptcy; (iii) total delinquent debt; and (iv) credit score, measured using the Equifax Risk Score. For each of the four measures, the age profiles are consistent with improvement in the measure as individuals get older. This is consistent with the literature on the lifecycle of financial strain (Brown et al., 2016). The large and significant drop in debts in collections is clear in Panel A of Figure 3, with a sharp discontinuity in the amount new debts in collections. In contrast, in Panels B, C, and D, there are no obvious discontinuities. For total debts past due, there does appear to be a drop, but as we confirmed in Panel B of Table 2, this drop is not statistically distinguishable from zero. ${ }^{19}$

Given evidence of a large reduction in average collections debt at 65 , we then examine whether this drop was concentrated in the upper end of the distribution, as would be predicted by prior evidence of Medicare's risk protection against large out-of-pocket spending (Finkelstein and McKnight, 2008; Barcellos and Jacobson, 2015). We estimate distributional impacts for three measures: amount of debt in collections, total amount of debt in delinquency, and amount of credit card debt in delinquency. For all three of these cases, we would expect that large out-of-pocket expenses would cause increases in the right tail of the distribution. To examine this, we calculate the share of the population in a county-year-age bin that has amounts in the following bins: 1-500, 501-1,000, $1,001-2,500,2,501-5,000,5,001-10,000$, and greater than 10,000 dollars. The residual category is any

the effect of Medicare on the level of delinquency could be of limited effectiveness. We also estimate the effect on delinquency as a share of total debt, where we scale each of our three delinquency measures by the average balance of borrowers of the same age-state-year bin. We use this average because some individuals have zero borrowing, which would cause this ratio to be undefined at the individual level. Across all three scaled measures, we find similarly small and statistically insignificant effects.

${ }^{19}$ We report additional figures for other outcomes from Table 2 in Appendix Figure A2. 
person with 0 dollars. We use the share within a given bin as the outcome variable in our main specification, so that our estimate is the change in the relative share of individuals within each bin due to Medicare eligibility. ${ }^{20}$

We summarize the set of estimates for collections debt in Figure 4, and include the underlying regression discontinuity graphs in Appendix Figure A3. Figure 4 plots the discontinuities at age 65 in terms of the raw shares of individuals in each bin of the collections distribution (first graph) and in terms of these shares scaled by the size of each bin for individuals at age 65 (prior to Medicare). The first panel shows that there is a modest, discontinuous increase in the share of individuals without collections at age 65 (about half a percentage point), and discontinuous decreases in the share of individuals in every bin of the distribution with collections. The second panel shows that there are larger proportional declines in the share of individuals with large amounts in collections than the share individuals with small amounts in collections, with a $40 \%$ decline in the frequency of collections over $\$ 10,000$ compared to a $10 \%$ decline in the frequency of collections between $\$ 500$ and $\$ 1,000$. A decline in especially large collections balances is consistent with evidence that Medicare curbs the upper tail of medical spending (Finkelstein and McKnight, 2008), and corroborates findings in Caswell and Goddeeris (2019). ${ }^{21}$

In Appendix A we examine how the Affordable Care Act (ACA) has reshaped the effects of Medicare eligibility at age 65, showing that the ACA roughly halved Medicare's effect on the uninsurance rate at age 65 (by covering the near-elderly) but only led to a small reduction in the discontinuity in collections debt at age 65, a point we return to in Section 6.

\subsection{Robustness}

In this section, we show that our results are robust to alternative specifications and bandwidths. As discussed in Section 3.1, our empirical methodology requires two tuning parameters: the band-

\footnotetext{
${ }^{20}$ An alternative approach would be to directly estimate quantile treatment effects using regression discontinuity, such as those proposed in Frandsen, Frölich and Melly (2012). However, we are not able to easily account for the discrete running variable in our estimation process using quantile treatment effects. As a result, we focus on our sharebased approach.

${ }^{21}$ We also examine these distributional impacts for total debt in delinquencies and credit card debt in delinquencies. We report the estimates across the distribution, as well as the underlying discontinuity graphs, in Appendix Figures A4, A5, A6 and A7. We also report the tabular form of all three sets of outcomes in Appendix Table A4. For both total debt in delinquency and credit card debt in delinquency, we find negligible effects in the tail. For total debt in delinquency, there are no effects statistically different from zero. For credit card debt, we do find statistically significant (negative) effects on the share of individuals whose credit card debt is 5,000-10,000 dollars, suggesting that there is potential benefit in the tail risk for consumers using credit cards to insure against shocks.
} 
width (standard regression discontinuity applications) and our upper bound on the magnitude of the second derivative. In Appendix Figures A9 and A10, we present sensitivity tests for our estimates for various outcome measures to the choice of bandwidth and our upper bound. Our results are qualitatively unchanged across our choice of bandwidth and upper bound.

In Appendix Table A8, we repeat our estimates for our consumer credit outcomes, using alternative RD methodologies. We do so in four ways. First, in Column 1, we replicate our main estimate from Table 2. Second, we consider three parametric models, fitting a linear, quadratic and cubic model in age on either side of the discontinuity and estimating the jump at age 65. For inference, we use heteroskedasticity-robust standard errors. We report these estimates in Columns 2, 3 and 4. Third, we estimate the same models, but cluster on the running variable of age, as suggested in Lee and Card (2008) (and subsequently shown to have coverage issues in Kolesár and Rothe (2018)). We report these models in Columns 4, 5 and 6. Finally, we use local linear estimation using the RDRobust package from Calonico, Cattaneo and Titiunik (2015). We report this estimate in Column 8.

Our estimates are similar across various estimation methodologies. However, many outcomes do appear statistically significant when we cluster on the running variable, unlike in our main specification. This is likely due to incorrect coverage, as highlighted in Kolesár and Rothe (2018). When using heteroskedasticity-robust standard errors, there are also additional significant estimates, but fewer, and they are not consistent across various parametric forms. Our estimates are quite similar, qualitatively, to using the Calonico, Cattaneo and Titiunik (2015) method, but our preferred estimate's point estimate is larger in magnitude and the confidence interval is smaller for our collection estimates.

\section{Medicare and the geography of financial health}

How do the effects of Medicare eligibility on consumer financial strain vary by geography? In this section, we expand our estimation procedure to separately estimate the effect of Medicare on our outcomes for each location. We then use this set of estimates to quantify how much Medicare reduces geographic disparities in consumer financial strain. 


\subsection{Estimating the effect of Medicare across localities}

To estimate the effect of Medicare eligibility varies across localities, we re-estimate our main estimating equation for each location collecting a set of $\gamma_{l}$, one for each location in our sample:

$$
y_{i, l, t}(\text { age })=\gamma_{l} \times 1(\text { age }>65)+f_{l}(\text { age }) \times 1(\text { age } \leq 65)+g_{l}(\text { age }) \times 1(\text { age }>65)+\epsilon_{i, l, t}(\text { age })
$$

Our goal is to use Equation 3 to estimate the causal effects of Medicare on outcomes at two geographic levels: states and commuting zones - groups of counties representing local labor markets (David and Dorn, 2013; Dorn, Hanson et al., 2019). To do this, we directly estimate each RD regression separately, following the procedure from Section 3 in each locality. In this section, for our financial health measures, we focus on debt in collections, given the large reduction in collections at age 65 estimated in Section 3. Once again, we collapse our data to location-age-year cells, and weigh each average by the underlying population. We present locality-level estimates for additional consumer financial strain variables in the Appendix. ${ }^{22}$

Due to smaller sample sizes, each locality-level estimate is noisier than the overall effects estimated in Section 3. Intuitively, our estimates of $\gamma_{l}$ have more inherent noise and variation than the true underlying estimates of $\gamma_{l}$ due to estimation error (in part due to smaller sample sizes). To address this, we use a standard empirical Bayes approach to shrink each estimate towards the overall average of the effects. We report statistical significance based on the confidence intervals for the raw estimates, but when presenting the estimates for the different localities, and the comparisons across characteristics, we focus on the shrinkage estimates. ${ }^{23}$ These shrinkage estimates

\footnotetext{
${ }^{22}$ We face a trade-off in selecting the appropriate geographic unit for these analyses. It is reasonable to expect that the impact of Medicare may vary depending on individual or local characteristics; most obvious, perhaps, is the existing level of uninsurance among the near-elderly. States are a natural unit to consider, as many policies that affect financial health and health insurance operate at the state-level. However, since we do not observe individual characteristics (e.g., health insurance status) in our credit report data, we link to them at the area-level. While doing so at the state-level allows us to estimate the effects of Medicare relatively precisely, commuting zones (CZs) serve as better proxies for demographic characteristics (e.g., race) and allow us to incorporate measures of local healthcare market characteristics (e.g., the hospital market composition). We resolve the trade-off by focusing at the state level when presenting our primary estimates of the geographic heterogeneity in the effect of Medicare and then turn to the CZ-level to examine the effects of Medicare on geographic disparities and forecast the causal effects of health insurance.

${ }^{23}$ Formally, using states as an example, we calculate the shrinkage estimator by assuming that the $\gamma_{s} \sim \mathcal{N}\left(\gamma_{0}, \sigma^{2}\right)$. We estimate these two parameters directly. Then, using the standard errors estimated for each $\gamma_{s}, \hat{\sigma}_{s}$, and following the standard James-Stein estimator approach (Morris, 1983), we construct $B=\frac{\sigma^{2}}{\hat{\sigma}_{s}^{2}+\sigma^{2}}$, and our shrinkage estimator is $\tilde{\gamma}_{s}=B \hat{\gamma}_{s}+(1-B) \gamma_{0}$. We present an example of the shrinkage estimates compared to the raw estimates in Appendix Figures A11 and A12.
} 
are distinct from our forecasts in Section 6.

For our locality-level estimates, we require a stronger version of our identifying assumption: smoothness of covariates in each locality at age 65 . We validate this assumption by running the same tests for our covariates from Panel A of Table 1, by state and commuting zone, and presenting them in Appendix Figures A13 and A14, respectively. While we would expect to see five percent of our estimates be statistically significant at the five percent level on average, for the vast majority of our covariates, we find no statistically significant effects.

\subsection{Location-specific effects of Medicare eligibility on health insurance coverage and financial health}

For ease of presentation, we first report state-level results of the effects of Medicare eligibility on our various health insurance outcomes in Appendix Figure A15. As we would expect, in Panel A, we see that there is a large and statistically significant increase in the insurance rate for most states. Two states have insignificant effects: Vermont and North Dakota, and there is substantial variation across all the states. Unsurprisingly, the smallest effect is in Massachusetts, which is a state that enacted a health care reform in 2006 to provide near-universal coverage to state residents. The largest effect is in Texas, with an estimated increase in coverage of over 12 percentage points at age 65.

In Panels B and C, we see large increases in the share of individuals with multiple forms of coverage and Medicare as their primary coverage, respectively. Finally, in Panel D, we document variation in the effect on Medicaid, with a handful of states experiencing discontinuous increases in Medicaid coverage at 65 and one notable outlier, Massachusetts, seeing a reduction in Medicaid coverage at 65 . Recall that the overall average effect was a statistically insignificant 1 percent increase in the share of individuals covered by Medicaid. However, at the state-level, there are 10 states - Florida and Texas, among others - that experienced statistically significant increases in Medicaid coverage (in excess of 2 percentage points). The estimated reduction in Massachusetts' Medicaid share at age 65 is likely due to the expansion of its Medicaid program to the non-elderly in the 2006 reform (see for e.g., Kolstad and Kowalski, 2012).

In Appendix Figure A16, we report state-level results of the effects of Medicare eligibility on our main financial health outcomes. In Panel A, we see that the large estimated reduction in debt 
collections from Section 3 is driven by a subset of the states, with 14 states having statistically significant declines in debts in collection. Mississippi, North Carolina and Texas experienced the largest declines in debt collections, with Medicare eligibility causing a reduction in debt collections of 80 dollars per capita for Mississippi residents. The states experiencing the smallest effects include Minnesota, Vermont and Rhode Island, which had insignificant effects and point estimates very close to 0 .

In Panel B, we examine the effect on bankruptcy, and find symmetric effects around zero, with only one state - Maine - experiencing a significant positive effect of 0.05 percentage points. Similarly in Panel C, when we look at the effect of Medicare eligibility on total delinquent debt, we find only one state, North Dakota, has a significant effect. Finally, in Panel D, we see a remarkably similar effect size, around 0.7 , for all the states, and none significant. In the interest of clarity and length, we focus on reporting the effects of Medicare on debt collection outcomes going forward.

\subsection{How does the geographic distribution of health insurance and consumer financial strain change at age 65 ?}

We now ask how much geographic disparities in consumer financial strain change at age 65 , focusing on variation at the commuting zone level. We use our RD estimates to construct CZ-level counterfactuals at age 65, with and without Medicare. ${ }^{24}$ We use Equation 3 to estimate the joint distribution of counterfactual outcomes at the CZ-level. Given our estimates of $f_{l}(\cdot), g_{l}(\cdot)$ and $\gamma_{l}$, we construct the conditional mean of $y_{i, l, t}($ age $)$ at age 65 , both with and without Medicare, across locations. We use the CZ-level counterfactuals for two analyses. First, we examine how much of the cross-sectional variance in collections is reduced at age 65 by Medicare. Second, we examine what share of the correlation between area-level characteristics (e.g., race, education, etc.) and consumer financial strain is eliminated by (nearly) universal health insurance. Identifying the share of these correlations that are causally due to health insurance vs. other factors is important as observational analyses have reported strong associations between financial health and health insurance (Braga et al., 2016).

Figure 5 maps the commuting zone estimates of counterfactual collections debt flows at age 65, with and without Medicare. It is clear from Panel A that, absent Medicare, collections debt for

\footnotetext{
${ }^{24}$ There is considerable within-state, across-CZ variation in the effects of Medicare (See Appendix Figure A17).
} 
the near-elderly is highly concentrated in the South. However, Panel B shows us that at age 65 much of this geographic variation disappears, with lower (though still elevated) levels of collections debt in states like Mississippi, Texas, and Nevada. We find that this reduction equates to a drop in the across- $\mathrm{CZ}$ variance in collections debt of $70 \%$ due to eligibility for Medicare. ${ }^{25}$ This coincides with a $93.5 \%$ reduction in the across- $\mathrm{CZ}$ variance in the health insurance rate (See Appendix Figure A19). These findings point to the substantial role health insurance plays in shaping geographic disparities, and highlight an understudied aspect of the Medicare program — the fact that it eliminates geographic disparities in access to insurance and more than halves geographic disparities in collections-related financial strain.

\subsection{How do the area-level correlates of consumer financial strain change at age 65?}

How does the relationship between area-level characteristics — income, education, racial composition, etc. - and area-level measures of consumer financial strain change when Americans become eligible for Medicare at age 65? We examine CZ-level demographic characteristics (Braga et al., 2016) and healthcare market characteristics. As we highlighted when describing Figure 1, the relationship between area-level uninsurance rates and financial health may be driven by omitted variables, rather than health insurance itself. In this section, we exploit the near-universal eligibility for, and relative uniformity of (Finkelstein, Gentzkow and Williams, 2016), Medicare across the country to examine whether relationships between area-level demographics and financial health are driven by unequal access to health insurance.

Figure 6 presents coefficients from bivariate OLS regressions of our counterfactual estimates of collections debt at age 65, with and without Medicare, against commuting zone-level characteristics. Panel A presents demographic characteristics constructed from the American Community Survey (ACS). Panel B presents healthcare market characteristics constructed from the Healthcare Cost Report Information System (HCRIS) and Dartmouth Atlas. For each characteristic, we run two bivariate regressions: first, we regress our counterfactual collections debt estimates at age 65 without Medicare, $\hat{f}_{l}(65)$, against each characteristic (with the characteristic standardized to have

\footnotetext{
${ }^{25}$ Formally, we calculate this as $\sigma_{\hat{f}_{l}(65)}^{2} / \hat{\sigma}_{\hat{g}_{l}(65)}^{2}$. We estimate a similar reduction in variance of $67 \%$ at the state-level (See Appendix Figure A18), suggesting that the results are unlikely to be driven by measurement error in the counterfactuals. We also document modest reductions in geographic variation for several other outcomes (e.g., number of collections, share of delinquent debt, etc.). However, this table is a work-in-progress and future drafts will test the significance of these results by adding inference to address the potential that regression to the mean is driving some of them.
} 
mean zero and a standard deviation of one). We plot this estimate as a dot in each row. Second, we regress the counterfactual collections debt estimates at age 65 with Medicare, $\hat{g}_{l}(65)$ against the same location characteristic. We plot this estimate with bars. The blue dots indicate statistically significant differences between the coefficients at age 65, with and without Medicare. Conceptually, since (nearly) all individuals are covered by health insurance after age 65 due to Medicare, the difference between the correlation at age 65, with and without Medicare, captures the share of the bivariate correlation driven by health insurance rates, with the remaining correlation at age 65 with Medicare due to other omitted factors.

In Panel A of Figure 6, in the absence of Medicare, demographic characteristics are highly correlated with collections debt. For example, a one standard deviation higher share of black residents in a commuting zone is associated with $\$ 20.6(21 \%)$ more in per capita collections debt while a one standard deviation higher $\mathrm{CZ}$ per capita income is associated with $\$ 26.2(27 \%)$ less in collections debt. However, once residents become eligible for Medicare at age 65, many of these cross-sectional correlations are substantially attenuated. For example, after age 65, a one standard deviation higher share of black residents in a CZ is associated with $\$ 11(16 \%)$ more in per capita collections debt, or approximately half of the pre-65 correlation. A similar pattern holds for other key demographics, such as the share of the residents with greater than a high school education, per capita income, median house value, and the share of people with disabilities. ${ }^{26}$ Nearly half of the bivariate correlation between several key area-level demographics (e.g., race, education, and income) and collections debt are driven by unequal access to health insurance.

In Panel B of Figure 6 we show that in the absence of Medicare, several CZ-level healthcare market characteristics are also correlated with collections debt. The share of for-profit hospitals in a $\mathrm{CZ}$ and the risk-adjusted Medicare spending per enrollee were both associated with higher collections debt prior to eligibility for Medicare. In contrast, the share of teaching hospitals and hospital occupancy rates were associated with lower collections prior to eligibility for Medicare. The remaining healthcare market characteristics had smaller (and statistically insignificant) correlations with collections debt pre-65. Only a few of the correlations with healthcare market char-

\footnotetext{
${ }^{26}$ More specifically, Medicare attenuated the bivariate cross-sectional correlations with collections debt by: $46 \%$ for black share, $44 \%$ for the share of residents with greater than a high school education, $45 \%$ for per capita income, $49 \%$ for median house value, and $56 \%$ for the share of the population that is disabled. One exception is the poverty rate in a CZ, where there is a smaller, and statistically insignificant, reduction in the cross-sectional correlation of $25 \%$.
} 
acteristics were attenuated with the advent of Medicare eligibility. The correlations between for-

profit and teaching hospital shares and collections debt were significantly attenuated by $37 \%$ and $60 \%$, respectively, a fact we explore further in Section 5.

Lastly, we examine how the Affordable Care Act has reshaped the effect of Medicare on the geography of financial health. Broadly, we find that reductions in the geographic variation of collections debt at age 65 are similar pre- and post-ACA, but Medicare does less to reduce the cross-sectional correlation between most measures of socio-economic status and consumer financial strain post-ACA. ${ }^{27}$ However, notably, we find that Medicare does more to reduce the correlation between the share of black residents in a $\mathrm{CZ}$ and financial strain after the implementation of the ACA (Appendix Table A10), a point consistent with evidence we present in Section 6 that the financial health benefits of Medicare have becoming increasingly concentrated in the South where the share of black residents is higher than elsewhere in the country.

\section{What are the characteristics of areas that experience the largest im- provements in financial health due to Medicare at age 65?}

In this section, we provide evidence about the area-level factors associated with reductions in consumer financial strain at age 65 . We start by examining whether the reductions in consumer financial strain at age 65 are driven by reductions in the uninsurance rate. We find that the largest (smallest) reductions in collections debt are concentrated in areas that experienced the largest (smallest) increases in the insurance rate at age 65, suggesting that the gains in financial health are driven by reducing the number of uninsured, rather than changes in the composition of coverage. We then examine the correlation of commuting zones characteristics with our place-based estimates of Medicare's causal effects. We focus on the same demographic and healthcare market measures as in Section 4. We find that areas with larger shares of black residents, people with disabilities, and for-profit hospitals experience the largest gains in financial health due to Medicare

\footnotetext{
${ }^{27}$ In Appendix Figure A20, we plot the CZ-level estimates of counterfactual collections debt at age 65 before and after the implementation of the ACA. Absent Medicare, collections debt for the near-elderly is highly concentrated in the South both before and after the implementation of the ACA. In the two right-hand panels, we see that eligibility for Medicare at age 65 eliminates much of this geographic variation. Appendix Table A9 formalizes this, providing estimates of the reduction in geographic variation for collections debt (as well as other outcomes) separately for the pre- and post-ACA periods. For collections debt, the reduction in geographic variation is very similar, at $68.2 \%$ in the pre-ACA period and $70.6 \%$ in the post-ACA period. For the other financial health outcomes, we see little evidence that Medicare's role in reshaping geographic disparities has been blunted due to the ACA.
} 
eligibility at age 65, across a variety of estimation approaches.

\subsection{Are the reductions in consumer financial strain at age 65 driven by reductions in the uninsurance rate?}

In Figure 7, we examine the correlation between the causal effect of Medicare on health insurance rates and financial health outcomes. We plot the state-level effect of Medicare eligibility on the insurance rate on the x-axis, and the estimated drop in debt collections on the $y$-axis. Since the state-level estimates are noisily estimated, we rely on our shrinkage estimates for the x-axis to avoid attenuation bias. ${ }^{28}$ The dashed line plots the estimated fit from a simple linear regression, and the reported numbers in the top left correspond to the regression.

There are three notable features of this graph. First, the increase in health insurance coverage explains a surprisingly large share of the debt collection effect. When we consider a simple linear regression, the estimated $R^{2}$ is 0.38 , implying that almost $40 \%$ of the variance in the effect on debts in collections is explained by the change in insurance rates. Second, the estimated reduction in debt collections is small for states with low estimated effects on insurance rates. Both of these facts suggest that the effect of Medicare eligibility on debt collections is driven by individuals who gain coverage, rather than those whose primary source of coverage is changing. Third, the estimated slope is large, at roughly 675 dollars. Compared to the estimated effect in Panel A of Figure 1, this coefficient is roughly half the size of the naive OLS coefficient. If we make the strong assumption that only Medicare's coverage of the uninsured affects debt collections (rather than other changes in the composition of coverage at age 65), then our estimates imply that health insurance coverage reduces debt collections by 675 dollars per newly insured individual. Moreover, it would suggest that omitted variable bias driven by other, non-health insurance variables explains roughly half of the observed correlation between debt collections and health insurance across states. ${ }^{29}$

\footnotetext{
${ }^{28}$ See Appendix Figures A11 and A12 for a comparison of the unshrunk and shrunk state-level estimates.

${ }^{29}$ We also examine whether the relationship between location-specific RD health insurance and financial health estimates changes after the implementation of the ACA. We continue to find a strong relationship between the state-level increases in insurance at age 65 and the reductions in the collections debt (See Appendix Figure A21). At the CZ-level we find similar results (See Appendix Figure A22).
} 


\subsection{Examining characteristics associated with the improvements in financial health due to Medicare}

In this section, we describe how we estimate the association between other area-level factors and the improvements in financial health at age 65. We use the same set of covariates considered in the previous section - demographic and healthcare market characteristics from the ACS, HCRIS, and the Dartmouth Atlas. We begin by estimating simple bivariate regressions between our placebased causal effects of Medicare and location characteristics:

$$
\gamma_{l}=\alpha+X_{l} \omega+v_{l}
$$

where $X_{l}$ is a scalar containing a single area-level characteristic (e.g. the share of black residents) and $\gamma_{l}$ is our RD estimate for location $l$. We separately estimate $\omega$ for each characteristic, weighting the regression by each location's near-elderly population.

Given that many of the area-level characteristics we study are highly correlated, we are also interested in the partial correlations between the characteristics and our place-based causal estimates (holding the other characteristics fixed). We re-estimate Equation 4 with the full set of area-level covariates:

$$
\gamma_{l}=\alpha+\vec{X}_{l} \vec{\omega}+v_{l}
$$

where $\vec{X}_{l}$ is the full set of area-level covariates. We estimate Equation 5 in two ways. First, we estimate the model using ordinary least squares (OLS) to recover the marginal association of each area-level characteristic with our place-based causal estimates. Second, since the dimension of $X_{l}$ is large (and many of the covariates are highly correlated), we use Lasso to perform covariate selection on $\vec{X}_{l}$, and then re-estimate the model using OLS(Belloni and Chernozhukov, 2013). Briefly, the Lasso estimation procedure penalizes covariates and shrinks terms in the estimated $\omega_{l}$ towards zero, in order to minimize mean squared error. As a result, the estimation procedure will select a subset of the covariates in $\vec{X}_{l}$, to have non-zero parameters, and set the remaining parameters to zero. ${ }^{30}$

\footnotetext{
${ }^{30}$ We implement this using a ten-fold cross-validation over the penalization parameter, implemented using $\mathrm{R} g \mathrm{lmnet}$ package.
} 


\subsection{What characteristics are associated with the reduction in collections debt per capita due to Medicare at age 65 ?}

We now provide suggestive evidence about the other area-level factors associated with reductions in collections debt per capita at age 65. In the Bivariate (leftmost) panel of Figure 8, we present the coefficients from separate bivariate OLS regressions of our regression discontinuity estimates of CZ-level reductions in collections debt per capita $\left(\hat{\gamma}_{l}\right)$ on CZ-level demographic and healthcare market characteristics. We standardize all the variables so the coefficients reflect the strength of the association between a one standard deviation change in the covariate and the estimated reduction in collections debt at age 65 .

Panel A shows that the share of high school graduates, income per capita, and median house value were associated with smaller reductions in collections debt at age 65 . CZ-level characteristics such as the share of black residents, the poverty rate, and the share of people with disabilities, on the other hand, were associated with larger reductions in collections at age 65. Unsurprisingly, the share of residents with health insurance (or Medicaid), was associated with a smaller reduction in per capita collections debt at age 65 .

Given that many of the area-level characteristics we study are highly correlated, we also present coefficients from multivariate OLS and post-Lasso multivariate OLS (see section 5.2 for details) in the adjacent panels in Figure 8. Only a handful of the CZ-level demographics were statistically significant in the multivariate analyses. The only characteristics associated with a smaller reduction in per capita collections at age 65 were the near-elderly health insurance rate and the high school graduation rate (Panel III.A). ${ }^{31}$ The share of black residents and people with disabilities in a $\mathrm{CZ}$ were consistently associated with larger reductions in collections debt in the multivariate OLS and post-Lasso.

We now examine the area-level healthcare market characteristics associated with reductions in the per capita collections debt at age 65. We start with a discussion of the bivariate OLS results. Panel B of Figure 8 shows that CZs with a higher share of for-profit hospitals or higher riskadjusted spending per Medicare beneficiariy experienced larger reductions in collections debt at age 65. In the case of the for-profit hospital share, a one standard deviation increase in measure

\footnotetext{
${ }^{31}$ While the Lasso procedure did not select the near-elderly health insurance rate, we note a very high correlation between that measure and the high school graduation rate $(\rho=0.45)$.
} 
was associated with an increase of $\$ 10$ in the reduction in collections at 65 , a $30 \%$ increase relative to the average effect of -29 dollars. CZs with a higher share of teaching hospitals and higher hospital occupancy rates, on the other hand, experienced smaller reductions in collections at age 65 . We did not find statistically significant bivariate correlations between the reduction in collections and hospital beds per capita, reported dollars of charity care, or reported dollar amounts recovered from charity care patients.

The adjacent panels use multivariate OLS and post-Lasso multivariate OLS to examine the associations between healthcare market characteristics and per capita reductions in collections debt. In these analyses, we find that the CZ-level share of for-profit hospitals is associated with larger reductions in collections debt per capita. Unlike not-for-profit hospitals, for-profits are not required to provide charity (discounted or free) care and observational evidence suggests that they offer less charity care than not-for-profit hospitals ( e.g., Horwitz, 2005; Schlesinger and Gray, 2006; Valdovinos, Le and Hsia, 2015). In addition, there is prior evidence that hospitals in markets with a higher share of for-profits respond to competition by reducing charity care and trying to avoid the uninsured (Frank, Salkever and Mitchell, 1990). ${ }^{32}$ None of the other healthcare market characteristics were associated with CZ-level reductions in collections debt per capita at age 65.

\subsection{What area-level characteristics are associated with the reduction in collections debt per newly-insured individual due to Medicare at age 65?}

We next examine the demographic and healthcare market characteristics of CZs associated with the largest reductions in collections debt per newly-insured. For this exercise, we estimate CZ-level reductions in collections per newly-insured using a fuzzy RD approach, with the insurance rate as the first-stage and collections debt as the outcome variable. While our heterogeneity analysis suggests that the primary mechanism through which Medicare affects financial strain is by reducing the uninsurance rate, it is unlikely that the exclusion restriction holds. As a result, we view this more as an informative scaling exercise rather than a well-identified causal effect of insurance coverage. We implement this procedure, rather than simply scale the two estimates directly, in order to correctly calculate the standard error associated with each commuting zone's estimate, a

\footnotetext{
${ }^{32}$ However, more recent work by Capps, Carlton and David (2017) examines whether not-for-profit hospitals increase the provision of charity care more in response to market power than for-profits and find no difference between the two on that dimension.
} 
necessary component for our forecasting and shrinkage exercise in Section 6.2.

Figure 9 presents the CZ-level correlates with our estimated reductions in collections debt pernewly insured. The share of black residents, people with disabilities, and for-profit hospitals in a $\mathrm{CZ}$ are consistently associated with larger reductions in collections debt per newly-insured. Few of the other area-level characteristics we studied were consistently associated with smaller reductions in collections debt per newly-insured. ${ }^{33}$ Given the relative uniformity of the Medicare health insurance environment (Finkelstein, Gentzkow and Williams, 2016), an alternative interpretation of these correlates is that they measure the characteristics of localities where the financial health consequences of being uninsured are the greatest for the near-elderly.

\section{Forecasts of causal effects of health insurance on financial strain}

Given that the effect of Medicare varies substantially across localities, where should a coverage expansion to the near-elderly be targeted to maximize impact? In what follows, we discuss how we construct our forecasts of CZ-level causal effects, how the forecasts have changed after the implementation of the ACA, and their implications for past and future coverage expansions.

\subsection{Methods}

We now consider the forecastable components of $\gamma_{l}$ and $\beta_{l}$, where $\beta_{l}$ is our fuzzy-RD estimates of CZ-level reductions in collections debt per newly-insured (See Section 5.4 for details). We are interested in the best predictions of $\gamma_{l}$ and $\beta_{l}$. Ideally, each forecast would be the unbiased causal estimate for the location from our RD design. However, in many locations, the near-elderly population is small and the estimates are noisy. To reduce noise, we follow Chetty and Hendren (2018) and construct forecasts using a shrinkage estimator that combines our unbiased RD estimates and the predicted effect for each commuting zone based on its demographic and healthcare market characteristics. Since the dimension of our set of predictors, $\vec{X}_{l}$, is large (and many of the covariates are highly correlated), we use our Lasso predictions from Section 5.2 in order to minimize over-fitting.

\footnotetext{
${ }^{33}$ Partial exceptions were the share of residents on Medicaid, the share of teaching hospitals, and the income per capita, all of which were associated with smaller reductions in collections per newly-insured (though none were selected by the Lasso procedure). While the share of near-elderly residents with health insurance was not associated with the reduction in collections debt per-newly insured in the bivariate OLS analysis, in the multivariate analyses the share of residents with insurance was associated with a larger reduction in collections debt per capita.
} 
We denote our predictions of $\gamma_{l}$ and $\beta_{l}$ estimated using our Lasso model from Section 5.2 as $\hat{\gamma}_{l}$ and $\hat{\beta}_{l}$, respectively. We then combine the Lasso estimates together with our RD estimates of $\gamma_{l}$ order to construct the mean square error-minimizing forecast for each commuting zone, defined as $\hat{\gamma}_{l}^{f}$. This MSE-minimizing forecast is constructed using the following formula (Chetty and Hendren, 2018): ${ }^{34}$

$$
\hat{\gamma}_{l}^{f}=\left(\frac{\chi^{2}}{\chi^{2}+s_{l}^{2}}\left(\gamma_{l}-\bar{\gamma}_{l}\right)+\frac{s_{l}^{2}}{\chi^{2}+s_{l}^{2}} \tau\left(\hat{\gamma}_{l}-\bar{\gamma}_{l}\right)\right)+\bar{\gamma}_{l} \text {, }
$$

where $\bar{\gamma}_{l}$ is the average RD prediction across locations, $\overline{\hat{\gamma}}_{l}$ is the average Lasso prediction across locations, $\tau=\operatorname{Cov}\left(\hat{\gamma}_{l}, \gamma_{l}\right) / \operatorname{Var}\left(\hat{\gamma}_{l}\right)$ is the coefficient of a regression of $\gamma_{l}$ on $\hat{\gamma}_{l}, \chi^{2}$ is the residual place effect variation after subtracting off the variance due to estimation of $\gamma_{l}$, and $s_{l}^{2}$ the squared standard error of the $\gamma_{l}$. For the purposes of the shrinkage, we demean our estimates and then add the overall mean back, such that the shrinkage is around the variation around the overall mean. We estimate $\tau$ using linear regression of the demeaned values, and calculate $\chi^{2}$ as

$$
\chi^{2}=\operatorname{Var}\left(\gamma_{l}-\tau\left(\hat{\gamma}_{l}-\bar{\gamma}_{l}\right)\right)-E\left(s_{l}^{2}\right)
$$

where $E\left(s_{l}^{2}\right)$ is the average sampling variance across locations. In all calculations, we weight by the precision of the fixed effect estimates $\left(1 / s_{l}^{2}\right)$ to maximize efficiency.

Note that this approach will shrink our estimates towards the predicted $\hat{\gamma}_{l}$ when the original estimate is noisy and the shrinkage will only occur if the lasso prediction has predictive power for $\gamma_{l}$. If this prediction has limited value, then $\tau$ will be zero, and the shrinkage will shrink towards the overall mean. By a similar argument, as $s^{2}$ goes to zero, the forecasted estimate will be exactly $\gamma_{l}$. We follow the same procedure to construct forecasts for $\beta_{l}$, defined as $\hat{\beta}_{l}^{f} .{ }^{35}$

\footnotetext{
${ }^{34}$ see Appendix D of Chetty and Hendren (2018) for the explicit derivation of this approach. Our approach deviates from Chetty and Hendren (2018) in that we use the Lasso predicted estimate, rather than the estimated mean value of residents (as Chetty and Hendren (2018) do). This extension is discussed in their Appendix D. Additionally, since our estimates are not mean zero by construction, we demean our estimates for the purposes of the shrinkage, and then add the overall mean back in. Our approach is otherwise identical.

${ }^{35}$ For calculating the prediction errors of the forecasts for Appendix Table A11, we again follow Chetty and Hendren (2018), where the root mean-squared error of the prediction is:

$$
\sqrt{e_{l}^{2}}=\sqrt{\frac{1}{\frac{1}{s_{l}^{2}}+\frac{1}{\chi^{2}}}}
$$

Note that as the variance for our unbiased estimate $\left(s_{l}^{2}\right)$ grows, $\chi^{2}$ places an upper bound on the size of the root MSE.
} 


\subsection{Forecasts for commuting zones}

Panel A of Figure 10 maps the forecast causal effects $\hat{\gamma}_{l}^{f}$ per capita across CZs for the near-elderly, with darker colors depicting areas predicted to experience larger reductions in financial strain associated with an expansion of (nearly) universal health insurance to the near-elderly (i.e. lowering the Medicare eligibility age). The largest forecast reductions are concentrated in the Southeast, ranging from $\$ 20-\$ 80$ in most CZs. The opposite is true in the Midwest, where forecast reductions in consumer financial strain are small across all CZs. Panel B of Figure 10 maps the forecast causal effects $\hat{\beta}_{l}^{f}$ per newly-insured individual across CZs for the near-elderly. Interestingly, the largest forecast reductions in consumer financial strain per newly-insured are also concentrated in the South.

Column 1 of Appendix Table A11 lists the forecasts for the 50 commuting zones with the largest near-elderly populations (which account for $52.6 \%$ of the near-elderly US population during our sample period), sorted alphabetically by state and then commuting zone. Column 2 contains the root mean squared error of the forecast, following Chetty and Hendren (2018). The forecasts range widely. The forecast reductions in collections debt are $\$ 45$ or greater per capita in seven of the CZs, including Miami, Nashville, and Las Vegas. On the other hand, there are five CZs with forecast reductions in collections debt of $\$ 10$ or less (e.g., Grand Rapids, Minneapolis, Providence). For the forecast reduction in collections debt per-newly insured in Column 3, we see that the localities with large forecasts tend to be those with higher values of $\beta_{l}^{f}$, the forecast reduction in collections debt per newly-insured individual. In fact, on average, the CZs with forecast reductions in collections of $\$ 45$ or greater had values of $\beta_{l}^{f}$ that were 3.5 times larger than the five CZs forecast to have reductions of $\$ 10$ or less in collections. By comparison, the mean $\gamma_{l}^{f}$ was approximately 6.5 times larger for the CZs with forecast reduction in collections of $\$ 45$ or greater, suggesting that differences in $\beta_{l}^{f}$ are an important driver of the differences in our forecasts.

\subsection{Has the ACA changed the forecast?}

We briefly examine how the forecasts have changed due to the Affordable Care Act. We show that the forecast reductions in consumer financial strain remain large after the implementation of the In contrast, if the sampling error gets very small, the forecast will place all the weight on the unbiased estimate, and send the root MSE to zero. 
ACA. But, they have become more geographically-concentrated in the "Deep South" region that comprises Louisiana, Alabama, Mississippi, Georgia, and South Carolina (as well as parts of Texas and Florida). Our data provide two insights into why this is the case. First, the coverage gains for the near-elderly due to the ACA were geographically diffuse despite higher existing levels of uninsurance in the South. Second, the forecast reductions in consumer financial strain per newly insured individual are also greater in the South (and the Deep South in particular).

Figure 11 presents maps of the forecast causal effects $\left(\gamma_{l}^{f}\right)$ for the near-elderly across CZs, before and after the implementation of the ACA. We do this by following the methods in Section 6.1 to construct mean square error-minimizing forecasts for $\mathrm{CZs}$ before and after the implementation of the ACA. In Panel A, we can see that the largest forecast causal effects on collections debt in the pre-ACA period are concentrated in the Southeast, but there are forecast reductions in collections debt in excess of $\$ 25$ per capita in much of the rest of the country, particularly the Northeast and Western regions of the US. However, in Panel B, we see that the forecast reductions in collections debt have become more geographically-concentrated in the Southeast, and particularly the Deep South.

Our data shed light on two reasons why the forecasts of gains from a coverage expansion to the near-elderly have become more geographically concentrated after the implementation of the ACA. First, the near-elderly uninsured are increasingly concentrated in the South after the implementation of the ACA (see Appendix Figure A23). This is, at least partly, attributable to the fact that the gains in health insurance coverage due to the ACA for the near-elderly were geographically diffuse. Appendix Figure A24 presents difference-in-discontinuities estimates of the increases in health insurance by commuting zone from the pre- to post-ACA periods. ${ }^{36}$ The gains are dispersed across the United States, with large increases in coverage in parts of the South but similar sized gains for other areas of the country as well (with the exception of the Midwest where the gains were smaller). While the ACA has been found to reduce some coverage disparities

\footnotetext{
${ }^{36}$ To construct these, we follow Duggan, Gupta and Jackson (2019) and estimate a regression discontinuity differencein-differences ("difference-in-discontinuity") research design. Intuitively, this design exploits the fact that for 65-yearolds (and older), the expansion of the ACA was limited (compared to the near-elderly). By considering how the effect at the discontinuity changed post-ACA-enactment, this allows us to back out the causal benefit to the non-elderly. E.g., any change in the effect of Medicare eligibility at age 65 is solely due to the change in the ACA. This requires two assumptions: first, we need to identify the relevant counterfactual discontinuity for the post-ACA period. We use the 2010-2013 period as the baseline comparison. Second, this approach assumes that the only time-varying difference in the age 65 discontinuity that occurred between 2010-2013 and 2014-2017 is due to the ACA. This is partially testable in that we can use 2008 and 2009 as a placebo period.
} 
(Courtemanche et al., 2019), our findings suggest that the gains in coverage were only partly targeted to the geographic areas with the highest near-elderly uninsurance rates. In Appendix Figure A25, we show that the ACA health insurance expansion only reduced $46 \%$ of the geographic variation in health insurance among the near-elderly. A second factor is that the forecast reductions in collections debt per newly-insured are greatest in the South and remain so after the implementation of the ACA. We map these estimates separately pre- and post-ACA in Appendix Figure A26.

We conclude this section by examining whether the ACA expanded coverage in the areas where the returns to financial health were the highest and how its "targeting" compares to that of Medicare. In Panel A of Figure 12, we plot difference-in-discontinuity estimates of the increases in health insurance coverage for the near-elderly due to the ACA against the forecast reductions in collections debt per newly-insured individual $\left(\beta_{l}^{f}\right)$ at the CZ-level. The slope is negative but statistically insignificant, implying that the ACA did not expand coverage more in the areas where being uninsured causes more financial strain (i.e. the South). This may have blunted its overall effects on collections debt for the near-elderly and contributed to the increase in geographic disparity. ${ }^{37}$ In Panel B of Figure 12 we plot the changes in coverage at age 65 due to Medicare in the post-ACA period (2014-2017) against the forecast reductions in collections debt per newlyinsured at the CZ-level. Unlike the comparison of $\beta_{l}^{f}$ to the changes in coverage due to the ACA, there is a statistically significant and positive relationship between the CZs where Medicare expanded coverage the most and the $\mathrm{CZs}$ with the highest forecast reductions in collections debt per newly-insured individual.

\section{Conclusion}

This paper examines the relationship between health insurance and financial health by studying financial outcomes for individuals as they age onto Medicare at 65. We find evidence of large reductions in financial strain at 65, particularly for debt in collections. These reductions are concentrated in areas where the uninsurance rates were highest for the near-elderly suggesting that the gains in financial health at age 65 are driven by reductions in the uninsurance rate, rather than changes in the composition of coverage. But, the gains in financial health at 65 are not the same

\footnotetext{
${ }^{37}$ Diff-in-disc estimates of the effects of the ACA on collections debt are noisy and it is difficult to disentangle the effects of the ACA from pre-trends in the discontinuity in collections debt.
} 
for the uninsured in all places. Being uninsured causes more financial strain in the South, where there are greater shares of black residents, people with disabilities, and for-profit hospitals. These findings help explain why the Affordable Care Act was less effective than Medicare at addressing geographic disparities. Our data show that Medicare increases coverage where the financial hardship associated with being uninsured is the largest (the South), whereas the coverage gains associated with the ACA, were diffuse and may have contributed to a worsening of the geographic disparity in collections debt. 


\section{References}

Allen, Heidi, Ashley Swanson, Jialan Wang, and Tal Gross. 2017. "Early Medicaid expansion associated with reduced payday borrowing in California." Health Affairs, 36(10): 1769-1776.

Allen, Heidi L, Erica Eliason, Naomi Zewde, and Tal Gross. 2019. "Can Medicaid Expansion Prevent Housing Evictions?" Health Affairs, 38(9): 1451-1457.

Angrist, Joshua D, Peter D Hull, Parag A Pathak, and Christopher R Walters. 2017. “Leveraging lotteries for school value-added: Testing and estimation." The Quarterly Journal of Economics, 132(2): 871-919.

Armstrong, Timothy, and Michal Kolesár. 2018a. "Simple and honest confidence intervals in nonparametric regression." Cowles Foundation Discussion Paper.

Armstrong, Timothy B, and Michal Kolesár. 2018b. "Optimal inference in a class of regression models." Econometrica, 86(2): 655-683.

Avery, Robert B, Paul S Calem, Glenn B Canner, and Raphael W Bostic. 2003. "An overview of consumer data and credit reporting." Fed. Res. Bull., 89: 47.

Baicker, Katherine, Sarah L Taubman, Heidi L Allen, Mira Bernstein, Jonathan H Gruber, Joseph P Newhouse, Eric C Schneider, Bill J Wright, Alan M Zaslavsky, and Amy N Finkelstein. 2013. "The Oregon experiment-effects of Medicaid on clinical outcomes." New England Journal of Medicine, 368(18): 1713-1722.

Barcellos, Silvia Helena, and Mireille Jacobson. 2015. "The effects of Medicare on medical expenditure risk and financial strain." American Economic Journal: Economic Policy, 7(4): 41-70.

Barreca, Alan I, Melanie Guldi, Jason M Lindo, and Glen R Waddell. 2011. "Saving babies? Revisiting the effect of very low birth weight classification." The Quarterly Journal of Economics, 126(4): 2117-2123.

Belloni, Alexandre, and Victor Chernozhukov. 2013. "Least squares after model selection in highdimensional sparse models." Bernoulli, 19(2): 521-547.

Bhattacharya, Jay, and Darius Lakdawalla. 2006. "Does Medicare benefit the poor?" Journal of Public Economics, 90(1-2): 277-292.

Braga, Breno, Signe-Mary Mckernan, Caroline Ratcliffe, Brett Theodos, John Chalekian, and Christopher Trepel. 2016. "Local Conditions and Debt in Collections." Journal of Consumer Affairs.

Brevoort, Kenneth, Daniel Grodzicki, and Martin B Hackmann. 2017. "Medicaid and financial health." National Bureau of Economic Research.

Brown, Meta, Donghoon Lee, Joelle Scally, Katherine Strair, and Wilbert van der Klaauw. 2016. "The graying of American debt." Federal Reserve Bank of New York, Research and Statistics Group, Microeconomic Studies, February, 12: 2016-9.

Calonico, Sebastian, Matias D Cattaneo, and Rocio Titiunik. 2015. "rdrobust: An r package for robust nonparametric inference in regression-discontinuity designs." $R$ Journal, 7(1): 38-51. 
Capps, Cory, Dennis W Carlton, and Guy David. 2017. "Antitrust Treatment of Nonprofits: Should Hospitals Receive Special Care?" National Bureau of Economic Research.

Card, David, Carlos Dobkin, and Nicole Maestas. 2008. "The impact of nearly universal insurance coverage on health care utilization: evidence from Medicare." American Economic Review, 98(5): 2242-58.

Card, David, Carlos Dobkin, and Nicole Maestas. 2009. "Does Medicare save lives?" The quarterly journal of economics, 124(2): 597-636.

Caswell, Kyle J., and John H. Goddeeris. 2019. “Does Medicare Reduce Medical Debt?" American Journal of Health Economics, 0(ja): null.

Cattaneo, Matias D, Richard K Crump, Max H Farrell, and Yingjie Feng. 2019. "On binscatter." arXiv preprint arXiv:1902.09608.

Chetty, Raj, and Nathaniel Hendren. 2018. "The impacts of neighborhoods on intergenerational mobility II: County-level estimates." The Quarterly Journal of Economics, 133(3): 1163-1228.

Chetty, Raj, Nathaniel Hendren, Patrick Kline, and Emmanuel Saez. 2014. "Where is the land of opportunity? The geography of intergenerational mobility in the United States." The Quarterly Journal of Economics, 129(4): 1553-1623.

Clemens, Jeffrey, and Joshua D Gottlieb. 2017. "In the shadow of a giant: Medicare's influence on private physician payments." Journal of Political Economy, 125(1): 000-000.

Cooper, Zack, Stuart V Craig, Martin Gaynor, and John Van Reenen. 2018. “The price ain't right? Hospital prices and health spending on the privately insured." The Quarterly Journal of Economics, 134(1): 51-107.

Courtemanche, Charles, James Marton, Benjamin Ukert, Aaron Yelowitz, and Daniela Zapata. 2017. "Early impacts of the Affordable Care Act on health insurance coverage in Medicaid expansion and non-expansion states." Journal of Policy Analysis and Management, 36(1): 178-210.

Courtemanche, Charles J, Ishtiaque Fazlul, James Marton, Benjamin D Ukert, Aaron Yelowitz, and Daniela Zapata. 2019. "The Impact of the ACA on Insurance Coverage Disparities After Four Years." National Bureau of Economic Research.

Dartmouth Institute. 2019. "Dartmouth Atlas of Health Care."

David, H, and David Dorn. 2013. "The growth of low-skill service jobs and the polarization of the US labor market." American Economic Review, 103(5): 1553-97.

Dorn, David, Gordon Hanson, et al. 2019. "When Work Disappears: Manufacturing Decline and the Falling Marriage Market Value of Young Men." American Economic Review: Insights, 1(2): 16178.

Duggan, Mark, Atul Gupta, and Emilie Jackson. 2019. “The Impact of the Affordable Care Act: Evidence from California's Hospital Sector." National Bureau of Economic Research.

Engelhardt, Gary V, and Jonathan Gruber. 2011. "Medicare Part D and the financial protection of the elderly." American Economic Journal: Economic Policy, 3(4): 77-102. 
Finkelstein, Amy, and Robin McKnight. 2008. "What did Medicare do? The initial impact of Medicare on mortality and out of pocket medical spending." Journal of public economics, 92(7): 1644-1668.

Finkelstein, Amy, Matthew Gentzkow, and Heidi L Williams. 2019. "Place-based drivers of mortality: Evidence from migration." National Bureau of Economic Research.

Finkelstein, Amy, Matthew Gentzkow, and Heidi Williams. 2016. "Sources of geographic variation in health care: Evidence from patient migration." The quarterly journal of economics, 131(4): 1681-1726.

Finkelstein, Amy, Sarah Taubman, Bill Wright, Mira Bernstein, Jonathan Gruber, Joseph P Newhouse, Heidi Allen, Katherine Baicker, and Oregon Health Study Group. 2012. "The Oregon health insurance experiment: evidence from the first year." The Quarterly journal of economics, 127(3): 1057-1106.

Frandsen, Brigham R, Markus Frölich, and Blaise Melly. 2012. "Quantile treatment effects in the regression discontinuity design." Journal of Econometrics, 168(2): 382-395.

Frank, RG, DS Salkever, and J Mitchell. 1990. "Market forces and the public good: competition among hospitals and provision of indigent care." Advances in health economics and health services research, 11: 159.

Frean, Molly, Jonathan Gruber, and Benjamin D Sommers. 2017. "Premium subsidies, the mandate, and Medicaid expansion: Coverage effects of the Affordable Care Act." Journal of Health Economics, 53: 72-86.

Gross, Tal, and Matthew J Notowidigdo. 2011. "Health insurance and the consumer bankruptcy decision: Evidence from expansions of Medicaid." Journal of Public Economics, 95(7): 767-778.

Horwitz, Jill R. 2005. "Making profits and providing care: comparing nonprofit, for-profit, and government hospitals." Health affairs, 24(3): 790-801.

Hu, Luojia, Robert Kaestner, Bhashkar Mazumder, Sarah Miller, and Ashley Wong. 2018. "The effect of the affordable care act Medicaid expansions on financial wellbeing." Journal of public economics, 163: 99-112.

Imbens, Guido, and Stefan Wager. 2019. "Optimized regression discontinuity designs." Review of Economics and Statistics, 101(2): 264-278.

Keys, Ben, Neale Mahoney, and Hanbin Yang. 2019. “The Geography of Financial Distress: Delinquency and Default in America."

Kolesár, Michal, and Christoph Rothe. 2018. "Inference in regression discontinuity designs with a discrete running variable." American Economic Review, 108(8): 2277-2304.

Kolstad, Jonathan T, and Amanda E Kowalski. 2012. "The impact of health care reform on hospital and preventive care: evidence from Massachusetts." Journal of Public Economics, 96(1112): 909-929.

Lee, David S, and David Card. 2008. "Regression discontinuity inference with specification error." Journal of Econometrics, 142(2): 655-674. 
Lee, Donghoon, and Wilbert Van der Klaauw. 2010. "An introduction to the frbny consumer credit panel." FRB of New York Staff Report 479.

Mazumder, Bhashkar, and Sarah Miller. 2016. "The effects of the Massachusetts health reform on financial distress." American Economic Journal: Economic Policy, 8(3): 284-313.

McClellan, Mark, and Jonathan Skinner. 2006. "The incidence of Medicare." Journal of Public Economics, 90(1-2): 257-276.

Miller, Sarah, and Cindy K Soo. 2018. "Do Neighborhoods Affect Credit Market Decisions of Low-Income Borrowers? Evidence from the Moving to Opportunity Experiment." National Bureau of Economic Research.

Morris, Carl N. 1983. "Parametric empirical Bayes inference: theory and applications." Journal of the American statistical Association, 78(381): 47-55.

Nelson, Alan. 2002. "Unequal treatment: confronting racial and ethnic disparities in health care." Journal of the National Medical Association, 94(8): 666.

Ruggles, Steven, Sarah Flood, Ronald Goeken, Josiah Grover, Erin Meyer, Jose Pacas, and Matthew Sobek. 2019. "IPUMS USA: Version 9.0 [dataset]."

Schlesinger, Mark, and Bradford H Gray. 2006. "How Nonprofits Matter In American Medicine, And What To Do About It: Reports of the demise of nonprofits in US health care are premature." Health affairs, 25(Suppl1): W287-W303.

Sommers, Benjamin D, Kao-Ping Chua, Genevieve M Kenney, Sharon K Long, and Stacey McMorrow. 2016. "California's early coverage expansion under the Affordable Care Act: a countylevel analysis." Health services research, 51(3): 825-845.

Sommers, Benjamin D, Munira Z Gunja, Kenneth Finegold, and Thomas Musco. 2015. "Changes in self-reported insurance coverage, access to care, and health under the Affordable Care Act." Jama, 314(4): 366-374.

Sommers, Benjamin D, Thomas Musco, Kenneth Finegold, Munira Z Gunja, Amy Burke, and Audrey M McDowell. 2014. "Health reform and changes in health insurance coverage in 2014." New England Journal of Medicine, 371(9): 867-874.

Tibshirani, Robert. 1996. "Regression shrinkage and selection via the lasso." Journal of the Royal Statistical Society: Series B (Methodological), 58(1): 267-288.

Valdovinos, Erica, Sidney Le, and Renee Y Hsia. 2015. "In California, not-for-profit hospitals spent more operating expenses on charity care than for-profit hospitals spent." Health Affairs, 34(8): 1296-1303.

Wallace, Jacob, and Zirui Song. 2016. “Traditional Medicare versus private insurance: how spending, volume, and price change at age sixty-five." Health Affairs, 35(5): 864-872. 


\section{Figure 1: Consumer credit outcomes and uninsurance rates across states}

\section{Panel A: Debt collections}

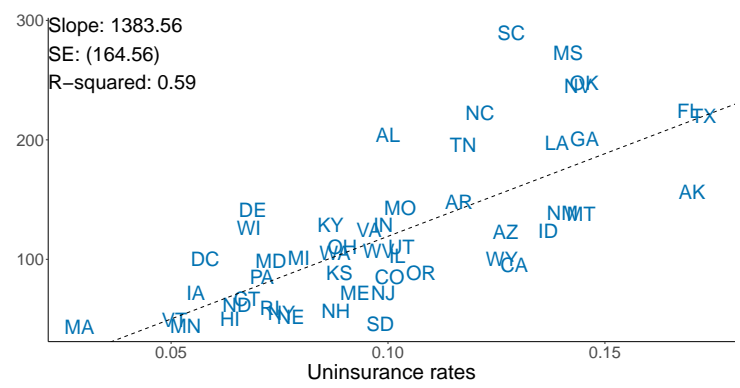

Panel C: Share debt past due

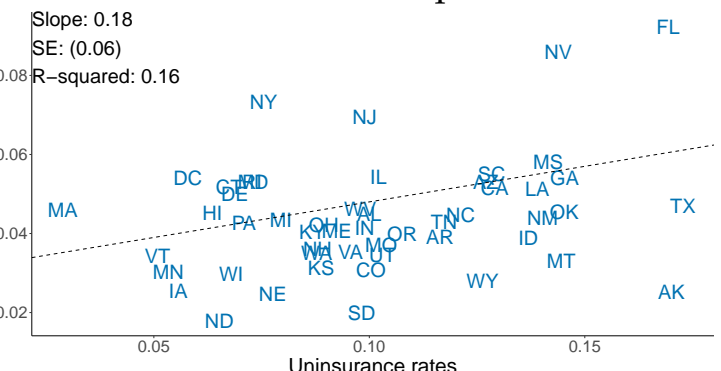

Panel B: Bankruptcy

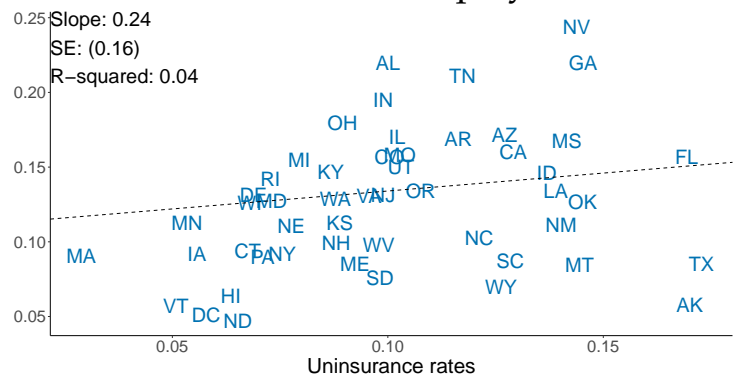

\section{Panel D: Credit Score}

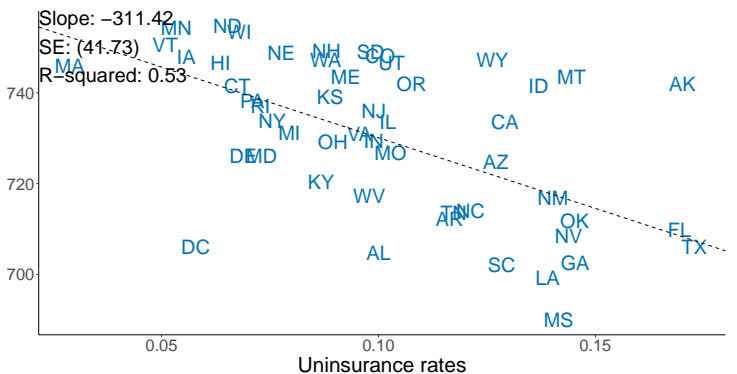

Note: This figure plots consumer credit outcomes against state uninsurance rates for individuals aged 55-64 years old. Panel A plots the dollar value of new collections debt reported on credit reports annually. Panel $B$ plots the annual rate of new bankruptcies in percentage points. Panel $\mathrm{C}$ plots the share of debt that is more than 30 days past due. The share debt past due is calculated as the average individual's debt more than 30 days past due, divided by the average total debt of all individuals of the same age living in that state. Panel D plots credit score data using the Equifax Risk Score 3.0. See Section 2 for additional details on the outcomes and sample. Source: Consumer credit outcomes are based on 137,340,577 person-year observations from the New York Fed Consumer Credit Panel / Equifax, 2008-2017. State-level uninsurance rates are from the American Community Survey, 2008-2017. 
Figure 2: Changes in health insurance coverage at age 65
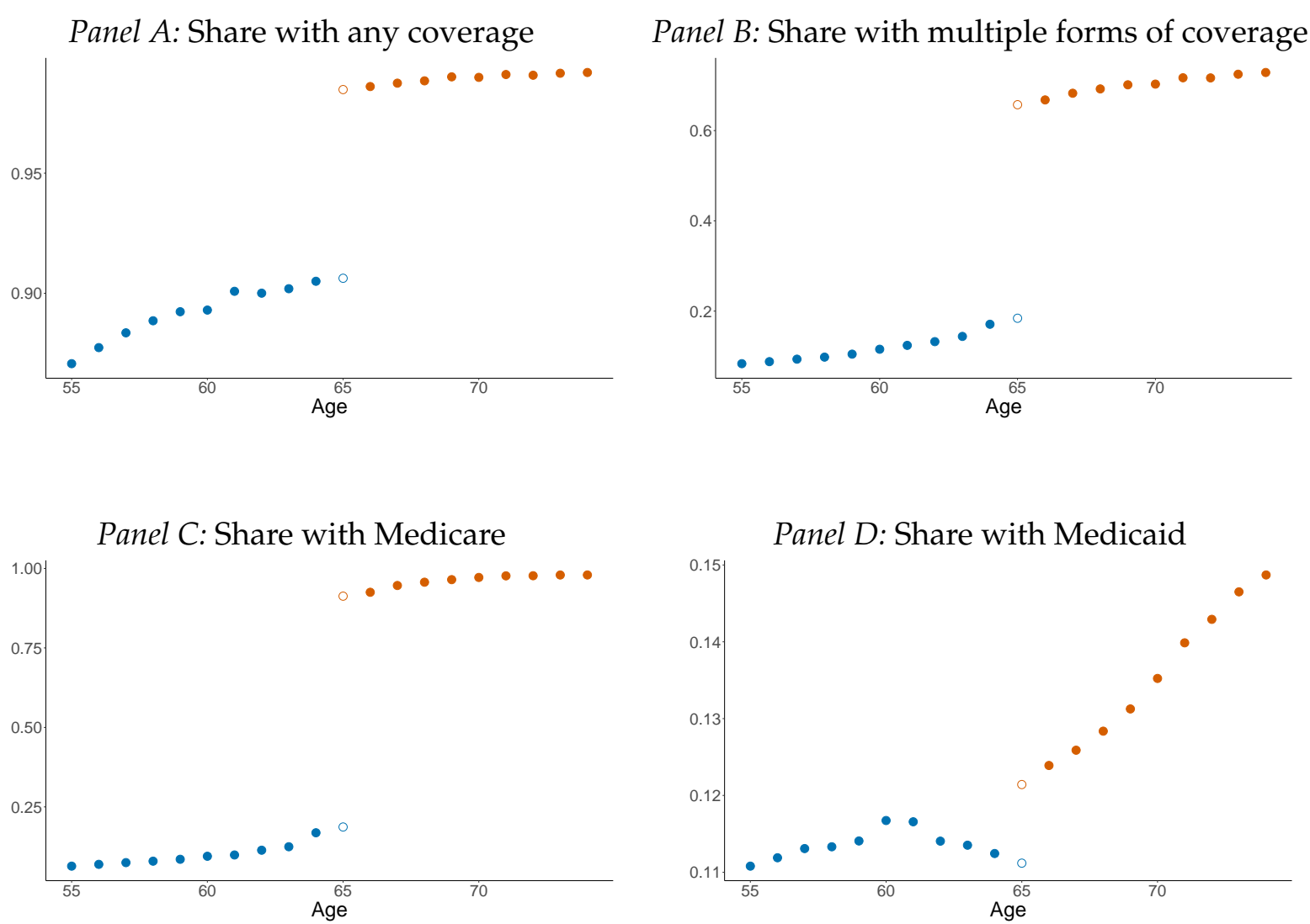

Note: This figure plots health insurance coverage by age. The horizontal axis denotes age in years. Hollow points are the predicted counterfactual outcomes with and without Medicare at 65 . The blue hollow dot is the predicted coverage rate without Medicare and the red hollow dot is the predicted coverage rate with Medicare, estimated using local linear estimation. Panel A plots the share of individuals with any form of coverage. Panel B plots the share of individuals with multiple forms of coverage. Panel C plots the share with Medicare as their primary source of coverage. Panel D plots the share with Medicaid as their primary source of coverage. The sample includes individuals who were age 55-75 between 2008 and 2017. See Section 2 for additional details on the outcomes and sample. Source: American Community Survey, 2008-2017. 
Figure 3: Changes in financial health at age 65

Panel A: Debt collections

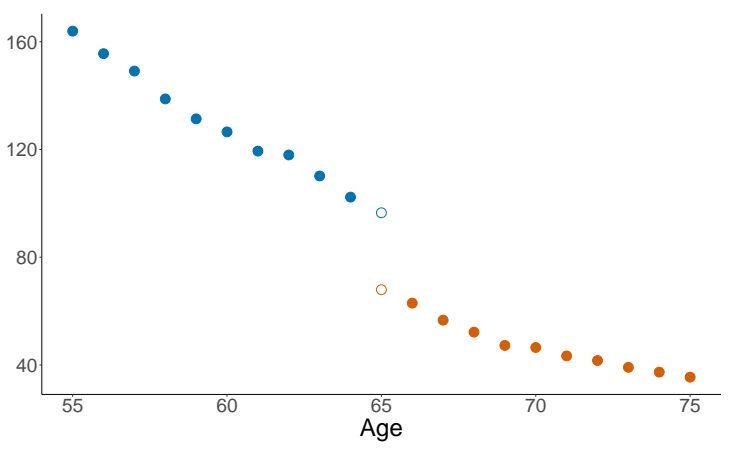

Panel C: Debt past due

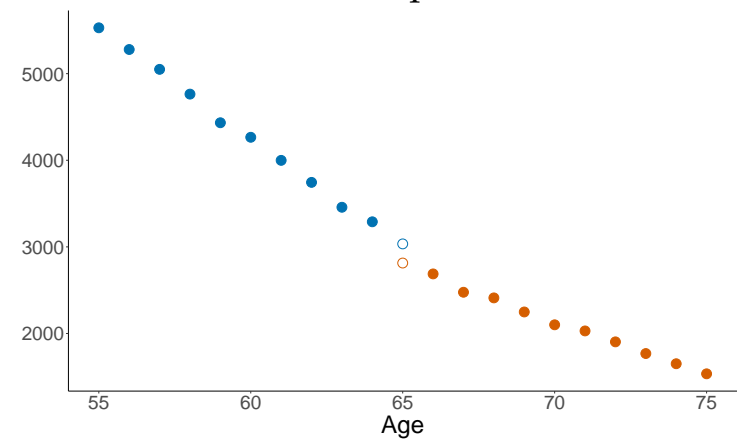

Panel B: Bankruptcy

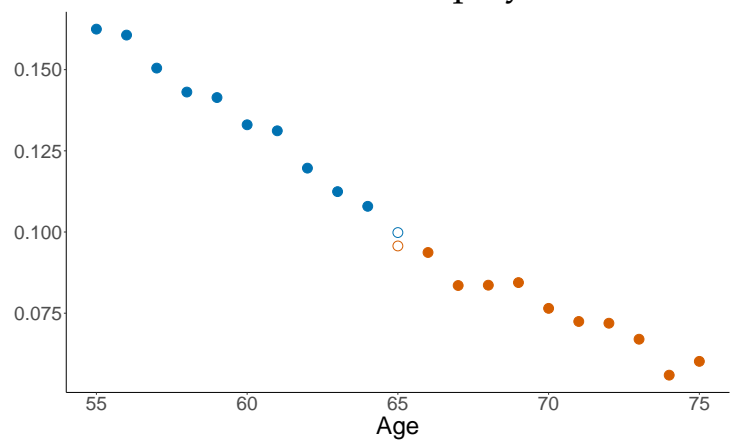

Panel D: Credit Score

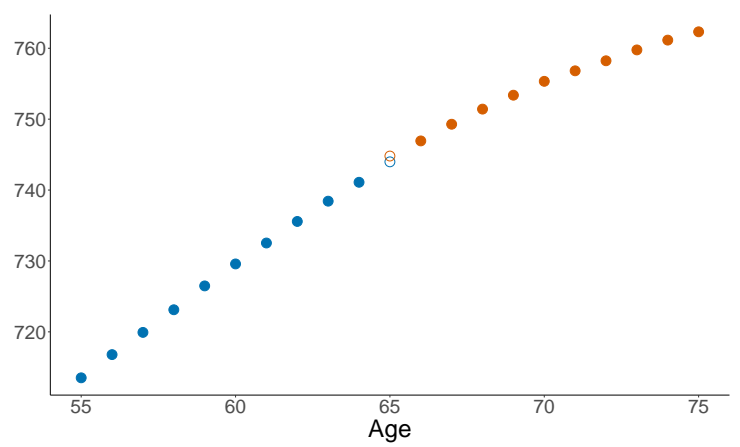

Note: This figure plots consumer credit outcomes by age. The horizontal axis denotes age in years. A local linear regression is fit on each side of the Medicare eligibility threshold using methods from Kolesár and Rothe (2018). We include hollow points that are the predicted counterfactual outcomes with and without Medicare at 65 . The blue hollow dot is the predicted outcome without Medicare at age 65 and the red hollow dot is the predicted consumer credit outcome with Medicare at age 65. Panel A plots the average balance for new debt in collections within the past year. Panel B plots the probability of a new bankruptcy filing within the past year. Panel $\mathrm{C}$ reports the average amount of debt that is more than 30 days past due. Panel D reports credit score data from the Equifax Risk Score 3.0. The sample includes individuals who were age 55-75 between 2008 and 2017. The regressions include 137,340,577 person-year observations. See Section 2 for additional details on the outcomes and sample. Source: New York Fed Consumer Credit Panel / Equifax, 2008-2017. 
Figure 4: Changes in the distribution of collections debt at age 65

Panel A: Raw shares

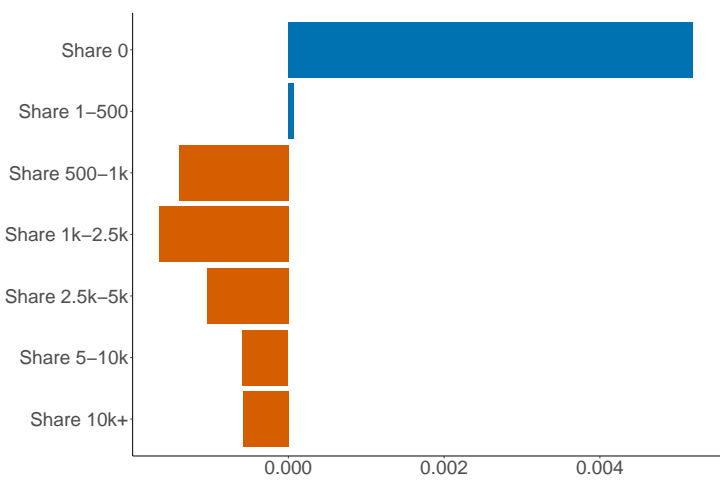

Panel B: Scaled shares

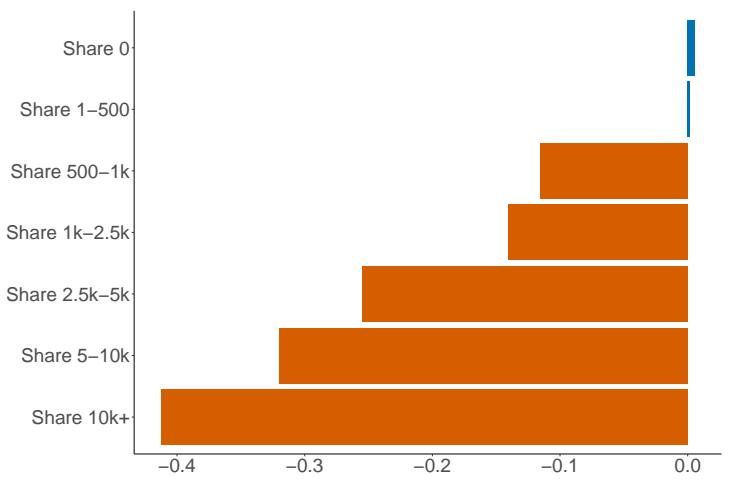

Note: This figure plots the effect of Medicare eligibility at age 65 on the distribution of new collections debts within the past year. The red bars indicate statistically significant results at the $5 \%$ level using methods from Kolesár and Rothe (2018). Panel A plots the effect of gaining Medicare eligibility at age 65 on the raw share of individuals in each mutually-exclusive bin defined by the flow of collections debt within the past year. Panel B scales the effect on the raw shares by the total share within each bin at age 64 . The sample includes individuals who were age 55-75 between 2008 and 2017. The regressions include 137,340,577 person-year observations. See Section 2 for additional details on the outcomes and sample. Source: New York Fed Consumer Credit Panel / Equifax, 2008-2017. 
Figure 5: Counterfactual levels of collections debt by commuting zone at age 65 with and without Medicare

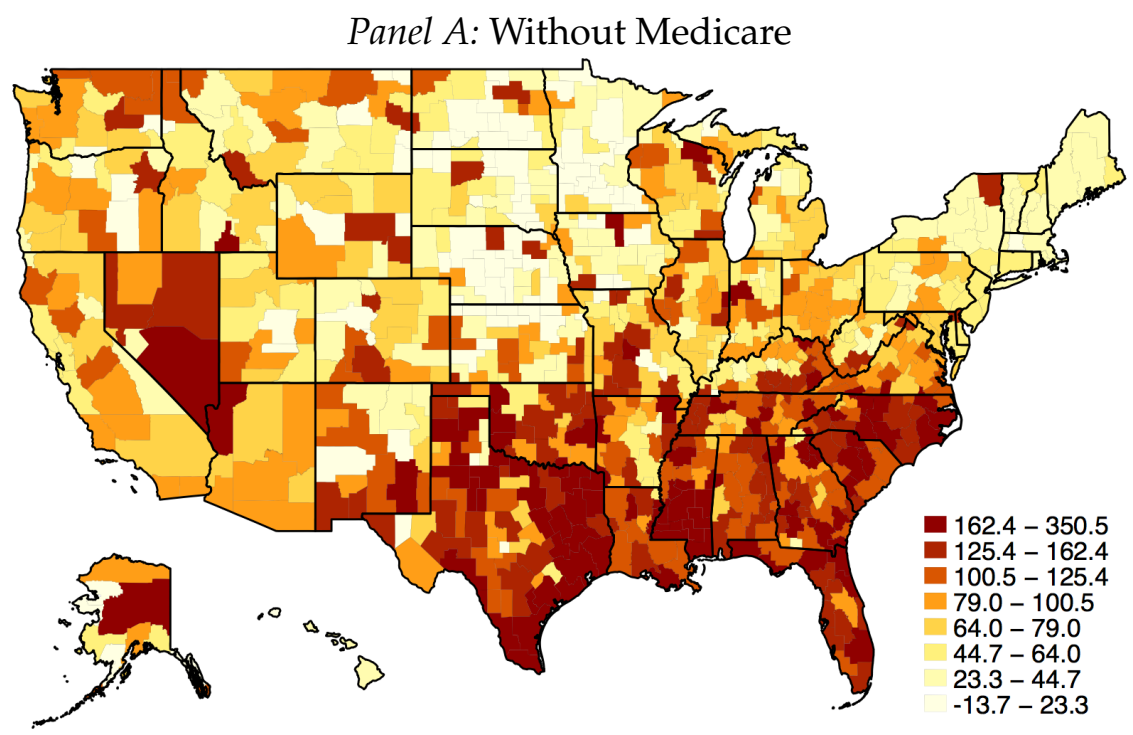

Panel B: With Medicare

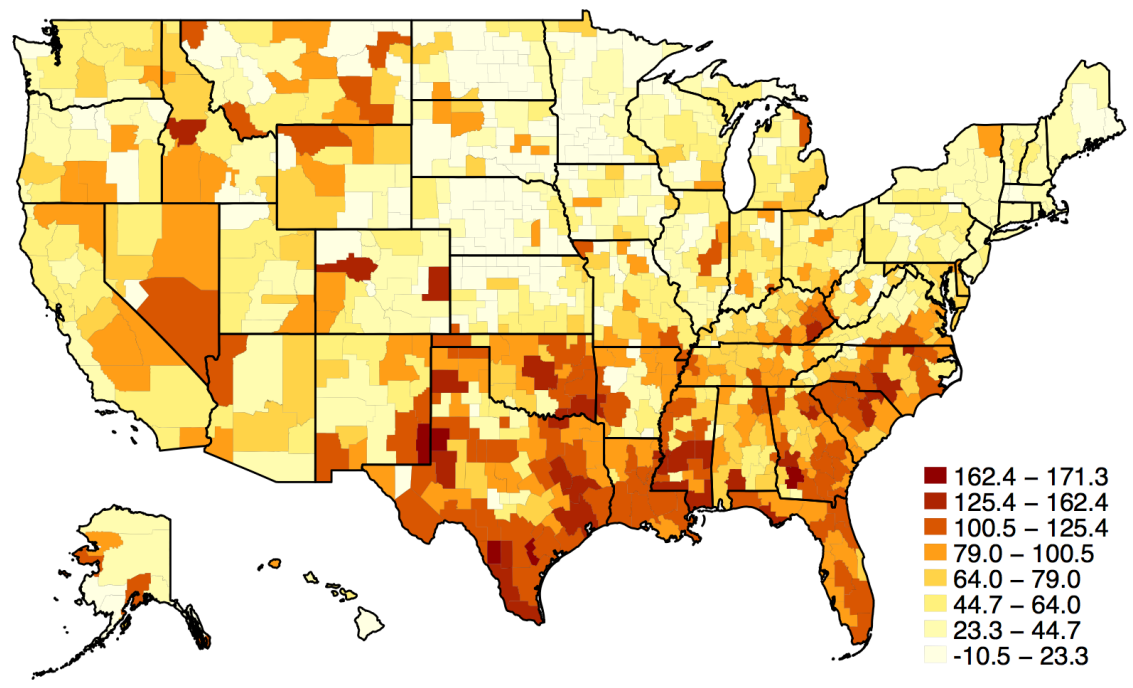

Note: This figure plots our counterfactual estimates of the flow of newly-reported collections debt (within the past year) per capita at age 65, with and without Medicare. The counterfactuals are based on local linear regressions, done separately by commuting zone, using the methods from Kolesár and Rothe (2018). These estimates are then shrunk using empirical Bayes, described in Section 3. Darker regions correspond to higher counterfactual collections debt per capita. Source: Consumer credit outcomes are based on 137,340,577 person-year observations from the New York Fed Consumer Credit Panel / Equifax, 2008-2017. 


\section{Figure 6: Correlates with collections debt with and without Medicare}

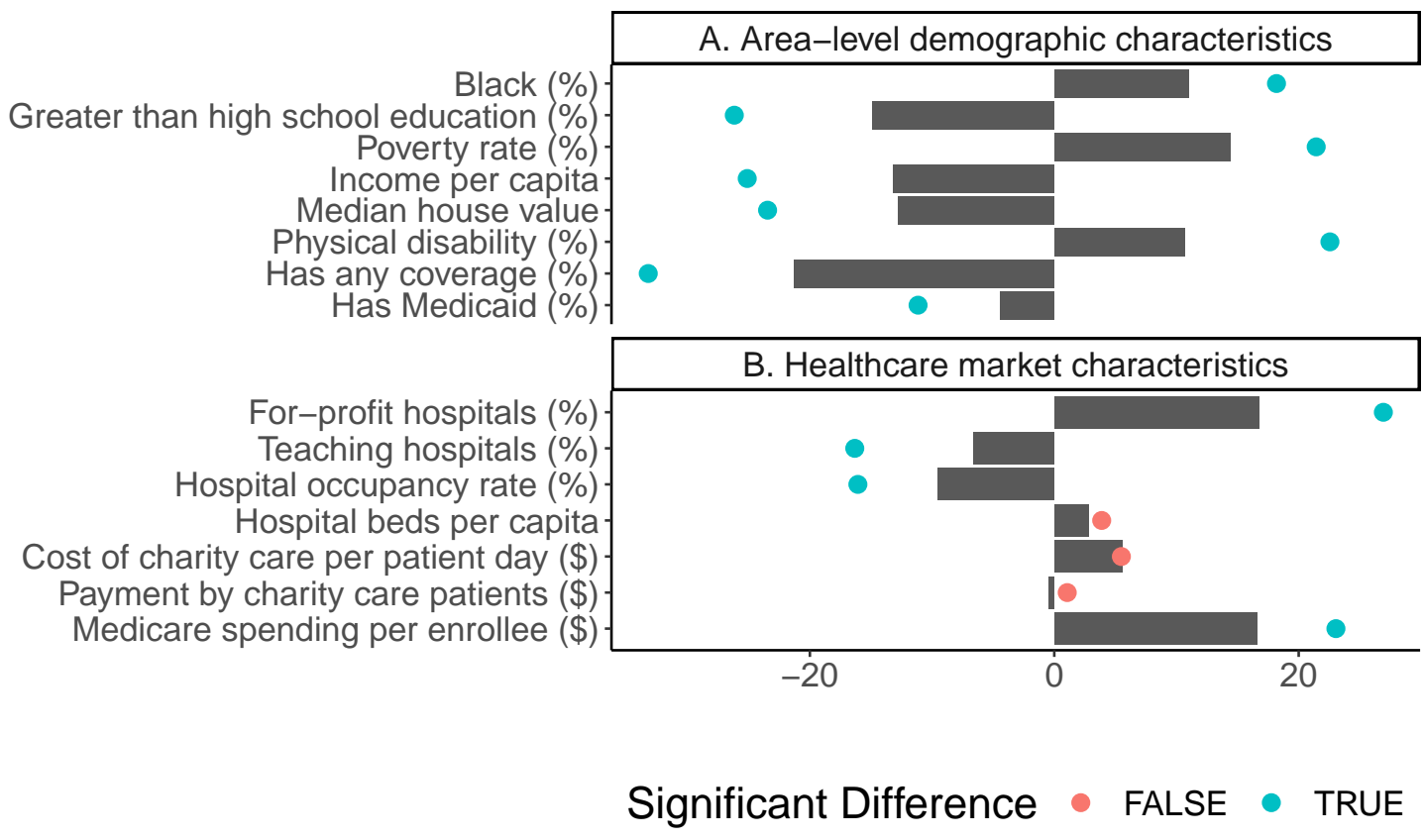

Note: This figure presents CZ-level correlates with our estimated counterfactual flows of newly-reported collections debt (within the past year) at age 65, with and without Medicare. The counterfactuals are estimated using local linear regressions separately for each commuting zone, using the methods from Kolesár and Rothe (2018). The x-axis plots the bivariate coefficient associated with a one standard deviation increase in the area-level correlate. The dots plot the bivariate coefficients from a regression of our counterfactual estimates of collections debt at age 65, without Medicare, and each area-level correlate. The horizontal bars plot the bivariate coefficients from a regression of our counterfactual estimates of collections debt at age 65, with Medicare, and each area-level correlate. The blue dots indicate statistically-significant differences between the bivariate coefficients at age 65, with and without Medicare. Source: Consumer credit outcomes are based on 137,340,577 person-year observations from the New York Fed Consumer Credit Panel / Equifax, 2008-2017. CZ-level uninsurance rates are from the American Community Survey, 2008-2017. Healthcare market characteristics are from the Healthcare Cost Report Information System (HCRIS) and the Dartmouth Atlas. For additional details on the data see Section 2. 
Figure 7: Effect of Medicare eligibility on the level of collections debt at age 65 vs. effects on insurance

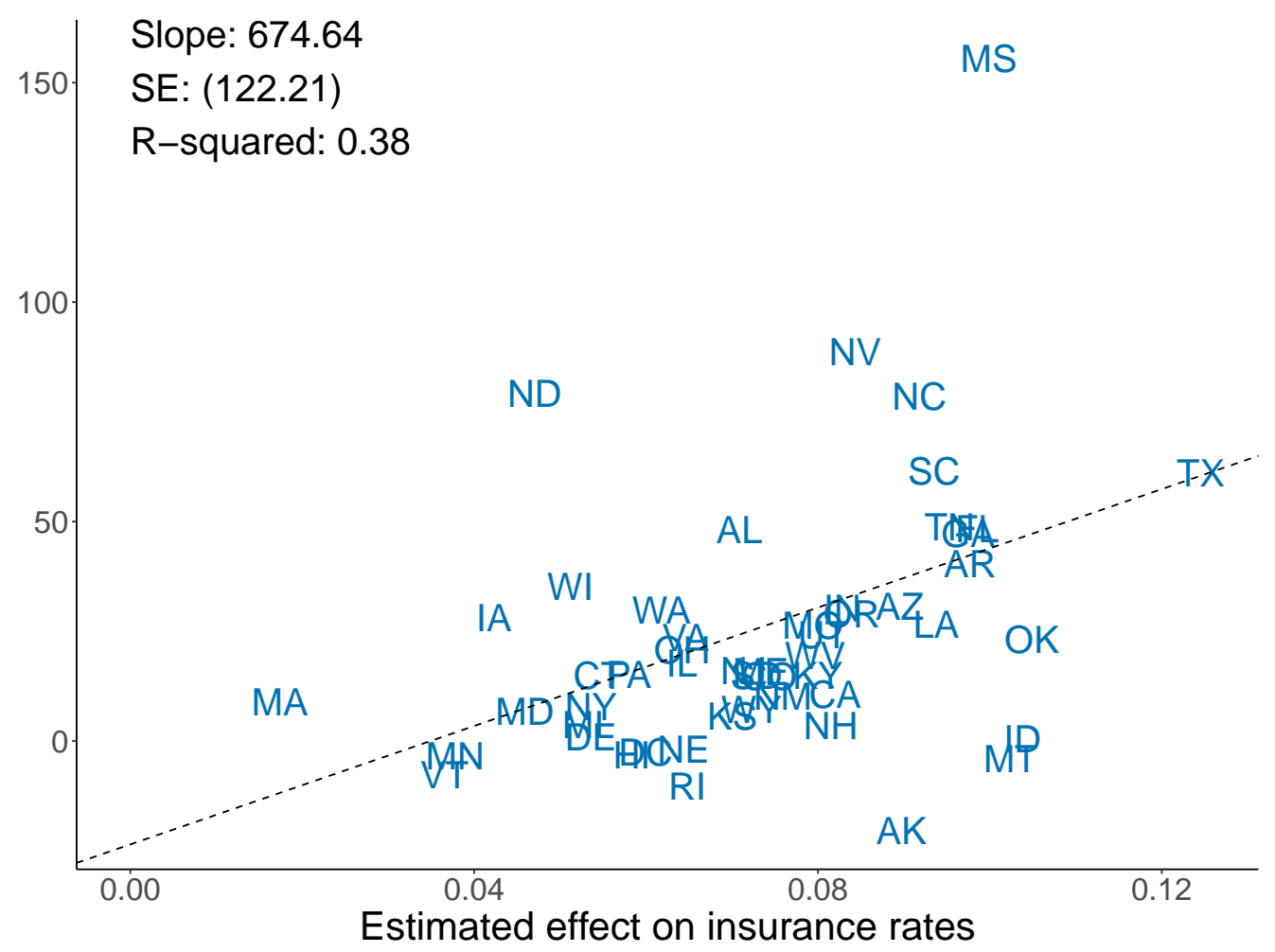

Note: This figure plots point estimates of the reduction in the flow of newly-reported collections debt (within the past year) and the increase in the insurance rate at age 65 based on local linear regressions, done separately by state, using the methods from Kolesár and Rothe (2018). The horizontal axis is the estimated effect on the insurance rate at age 65 by state. The vertical axis is the reduction in the flow of collections debt at age 65 by state. Source: Consumer credit outcomes are based on 137,340,577 person-year observations from the New York Fed Consumer Credit Panel / Equifax, 2008-2017. State-level uninsurance rates are from the American Community Survey, 2008-2017. 


\section{Figure 8: Correlates with reduction in collections debt per capita at age 65}

\section{Panel A: Area-level demographic characteristics}

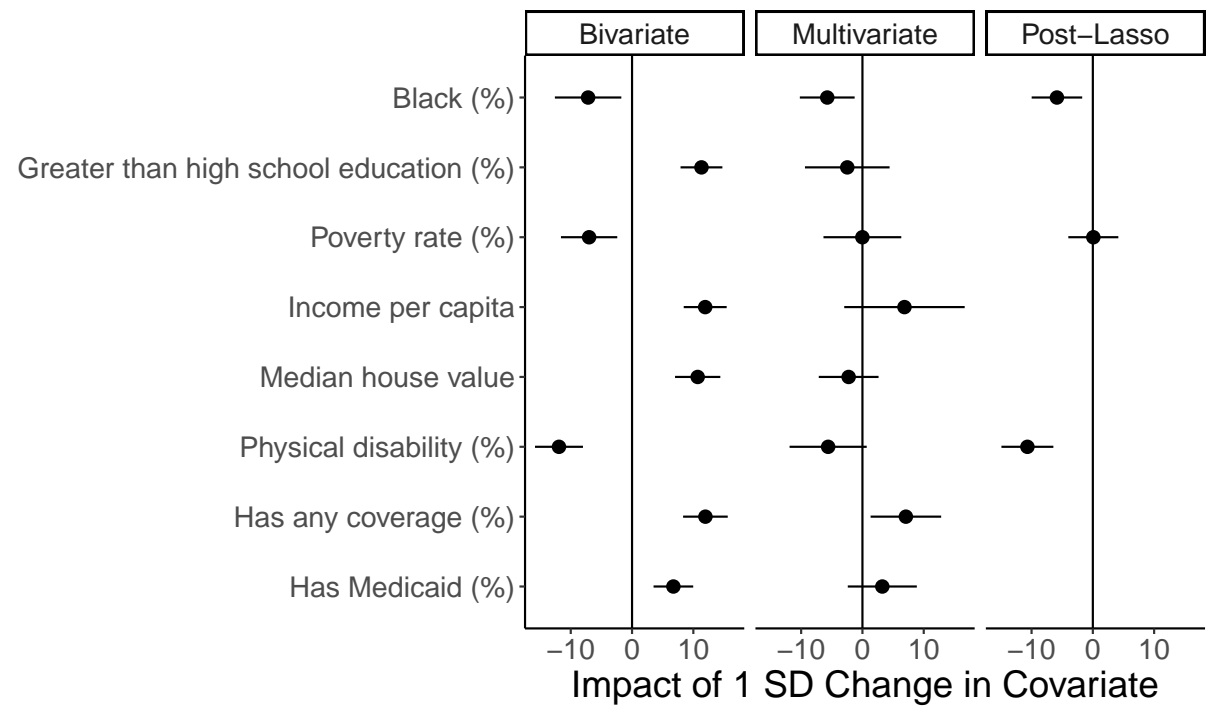

Panel B: Healthcare market characteristics

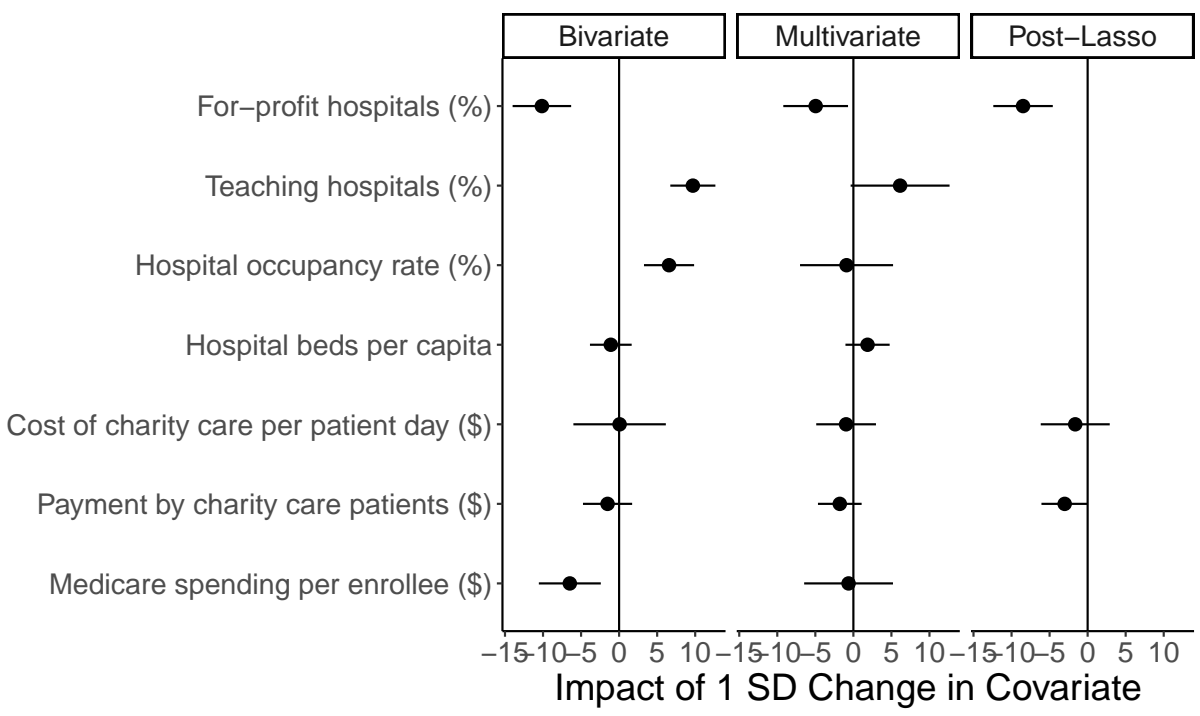

Note: This figure plots bivariate OLS regression results (left panel), multivariate OLS regression results (center panel), and post-Lasso multivariate regression results (right panel) of CZ-level estimated reductions in collections debt per capita on a set of CZ-level characteristics. We standardize all the variables so the coefficients reflect the strength of the association between a one standard deviation change in the covariate and the estimated reduction in collections debt at age 65 . The horizontal bars are 95\% confidence intervals. The multivariate OLS regression results and post-Lasso multivariate regression results are both run on the full set of characteristics in Panels A and B. For post-Lasso, we first estimate a Lasso regression on the full set of characteristics and then report the results of multivariate OLS run on the characteristics chosen by the Lasso regression. Source: Consumer credit outcomes are based on 137,340,577 person-year observations from the New York Fed Consumer Credit Panel / Equifax, 2008-2017. CZ-level uninsurance rates are from the American Community Survey, 2008-2017. Healthcare market characteristics are from the Healthcare Cost Report Information System (HCRIS) and the Dartmouth Atlas. For additional details on the data see Section 2. 


\section{Figure 9: Correlates with reduction in collections debt per newly-insured at age 65}

\section{Panel A: Area-level demographic characteristics}

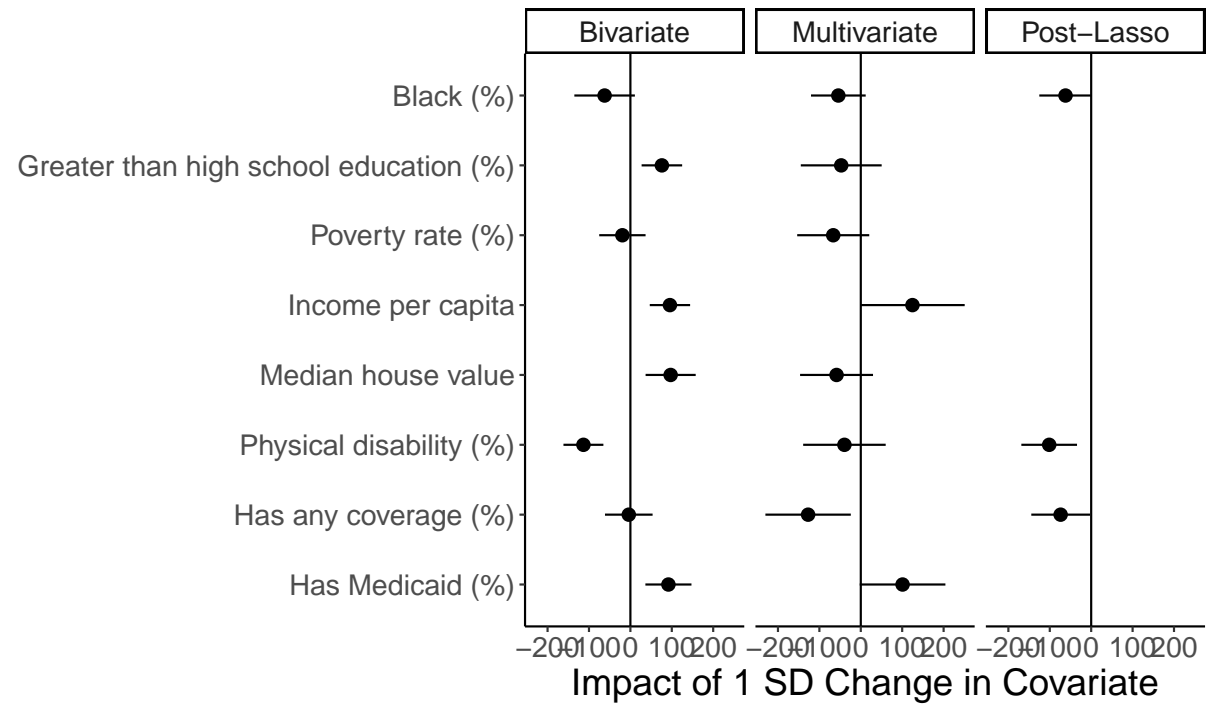

Panel B: Healthcare market characteristics

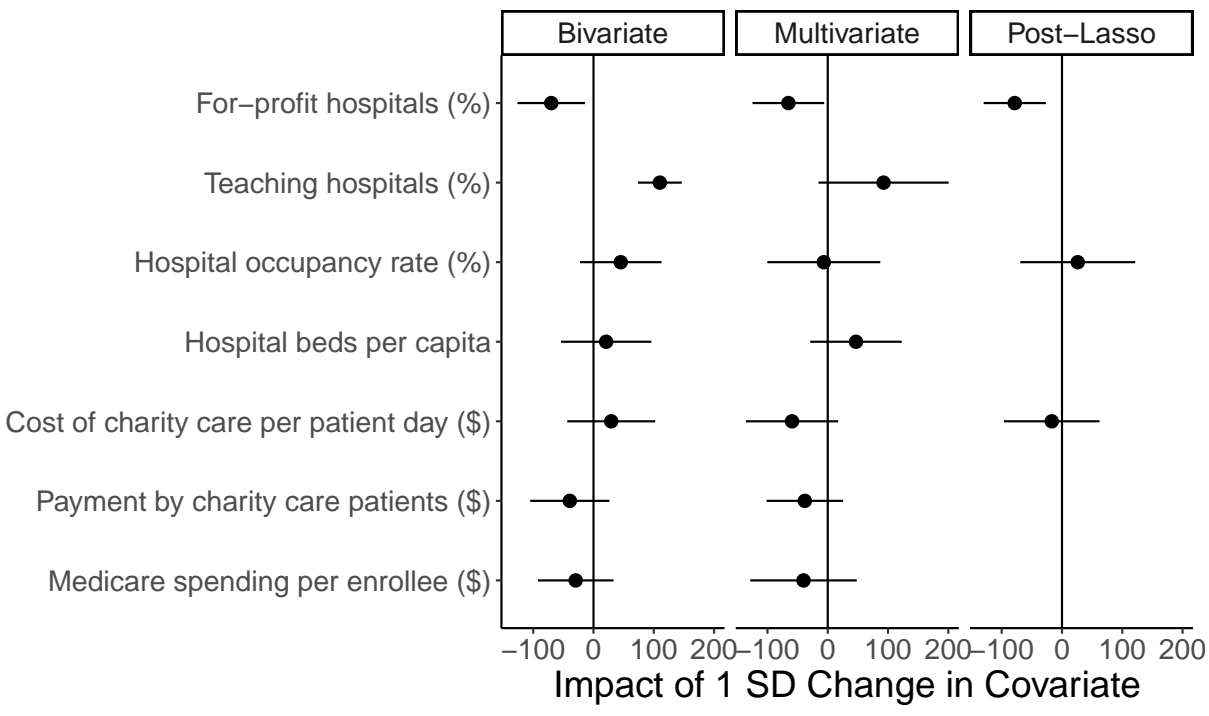

Note: This figure plots bivariate OLS regression results (left panel), multivariate OLS regression results (center panel), and post-Lasso multivariate regression results (right panel) of CZ-level estimated reductions in collections debt per newly-insured on a set of CZ-level characteristics. We standardize all the variables so the coefficients reflect the strength of the association between a one standard deviation change in the covariate and the estimated reduction in collections debt at age 65 . The horizontal bars are $95 \%$ confidence intervals. The multivariate OLS regression results and postLasso multivariate regression results are both run on the full set of characteristics in Panels A and B. For post-Lasso, we first estimate a Lasso regression on the full set of characteristics and then report the results of multivariate OLS run on the characteristics chosen by the Lasso regression. Source: Consumer credit outcomes are based on 137,340,577 person-year observations from the New York Fed Consumer Credit Panel / Equifax, 2008-2017. CZ-level uninsurance rates are from the American Community Survey, 2008-2017. Healthcare market characteristics are from the Healthcare Cost Report Information System (HCRIS) and the Dartmouth Atlas. For additional details on the data see Section 2. 
Figure 10: Forecasts of causal reductions in collections debt from expanding health insurance to the near-elderly by commuting zone

Panel A: Per capita, 2008-2017

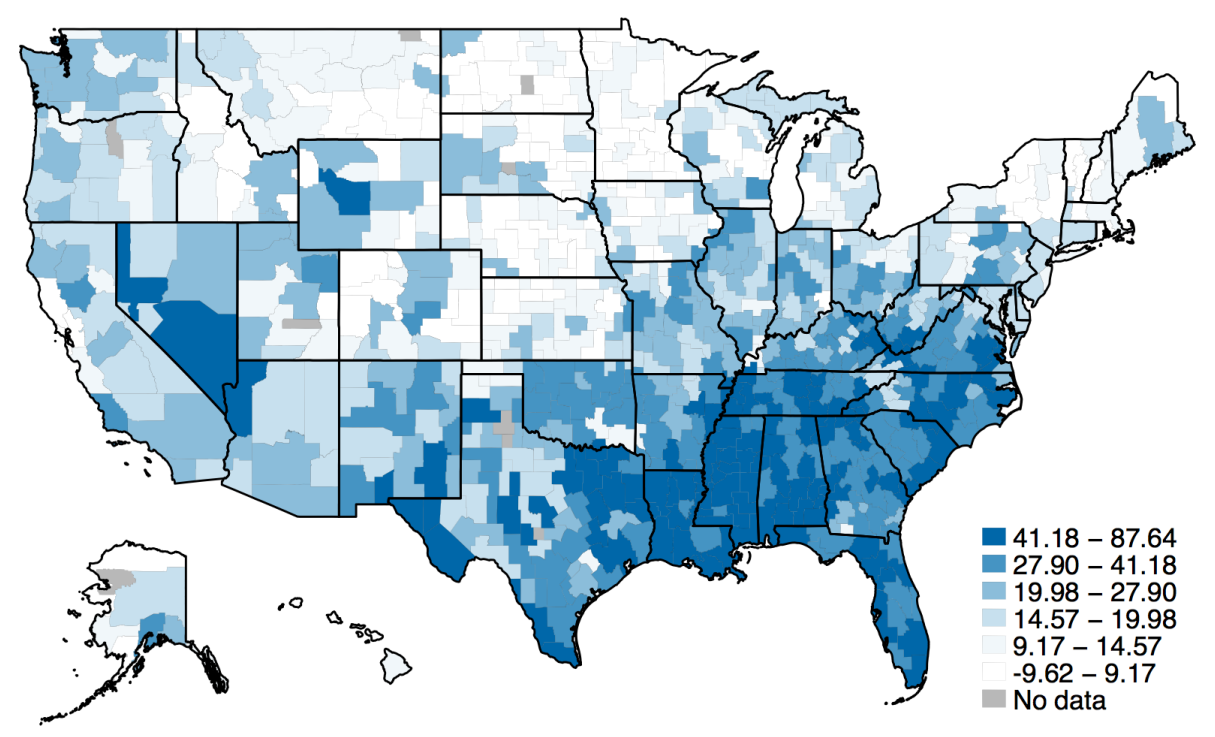

Panel B: Per newly insured, 2008-2017

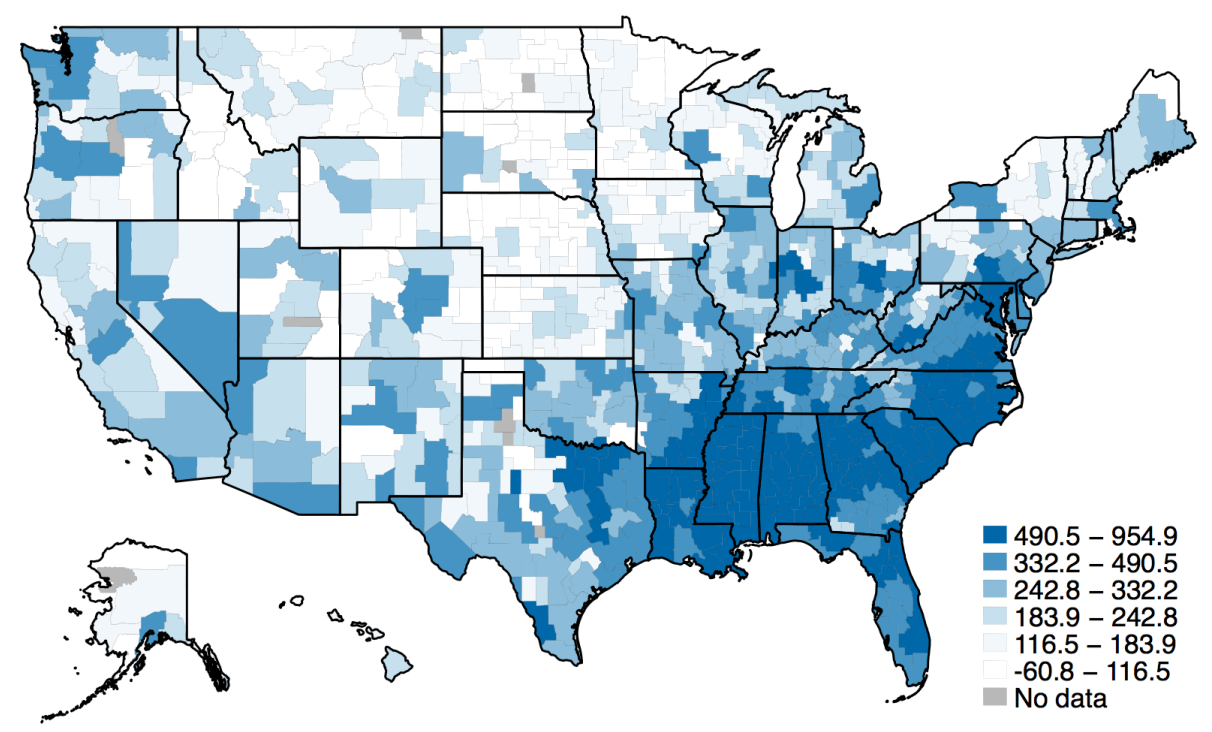

Note: This figure plots mean square error (MSE)-minimizing forecasts of the reductions in collections debt per capita (Panel A) and the reduction in collections debt per newly-insured (Panel B). We construct the MSE-minimizing forecasting by first running a Lasso regression to predict the CZ-level reductions in collections debt per capita (or per newly-insured). This generates a prediction for each CZ, which we call $\hat{\gamma}_{l}$. Following Chetty and Hendren (2018) we then combine the $\hat{\gamma}_{l}$ estimates with our estimates of $\gamma_{l}$ to construct the mean square error-minimizing forecast for each commuting zone, $\gamma_{l}^{f}$. Source: Consumer credit outcomes are based on 137,340,577 person-year observations from the New York Fed Consumer Credit Panel / Equifax, 2008-2017. CZ-level uninsurance rates are from the American Community Survey, 20082017. Healthcare market characteristics are from the Healthcare Cost Report Information System (HCRIS) and the Dartmouth Atlas. For additional details on the data see Section 2. 
Figure 11: Forecasts of causal reductions in collections debt from expanding health insurance to the near-elderly by commuting zone

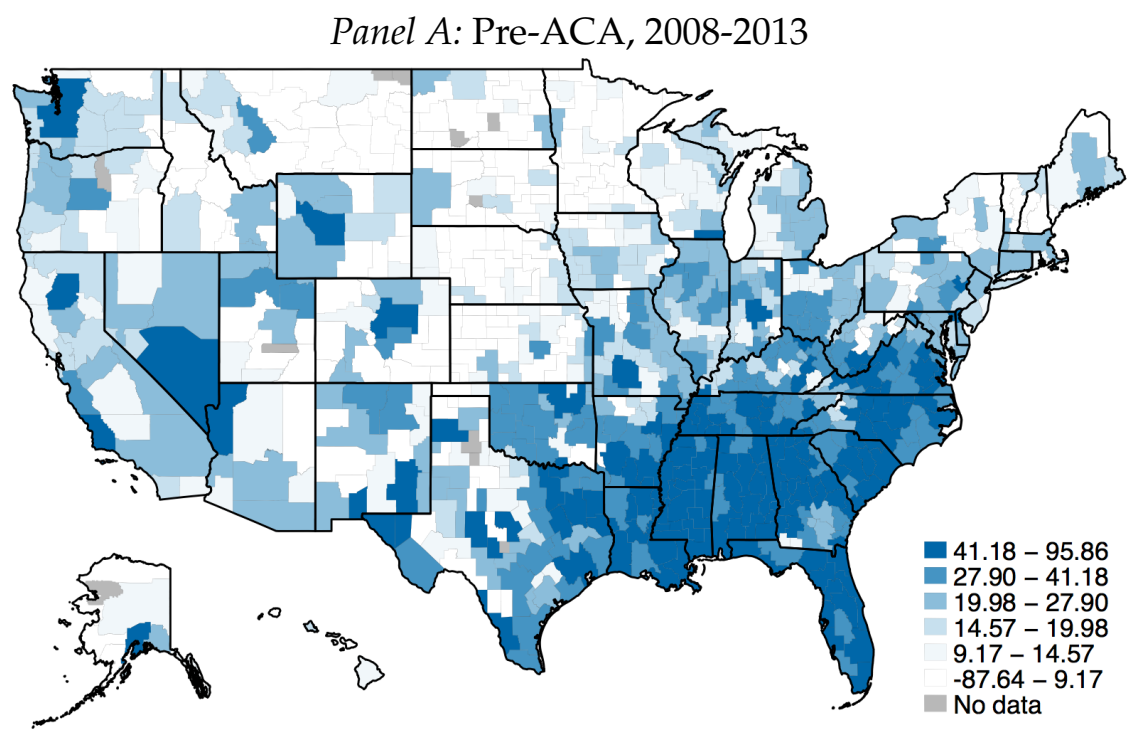

Panel B: Post-ACA, 2014-2017

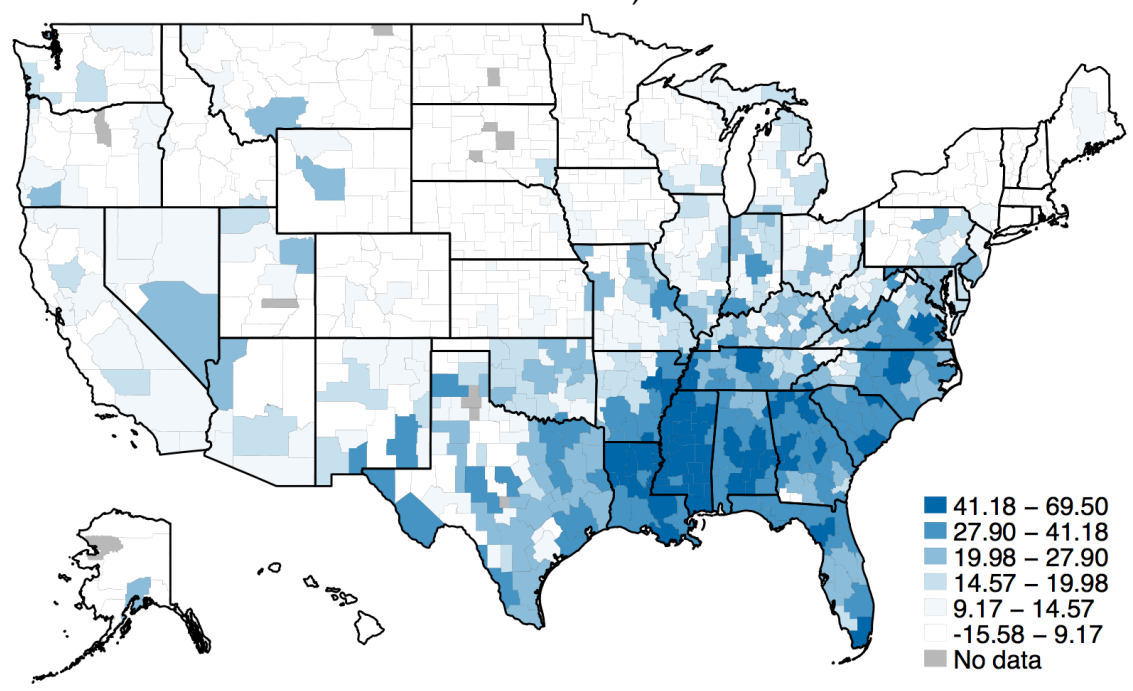

Note: This figure plots mean square error (MSE)-minimizing forecasts of the reductions in collections debt per capita in the pre-ACA (Panel A) and post-ACA period (Panel B). We construct the MSE-minimizing forecasting by first running a Lasso regression to predict the CZ-level reductions in collections debt per capita separate for each period. This generates a prediction for each $\mathrm{CZ}$ in each period, which we call $\hat{\gamma}_{l}$. Following Chetty and Hendren (2018) we then combine the $\hat{\gamma}_{l}$ estimates with our estimates of $\gamma_{l}$ to construct the mean square error-minimizing forecast for each commuting zone in each period, $\gamma_{l}^{f}$. Source: Consumer credit outcomes are based on 137,340,577 person-year observations from the New York Fed Consumer Credit Panel / Equifax, 2008-2017. CZ-level uninsurance rates are from the American Community Survey, 2008-2017. Healthcare market characteristics are from the Healthcare Cost Report Information System (HCRIS) and the Dartmouth Atlas. For additional details on the data see Section 2.. 
Figure 12: Estimated increases in health insurance coverage at the CZ-level vs. forecasts of causal reductions in collections debt per newly-insured

Panel A: ACA Diff-in-disc estimates, 2014-2017 (vs. 2010-2013)

vs. forecasted reductions in collections debt per newly-insured

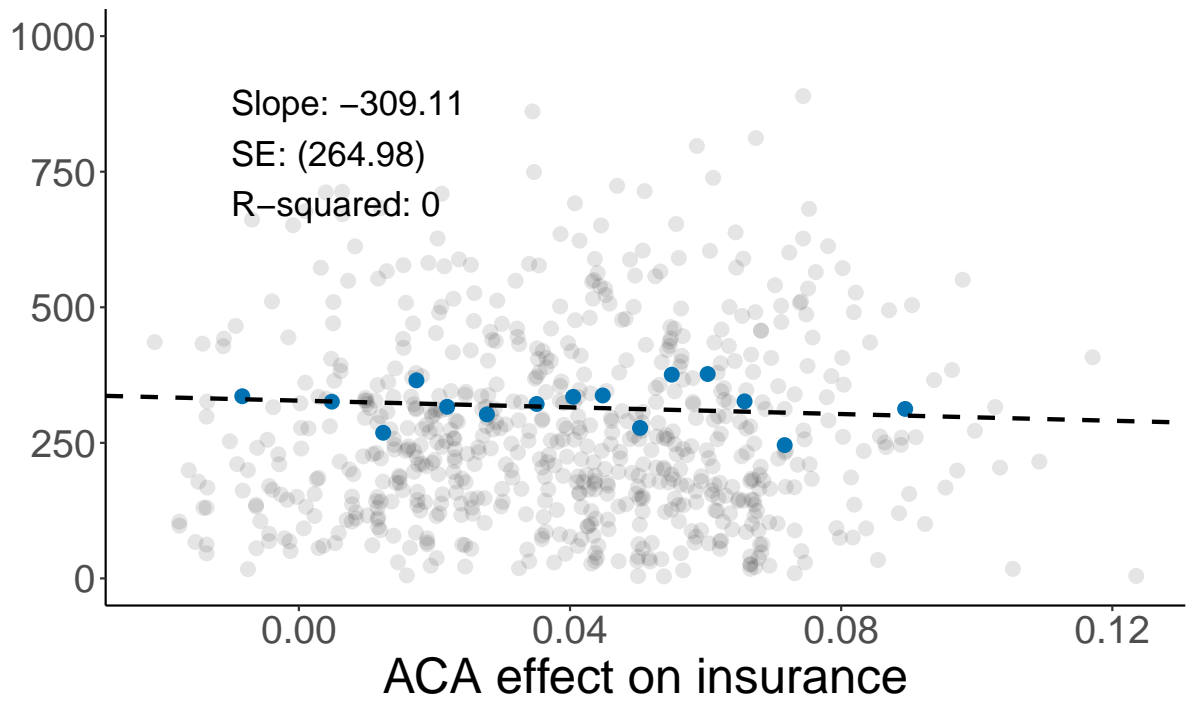

Panel B: Changes in coverage at 65 due to Medicare, 2014-2017

vs. forecasted reductions in collections debt per newly-insured

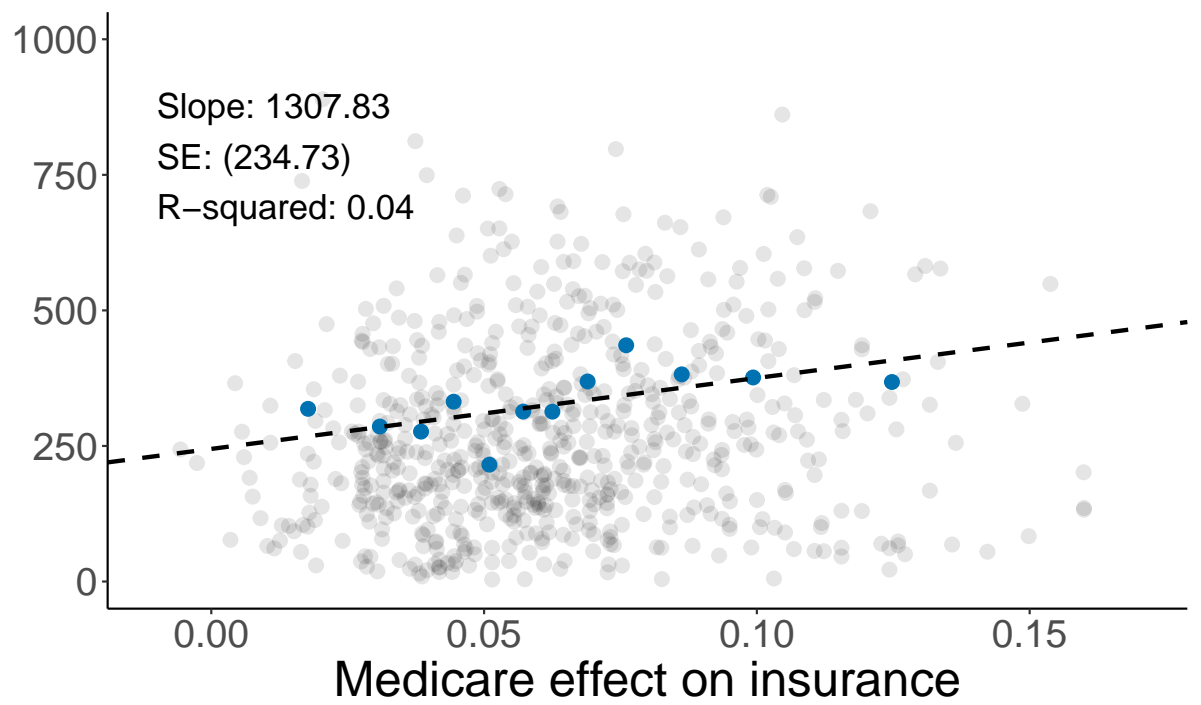

Note: This figure plots CZ-level estimates of the increase in health insurance coverage due to the Affordable Care Act (Panel A) and Medicare eligibility at age 65 (Panel B) against CZ-level mean square error-minimizing forecasts of the reduction in collections per newly-insured. Each light grey dot reflects a commuting zone estimate. The solid blue dots reflect binscatters constructed using optimally chosen bins following Cattaneo et al. (2019). The fitted line comes from the bivariate linear fit, weighted by population. The CZ-level changes in coverage due to the ACA are estimated using a difference-in-discontinuities design similar to Duggan, Gupta and Jackson (2019), comparing the discontinuity in health insurance at age 65 in the post-ACA period (2014-2017) to the discontinuity in health insurance at age 65 prior to its full implementation (2008-2013). The CZ-level changes in coverage due to Medicare eligibility at age 65 are estimated using our CZ-level RD estimation strategy. We construct the MSE-minimizing forecasting of the reduciton in collections debt per newly-insured by combining predictions from a Lasso regression with area-level correlates with our RD estimates to construct the mean square error-minimizing forecast for each commuting zone in each period, $\beta_{1}^{f}$, following Chetty and Hendren (2018). Source: Consumer credit outcomes are based on 137,340,577 person-year observations from the New York Fed Consumer Credit Panel / Equifax, 2008-2017. CZ-level uninsurance rates are from the American Community Survey, 2008-2017. 
Table 1: Changes in covariates and insurance at age 65

\begin{tabular}{|c|c|c|c|c|}
\hline & \multirow[b]{2}{*}{ 65- Mean } & \multirow[t]{2}{*}{ Overall } & \multicolumn{2}{|c|}{ Near-elderly uninsurance } \\
\hline & & & Bottom Half & Top Half \\
\hline & (1) & (2) & (3) & (4) \\
\hline \multicolumn{5}{|l|}{ Panel A: Covariate smoothness } \\
\hline \multirow[t]{2}{*}{ Homeowner } & 0.812 & $\begin{array}{c}0.002 \\
(0.007)\end{array}$ & $\begin{array}{l}0 \\
(0.01)\end{array}$ & $\begin{array}{c}0.004 \\
(0.009)\end{array}$ \\
\hline & & $\begin{array}{r}{[-0.011,} \\
0.015]\end{array}$ & $\begin{array}{r}{[-0.018,} \\
0.018]\end{array}$ & {$\left[\begin{array}{r}-0.013 \\
0.021]\end{array}\right.$} \\
\hline \multirow[t]{2}{*}{ Married } & 0.650 & $\begin{array}{c}-0.001 \\
(0.003)\end{array}$ & $\begin{array}{c}-0.004 \\
(0.005)\end{array}$ & $\begin{array}{c}0.001 \\
(0.004)\end{array}$ \\
\hline & & $\begin{array}{r}{[-0.008,} \\
0.006]\end{array}$ & $\begin{array}{r}{[-0.014,} \\
0.006]\end{array}$ & $\begin{array}{r}{[-0.007,} \\
0.009]\end{array}$ \\
\hline \multirow[t]{2}{*}{ Employed } & 0.377 & $\begin{array}{c}-0.028 \\
(0.004)\end{array}$ & $\begin{array}{c}-0.034 \\
(0.006)\end{array}$ & $\begin{array}{c}-0.023 \\
(0.006)\end{array}$ \\
\hline & & $\begin{array}{c}{[-0.087,} \\
0.03]\end{array}$ & $\begin{array}{c}{[-0.099,} \\
0.03]\end{array}$ & $\begin{array}{r}{[-0.082,} \\
0.036]\end{array}$ \\
\hline \multirow[t]{3}{*}{ Income } & 41122.287 & 762.155 & 836.462 & 672.828 \\
\hline & & $(608.73)$ & $(831.22)$ & (944.432) \\
\hline & & $\begin{array}{r}{[-839.963,} \\
2364.274]\end{array}$ & $\begin{array}{r}-1287.841 \\
2960.765]\end{array}$ & $\begin{array}{r}{[-1314.416} \\
2660.072\end{array}$ \\
\hline \multirow[t]{3}{*}{ Usual hours worked per week } & 15.676 & -1.002 & -1.246 & -0.771 \\
\hline & & $(0.179)$ & $(0.263)$ & $(0.256)$ \\
\hline & & $\begin{array}{r}{[-3.659,} \\
1.654]\end{array}$ & $\begin{array}{r}{[-4.126} \\
1.634]\end{array}$ & {$\left[\begin{array}{c}-3.463 \\
1.92]\end{array}\right.$} \\
\hline \multirow[t]{4}{*}{ Social security income } & 7351.377 & 1870.841 & 1947.382 & 1795.787 \\
\hline & & $(125.884)$ & $(130.865)$ & (189.349) \\
\hline & & {$[-596.668$,} & {$[-614.322$,} & {$[-691.617$} \\
\hline \multirow{2}{*}{\multicolumn{5}{|c|}{ Panel B: Health Insurance Outcomes }} \\
\hline & & & & \\
\hline \multirow[t]{3}{*}{ Has health insurance coverage } & 0.906 & $\begin{array}{r}0.079 * \\
(0.004)\end{array}$ & $\begin{array}{c}0.058 * \\
(0.002)\end{array}$ & $\begin{array}{r}0.098 * \\
(0.005)\end{array}$ \\
\hline & & {$[0.068$,} & {$[0.051$} & {$[0.084$} \\
\hline & & $0.089]$ & $0.065]$ & $0.112]$ \\
\hline \multirow[t]{3}{*}{ Has multiple insurance coverages } & 0.184 & $0.473 *$ & $0.508 *$ & $0.439 *$ \\
\hline & & $\begin{array}{l}(0.006) \\
{[0.448}\end{array}$ & $\begin{array}{l}(0.005) \\
{[0.482}\end{array}$ & $(0.008)$ \\
\hline & & 0.498 & $0.533]$ & 0.466 \\
\hline \multirow[t]{4}{*}{ Has insurance through Medicare } & 0.187 & $0.726 *$ & $0.739 *$ & $0.713 *$ \\
\hline & & $(0.003)$ & $(0.004)$ & $(0.005)$ \\
\hline & & {$[0.695$} & {$[0.708$} & {$[0.678$,} \\
\hline & & $0.757]$ & $0.771]$ & $0.748]$ \\
\hline \multirow[t]{4}{*}{ Has insurance through Medicaid } & 0.111 & 0.01 & 0.008 & 0.013 \\
\hline & & $(0.005)$ & $(0.006)$ & $(0.007)$ \\
\hline & & {$[-0.001$,} & {$[-0.005$,} & {$[-0.003$} \\
\hline & & $0.021]$ & $0.021]$ & $0.028]$ \\
\hline
\end{tabular}

Note: This table reports regression discontinuity estimates of the effect of Medicare eligibility on covariates and health insurance outcomes. Column 1 reports the predicted dependent variable mean at age 65 without Medicare. Column 2 reports the point estimate, standard error, and bias-adjusted 95\% confidence interval from a local linear regression using techniques from Kolesár and Rothe (2018). Columns 3 and 4 report the point estimate, standard error, and bias-adjusted $95 \%$ confidence intervals from estimating our model on samples split by above- and below-median state near-elderly uninsurance rates. The sample includes individuals who were age 55-75 between 2008 and 2017. See Section 2 for additional details on the outcomes and sample. Source: American Community Survey, 2008-2017. 
Table 2: Changes in financial outcomes at age 65

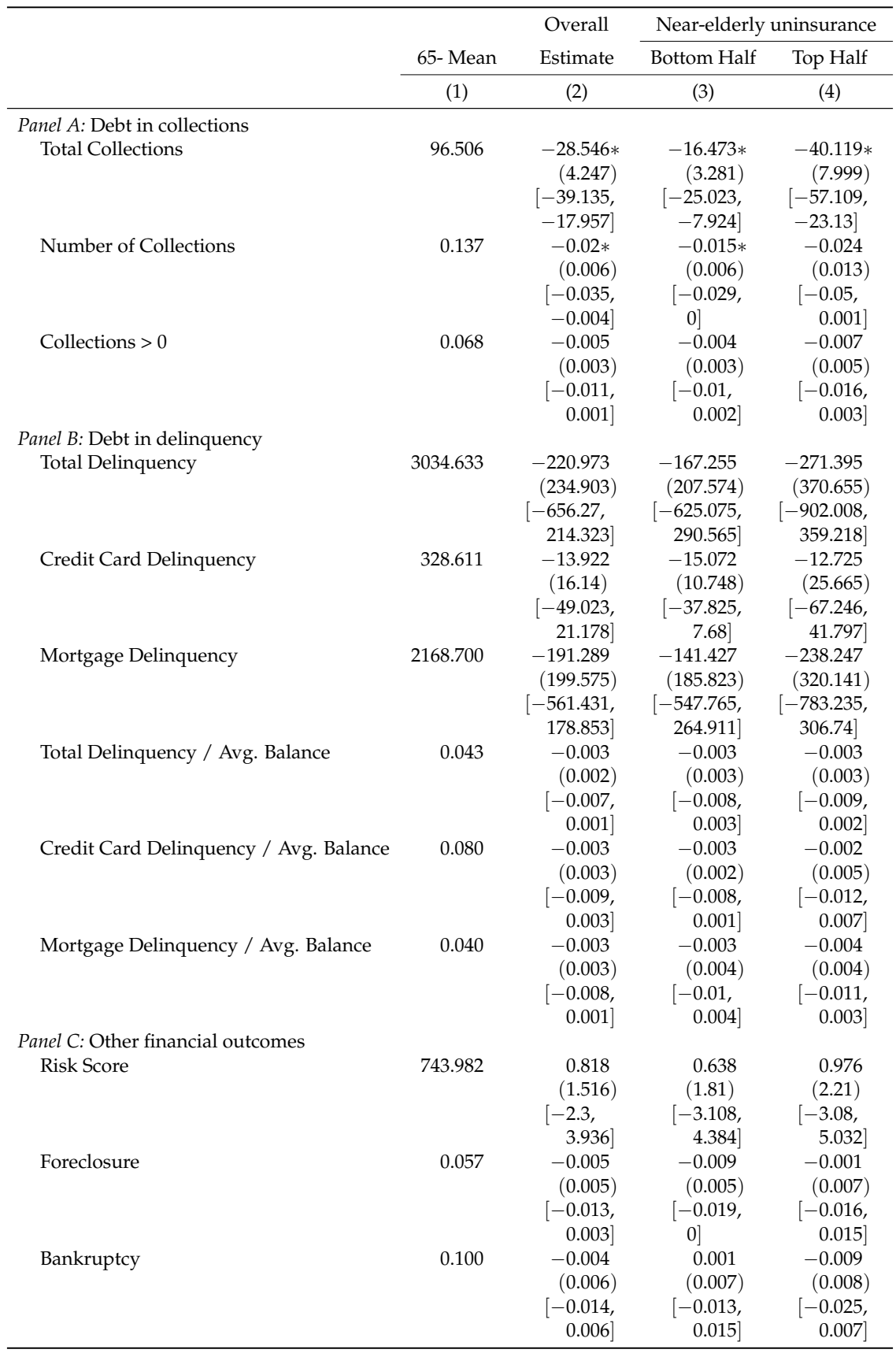

Note: This table reports regression discontinuity estimates of the effect of Medicare eligibility on financial health. Column 1 reports the predicted dependent variable mean at age 65 without Medicare. Column 2 reports the point estimate, standard error, and bias-adjusted 95\% confidence interval from a local linear regression using techniques from Kolesár and Rothe (2018). Columns 3 and 4 report the point estimate, standard error, and bias-adjusted $95 \%$ confidence intervals from estimating our model on samples split by above- and below-median state near-elderly uninsurance rates. The share debt delinquent is calculated as the average individual's debt currently in delinquency, divided by the average total debt of all individuals of the same age living in that state. We divide by this average, rather than individuals' own debt levels, to avoid the divide-by-zero problem. The sample includes individuals who were age 55-75 between 2008 and 2017. Credit score data used is from Equifax Risk Score 3.0. The regressions include 137,340,577 person-year observations. See Section 2 for additional details on the outcomes and sample. New York Fed Consumer Credit Panel / Equifax, 2008-2017. 


\section{A The effects of Medicare eligibility at the national level before and after implementation of the ACA}

In this section, we study how the passage of the Affordable Care Act (ACA) has reshaped the transition to Medicare. We do so by estimating Equation 2 before and after the implementation of the Affordable Care Act in 2014. To provide some graphical motivation for this exercise, Appendix Figure A8 presents estimates of the share of individuals with different forms of health insurance by age before and after the implementation of the Affordable Care Act (ACA). Panel A shows that post-ACA, the discontinuity in health insurance at age 65 shrinks considerably. This is not surprising, given the broad evidence that the ACA expanded coverage, but it does raise questions about whether eligibility for Medicare at age 65 still causally reduces consumer financial strain. ${ }^{38}$

In Appendix Table A5, we report the regression discontinuity estimates of the effect of Medicare eligibility on health insurance status and financial health, split by pre- and post-ACA. In Columns 1 and 5, we report the estimated mean of individuals at age 65, without Medicare, as estimated using $\hat{f}(65)$ from Equation 2. Column 1 reports the mean in the pre-ACA period and Column 5 reports the mean in the post-ACA period. In Columns 2 and 6 we report the overall estimated discontinuities in health insurance coverage pre- and post-ACA, respectively. We then examine whether the pre- and post-ACA average treatment effects vary based on whether a state was in the bottom (Columns 3 and 6) or top (Column 4 and 7) half of the near-elderly uninsurance rate distribution according to the 2012 American Community Survey 5-year estimates. We discuss formal tests of the difference between the estimates below.

The implementation of the ACA muted the effects of Medicare on health insurance rates. This is due to the large increase in the share of individuals with insurance prior to becoming eligible for Medicare at age 65, which rose from 88.7 percentage points in the pre-ACA period to 92.9 percentage points in the post-ACA period, a sharp reduction (37 percent) in the uninsurance rate for the near-elderly consistent with an expansion of coverage due to the ACA (Sommers et al., 2014, 2015, 2016; Courtemanche et al., 2017; Frean, Gruber and Sommers, 2017). As a result, Medicare's effect on the insurance rate declined from a 9.7 percentage point increase pre-ACA to a 5.6 percentage point increase post-ACA, a decrease of $42 \%$.

Panel B of Appendix Table A5 reports regression discontinuity estimates of the effect of Medicare eligibility on debts in collection pre- and post-ACA. ${ }^{39}$ In Columns 1 and 5, we see that the

\footnotetext{
${ }^{38}$ Panel A shows a large, and discontinuous, increase in the share of individuals with any form of coverage at 65 . The discontinuity shrinks considerably from the pre- to post-ACA periods. The increase in coverage at 65 is coupled with an increase of approximately 40 percentage points (or 200\%) in the share of individuals with more than one form of health insurance (Panel B). Panel C of Appendix Figure A8 shows that the coverage increases were driven by a large increase in the share of individuals with Medicare which rises to nearly $100 \%$ after age 65 . The estimated discontinuities in the share of individuals with multiple forms of coverage and Medicare almost identical between the pre- and post-ACA period. Panel D provides graphical evidence of a change in the discontinuity in Medicaid coverage at 65 . Prior to the implementation of the ACA, there was a small, but discontinuous, increase in the share of individuals with Medicaid coverage at 65 . After the implementation of the ACA, the discontinuity reversed, with a small, but insignificant, decrease in the share of individuals with Medicaid coverage at 65. The ACA Medicaid expansions did not apply to individuals aged 65 and older, which may explain why the discontinuity in Medicaid coverage at 65 is now slightly negative.

${ }^{39}$ We focus on collection-related variables because the effects of turning 65 on other financial measures that we have
} 
flow of collections debt for individuals at age 65, without Medicare, falls from $\$ 106$ pre-ACA to $\$ 87$ post-ACA. However, the estimated discontinuity in collections debt was relatively stable in the two periods, despite the smaller effect of Medicare eligibility on the insurance rate. Prior to the ACA (2008-2013) the estimated discontinuity was $\$ 31.4$ on a baseline of $\$ 106.5$ (29.5\%) and after the ACA was implemented (2014-2017) the estimated discontinuity was $\$ 25.5$ on a baseline of $\$ 87.1$ (29.3\%).

We find heterogeneity in the reductions in collections debt based on a state's uninsurance rate for the near-elderly before and after the implementation of the ACA. For both periods, reductions in collections debt in states with above median near-elderly uninsurance rates were approximately 2.5 times larger than states with below median near-elderly uninsurance rates. When we examined the number of per capita collections debts, as opposed to the dollar amount in collections, we found smaller but statistically significant reductions of approximately $14 \%$ in the number of collections per capita at 65 . Similarly, we found small (7\%), and statistically insignificant, reductions in the share of individuals with any debt in collections pre- and post-ACA. If we scale our total collections debt in dollars estimates by the share of pre-65 year olds with nonzero collections, the reductions in debt collections at 65 conditional on having a collections debt were $\$ 450$ and $\$ 385$ preand post-ACA, respectively.

Next, we explore the apparent paradox of a sharp reduction in the discontinuity in health insurance post-ACA without a concomitant reduction in the discontinuity in collections debt. To do so, we consider whether the ACA's impact on consumer financial strain depended on the type of coverage expansion (i.e. Medicaid vs. exchange). We follow Duggan, Gupta and Jackson (2019) and identify the 32 states that expanded Medicaid. In Appendix Table A6 we report differencein-discontinuities estimates of the effect of the ACA on health insurance and financial health. First, we document that the near-elderly experienced similar reductions in uninsurance in both sets of states, but the sources of these coverage expansions were very different. Second, for debts in collection, we find a statistically significant $\$ 11$ per capita reduction in the discontinuity in expansion states but no effect in the nonexpansion states. Since over half the coverage gains from the ACA for the near-elderly were via private insurance, one explanation for why Medicare still sharply reduces collections debt in the post-ACA period is that much of the takeup of insurance among the near-elderly was of less generous private insurance coverage. ${ }^{40}$

considered are insignificant; we present estimated effects for other financial measures in Appendix Table A7.

${ }^{40}$ Since Medicaid does not typically have copayments, coinsurance, or deductibles for its services and does not allow balance billing of the patient, it provides protection against the possibility that a patient's healthcare use would generate bills that eventually create debts in collection. 


\section{Figure A1: Smoothness of covariates at age 65}

Panel A: Share homeowners by age in years

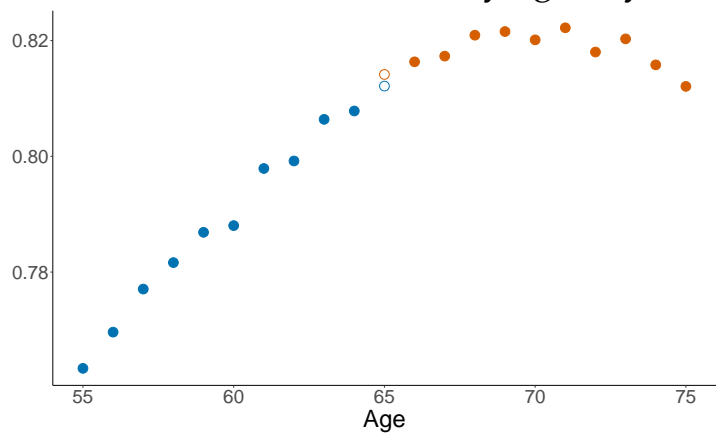

Panel C: Share employed by age in years

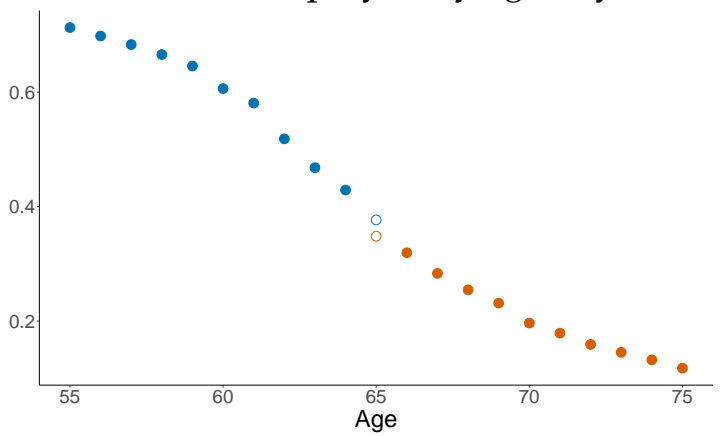

Panel E: Usual hours worked per week

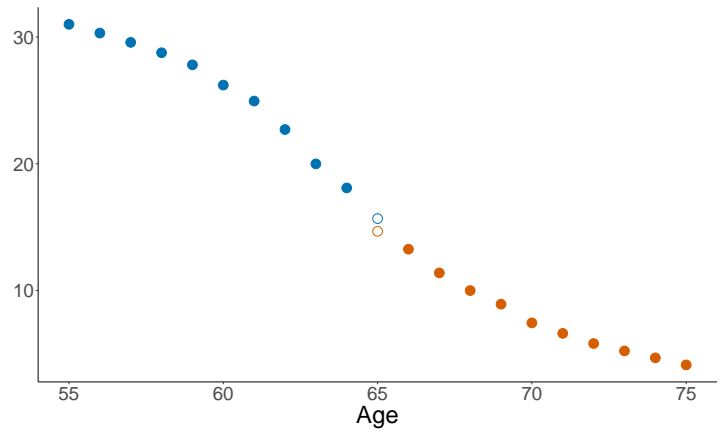

Panel B: Share married by age in years

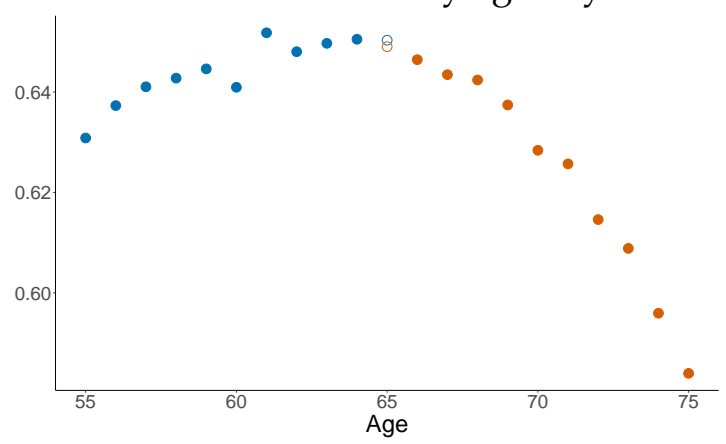

Panel D: Income by age in years

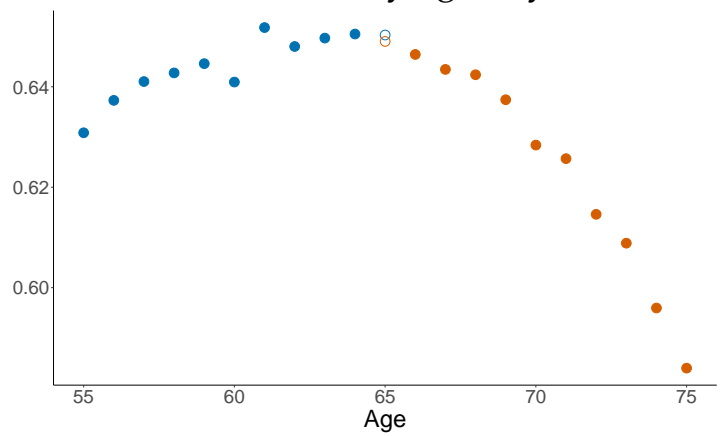

Panel F: Social Security income

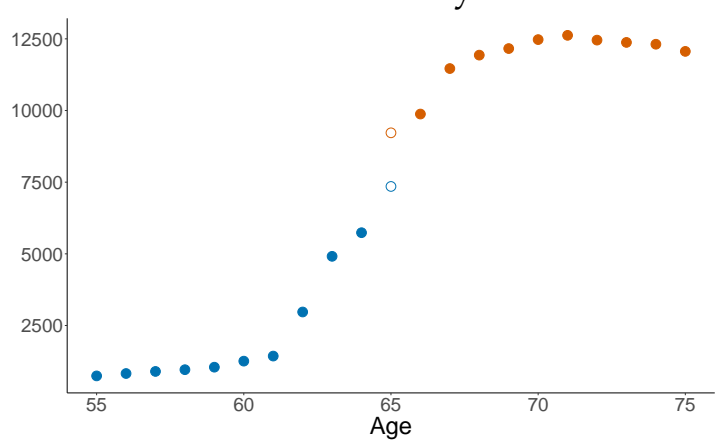

Note: This figure plots a series of individual covariates by age. The horizontal axis denotes age in years. A local linear regression is fit on each side of the Medicare eligibility threshold using methods from Kolesár and Rothe (2018). We include hollow points that are the predicted counterfactual outcomes with and without Medicare at 65. The blue hollow dot is the predicted covariate without Medicare and the red hollow dot is the predicted covariate with Medicare. Panel A plots homeownership rates by age. Panel B reports the share married by age. Panel C plots the share employed by age. Panel D plots income by age. Panel E plots weekly hours worked by age. Panel F plots social security income by age. The sample includes individuals who were age 55-75 between 2008 and 2017. See Section 2 for additional details on the outcomes and sample. Source: American Community Survey, 2008-2017. 


\section{Figure A2: Additional outcomes for changes in financial health at age 65}
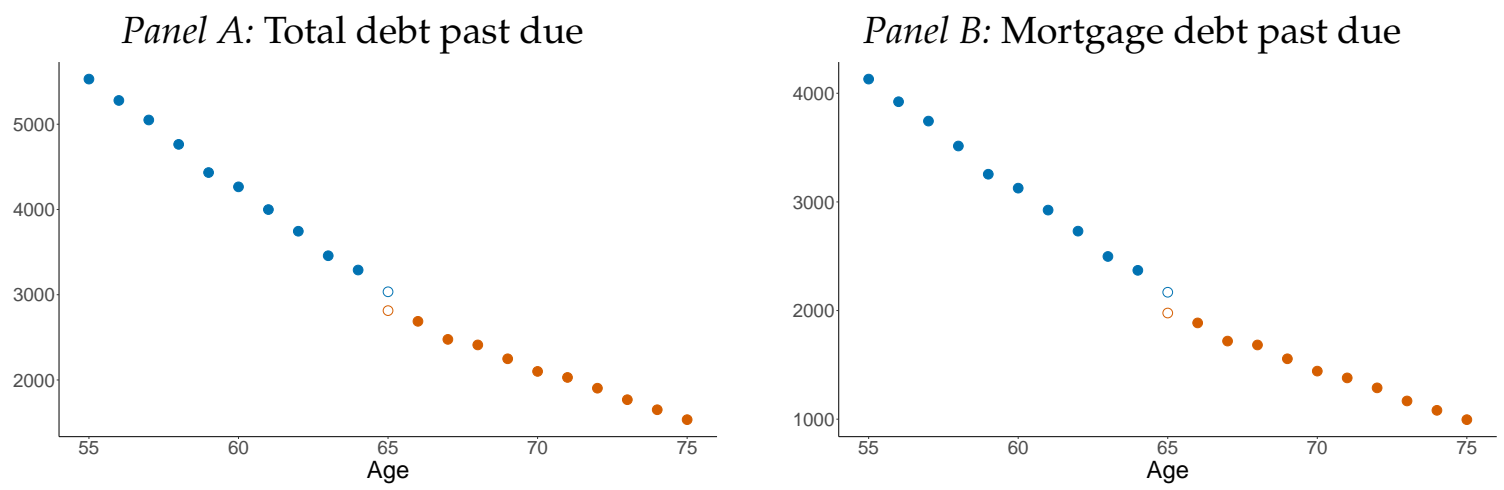

Panel C: Credit card debt past due
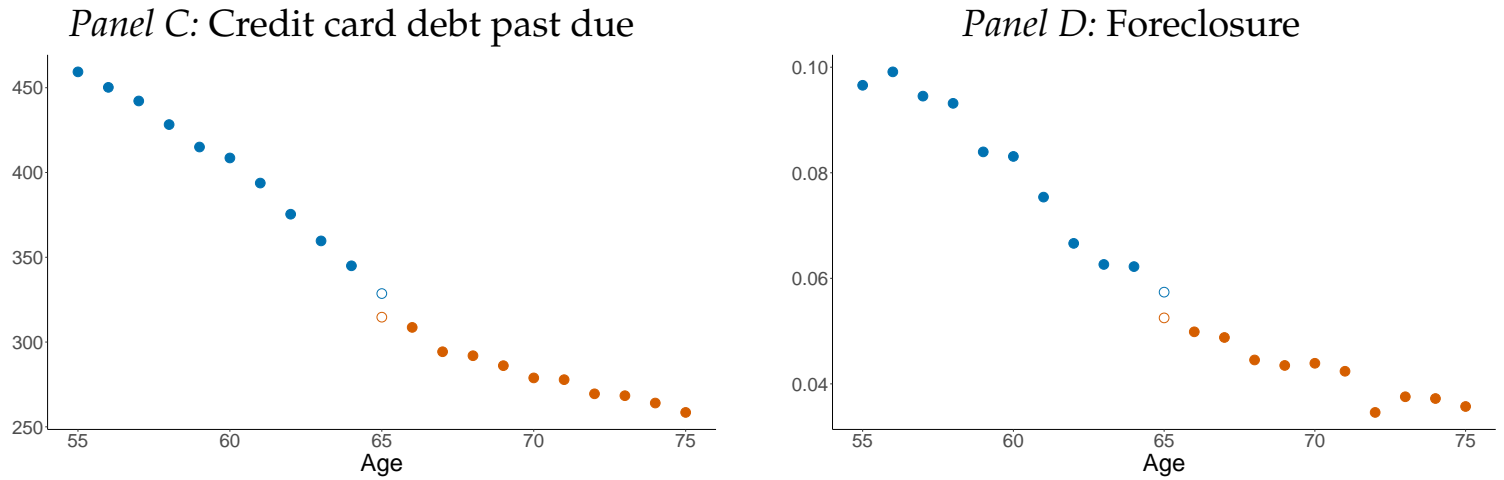

Panel E: Share of credit card debt past due

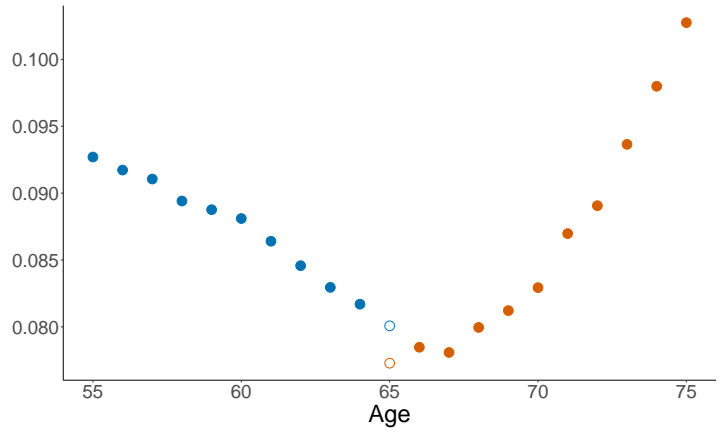

Panel F: Share of mortgage debt past due

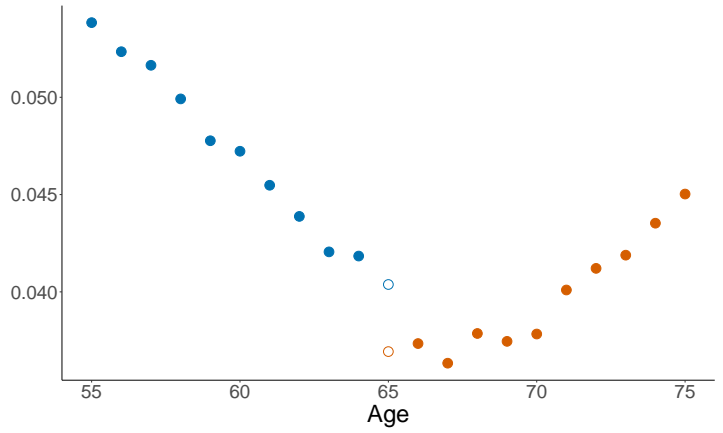

Note: This figure plots consumer credit outcomes by age. The horizontal axis denotes age in years. A local linear regression is fit on each side of the Medicare eligibility threshold using methods from Kolesár and Rothe (2018). We include hollow points that are the predicted counterfactual outcomes with and without Medicare at 65. The blue hollow dot is the predicted outcome without Medicare at age 65 and the red hollow dot is the predicted consumer credit outcome with Medicare at age 65. Panel A plots average amount of debt that is more than 30 days past due by age. Panel B plots the average amount of mortgage debt that is more than 30 days past due by age. Panel $\mathrm{C}$ plots the average amount of credit card debt that is more than 30 days past due by age. Panel D plots the share of individuals experiencing a foreclosure by age. Panel E reports the share of credit card that is more than 30 days past due. Panel F reports the share of mortgage debt that is more than 30 days past due. The share debt past due outcomes are calculated as the average individual debt past due, divided by the average total debt of all individuals of the same age living in that state. We divide by this average, rather than individuals' own debt levels, to avoid the divide-byzero problem. The sample includes individuals who were age 55-75 between 2008 and 2017. See Section 2 for additional details on the outcomes and sample. Source: The financial health outcomes are based on 137,340,577 person-year observations from the New York Fed Consumer Credit Panel / Equifax, 2008-2017. 


\section{Figure A3: Changes in the distribution of collections debt at age 65}

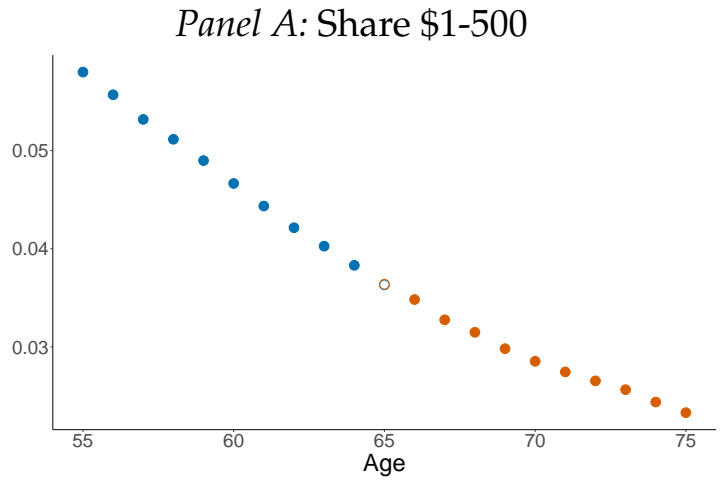

Panel C: Share $\$ 1,000-2,500$

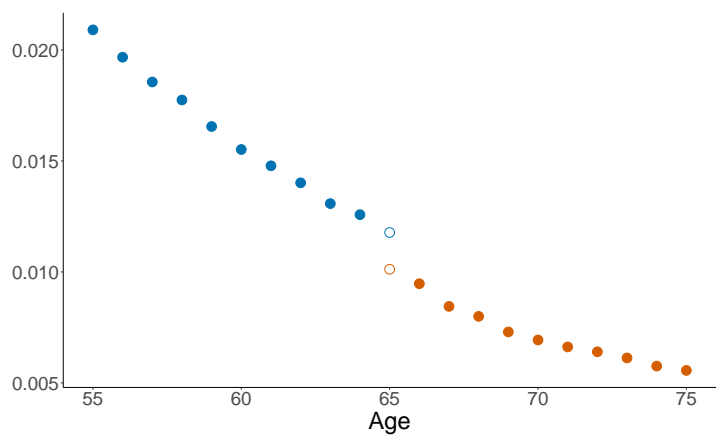

Panel E: $\$ 5,001-10,000$

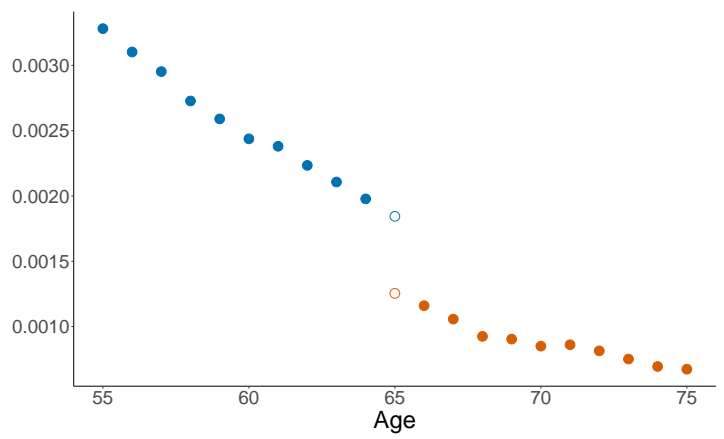

Panel B: Share $\$ 500-1,000$

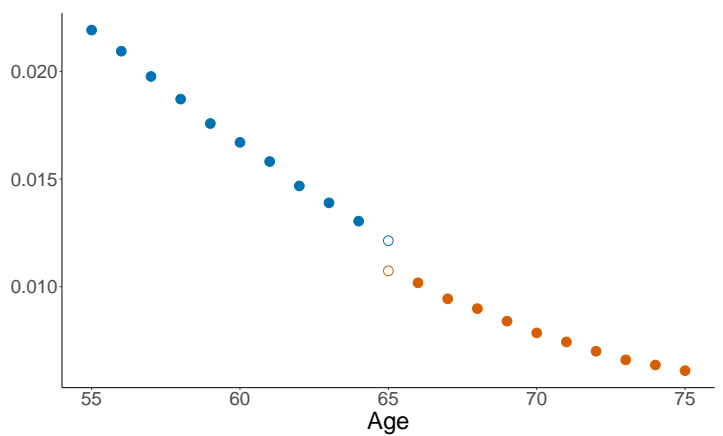

Panel D: Share $\$ 2,501-5,000$

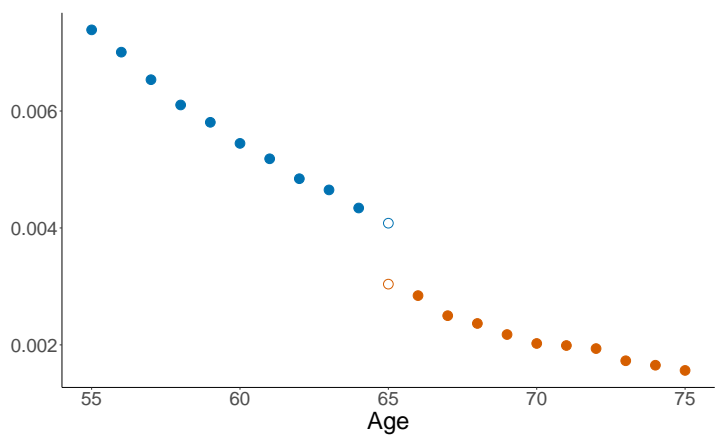

Panel F: Share over $\$ 10,000$

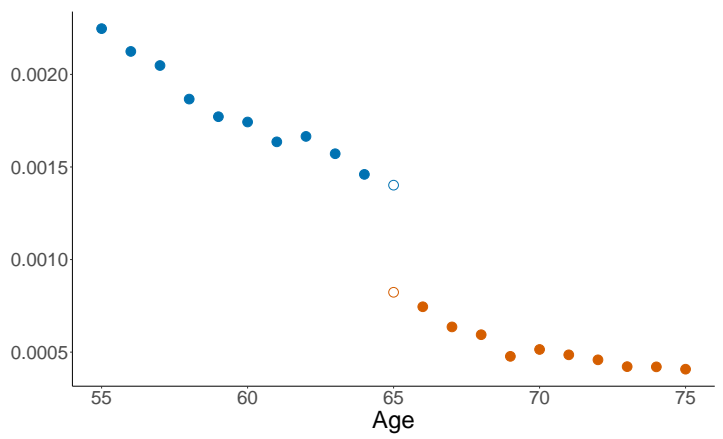

Note: This figure plots the effect of Medicare eligibility at age 65 on the distribution of new collections debts within the past year. A local linear regression is fit on each side of the Medicare eligibility threshold using methods from Kolesár and Rothe (2018). We include hollow points that are the predicted counterfactual outcomes with and without Medicare at 65 . The blue hollow dot is the predicted outcome without Medicare at age 65 and the red hollow dot is the predicted consumer credit outcome with Medicare at age 65. Panel A plots the share of individuals with collections debt between \$1-500 by age. Panel B plots the share of individuals with collections debt between $\$ 500-1,000$ by age. Panel $C$ plots the share of individuals with collections debt between $\$ 1,000-2,500$ by age. Panel D plots the share of individuals with collections debt between $\$ 2,501-5,000$ by age. Panel E plots the share of individuals with collections debt between $\$ 5,001$ 10,000 by age. Panel F plots the share of individuals with collections debt greater than $\$ 10,000$ by age. The sample includes individuals who were age 55-75 between 2008 and 2017. See Section 2 for additional details on the outcomes and sample. Source: The financial health outcomes are based on 137,340,577 person-year observations from the New York Fed Consumer Credit Panel / Equifax, 2008-2017 


\section{Figure A4: Changes in the distribution of delinquent debt at age 65}

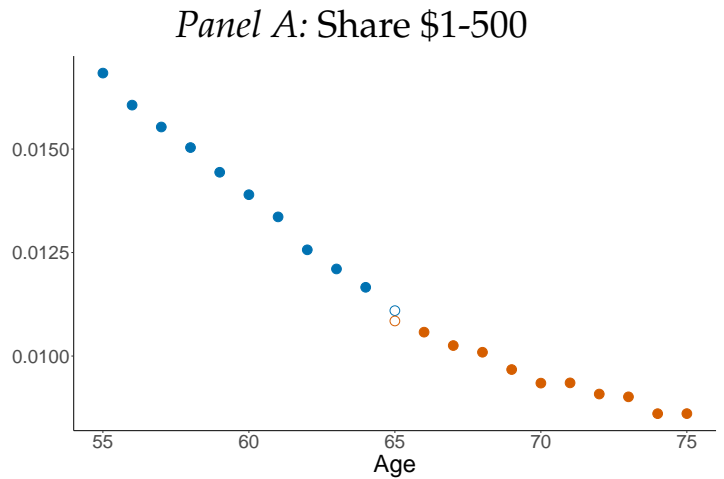

Panel C: Share $\$ 1,000-2,500$

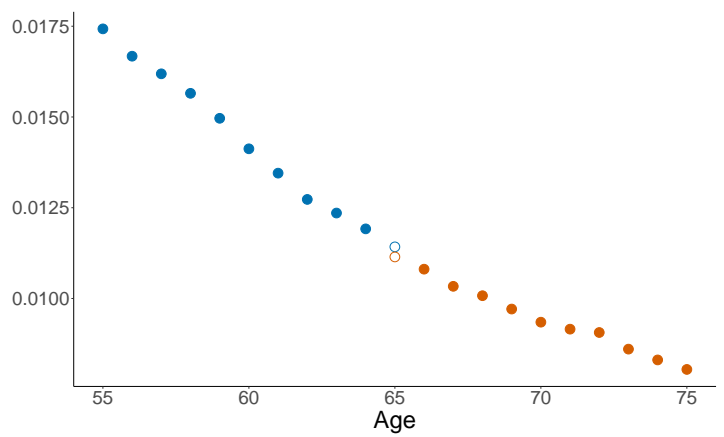

Panel E: $\$ 5,000-10,000$

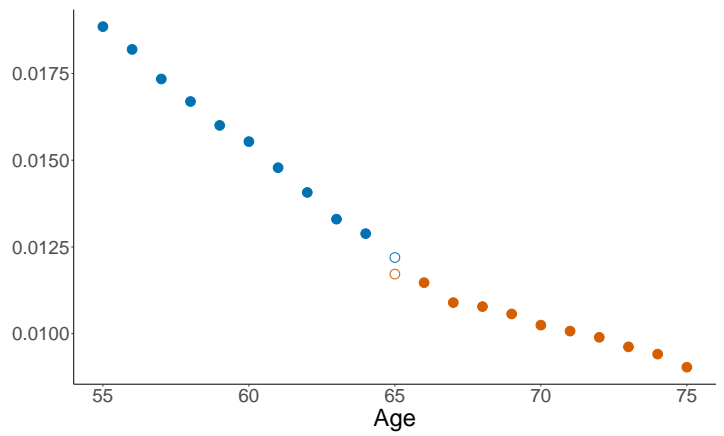

Panel B: Share $\$ 500-1,000$

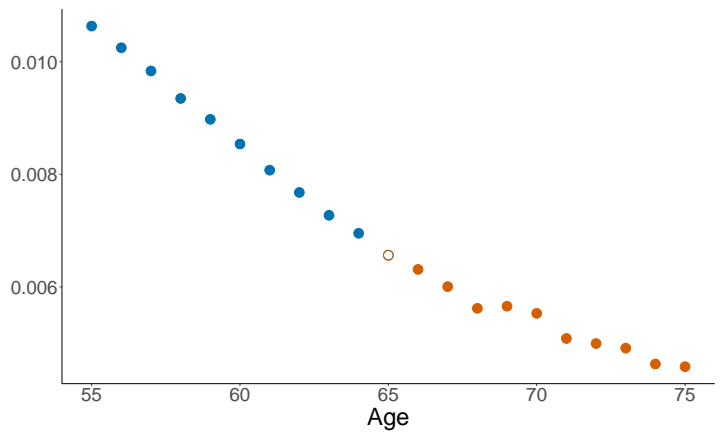

Panel D: Share $\$ 2,500-5,000$

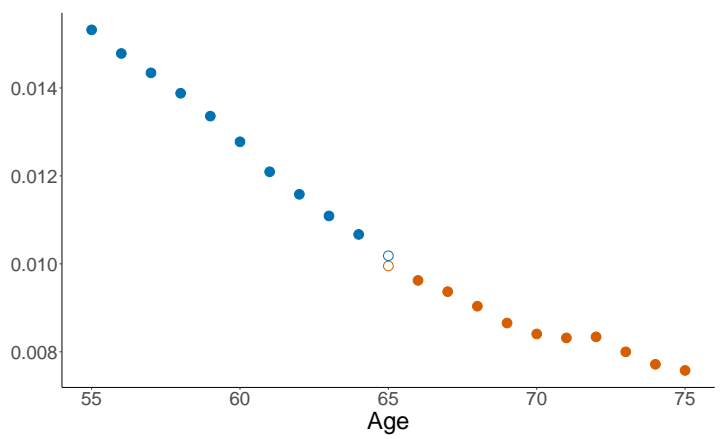

Panel F: Share over $\$ 10,000$

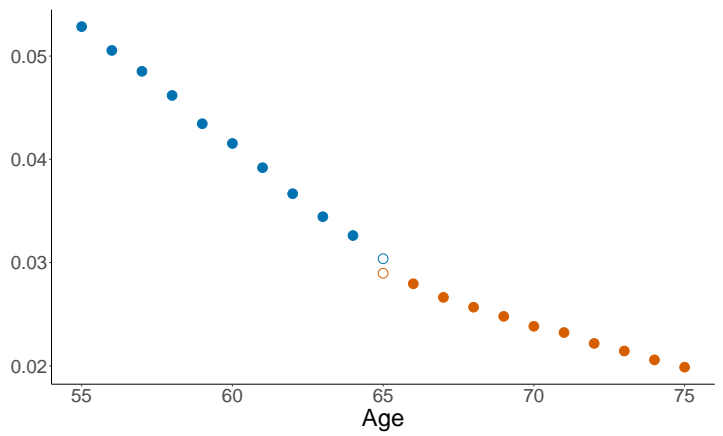

Note: This figure plots the effect of Medicare eligibility at age 65 on the distribution of delinquent debts. A local linear regression is fit on each side of the Medicare eligibility threshold using methods from Kolesár and Rothe (2018). We include hollow points that are the predicted counterfactual outcomes with and without Medicare at 65. The blue hollow dot is the predicted outcome without Medicare at age 65 and the red hollow dot is the predicted consumer credit outcome with Medicare at age 65. Panel A plots the share of individuals with $\$ 1-500$ in debt 30 days past due by age. Panel B plots the share of individuals with $\$ 500$ 1,000 in debt 30 days past due by age. Panel $C$ plots the share of individuals with $\$ 1,000-2,500$ in debt 30 days past due by age. Panel D plots the share of individuals with $\$ 2,501-5,000$ in debt 30 days past due by age. Panel E plots the share of individuals with $\$ 5,001-10,000$ in debt 30 days past due by age. Panel F plots the share of individuals with greater than $\$ 10,000$ in debt 30 days past due by age. The sample includes individuals who were age 55-75 between 2008 and 2017. See Section 2 for additional details on the outcomes and sample. Source: The financial health outcomes are based on 137,340,577 person-year observations from the New York Fed Consumer Credit Panel / Equifax, 2008-2017 


\section{Figure A5: Estimated changes in the distribution of delinquent debt at age 65}

Panel A: Raw shares

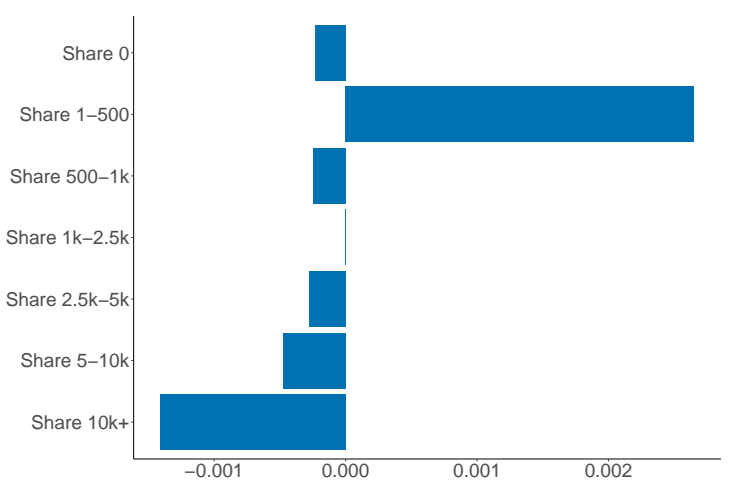

Panel B: Scaled shares

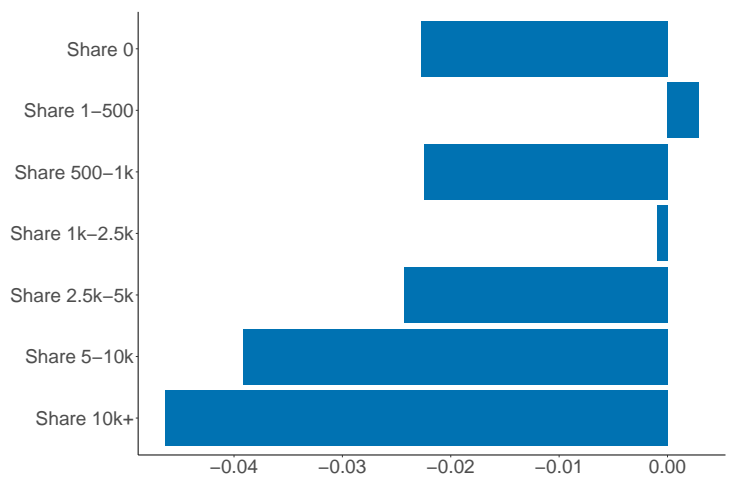

Note: This figure plots the effect of Medicare eligibility at age 65 on the distribution of debts 30 days past due. The red bars indicate statistically significant results at the $5 \%$ level using methods from Kolesár and Rothe (2018). Panel A plots the effect of gaining Medicare eligibility at age 65 on the raw share of individuals in each mutually-exclusive bin defined by the amount of debt that is 30 days past due. Panel B scales the effect on the raw shares by the total share within each bin at age 64 . The sample includes individuals who were age 55-75 between 2008 and 2017. See Section 2 for additional details on the outcomes and sample. Source: The financial health outcomes are based on 137,340,577 person-year observations from the New York Fed Consumer Credit Panel / Equifax, 2008-2017 
Figure A6: Changes in the distribution of delinquent credit card debt at age 65
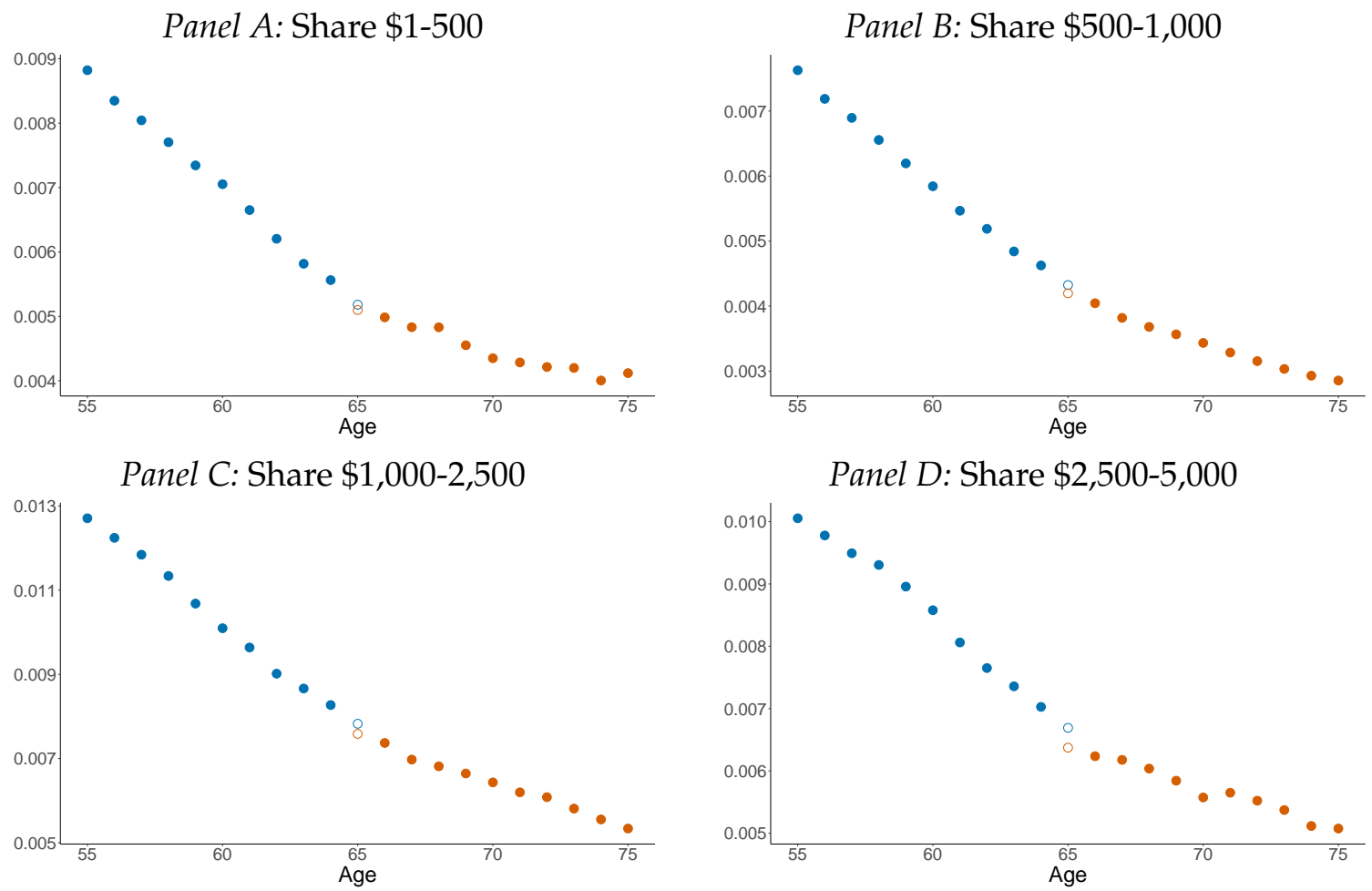

Panel E: $\$ 5,000-10,000$
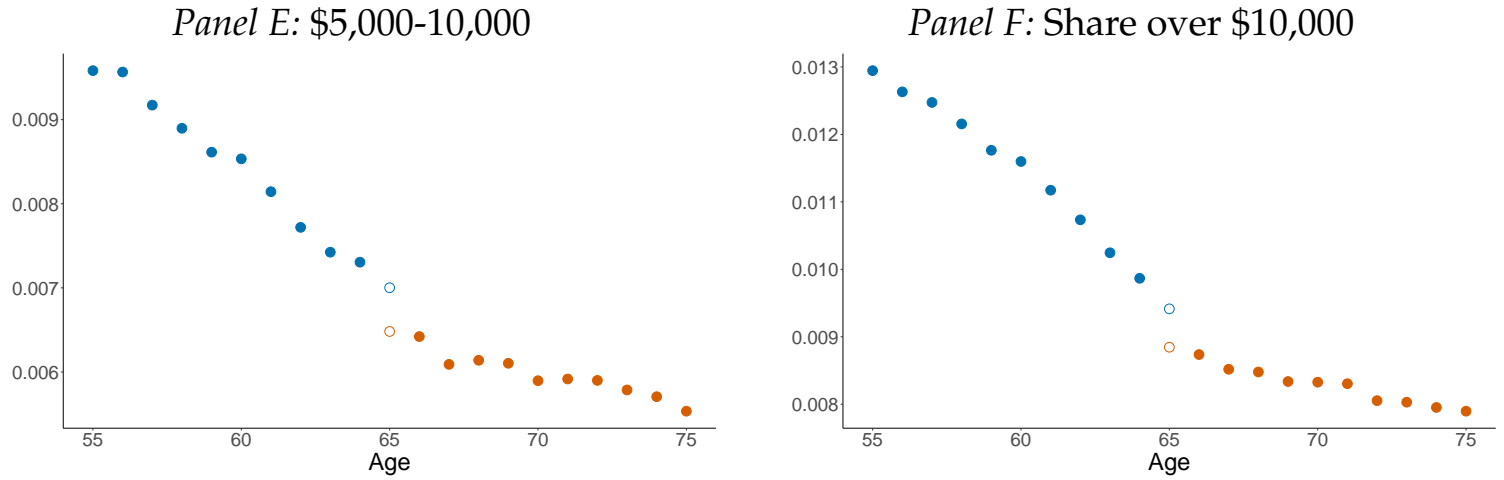

Note: This figure plots the effect of Medicare eligibility at age 65 on the distribution of delinquent debts. A local linear regression is fit on each side of the Medicare eligibility threshold using methods from Kolesár and Rothe (2018). We include hollow points that are the predicted counterfactual outcomes with and without Medicare at 65. The blue hollow dot is the predicted outcome without Medicare at age 65 and the red hollow dot is the predicted consumer credit outcome with Medicare at age 65. Panel A plots the share of individuals with $\$ 1-500$ in credit card debt 30 days past due by age. Panel B plots the share of individuals with $\$ 500-1,000$ in credit card debt 30 days past due by age. Panel $C$ plots the share of individuals with $\$ 1,000-2,500$ in credit card debt 30 days past due by age. Panel D plots the share of individuals with $\$ 2,501-$ 5,000 in credit card debt 30 days past due by age. Panel E plots the share of individuals with $\$ 5,001-10,000$ in debt 30 days past due by age. Panel F plots the share of individuals with greater than $\$ 10,000$ in debt 30 days past due by age. The sample includes individuals who were age 55-75 between 2008 and 2017. See Section 2 for additional details on the outcomes and sample. Source: The financial health outcomes are based on 137,340,577 person-year observations from the New York Fed Consumer Credit Panel / Equifax, 2008-2017 


\section{Figure A7: Changes in the distribution of delinquent credit card debt at age 65}

Panel A: Raw shares

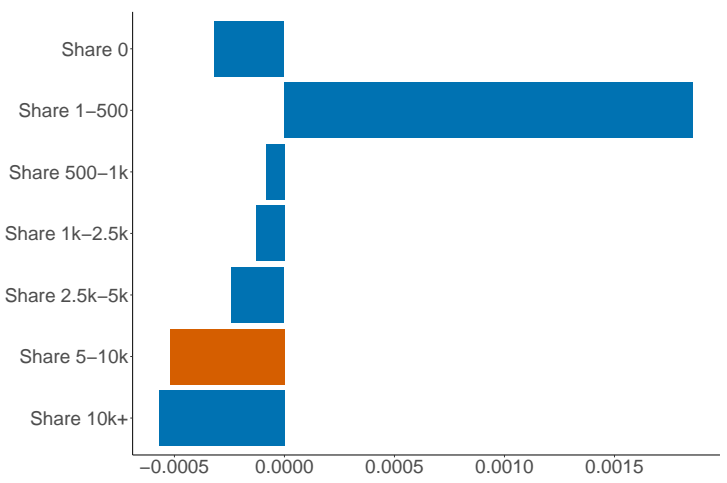

Panel B: Scaled shares

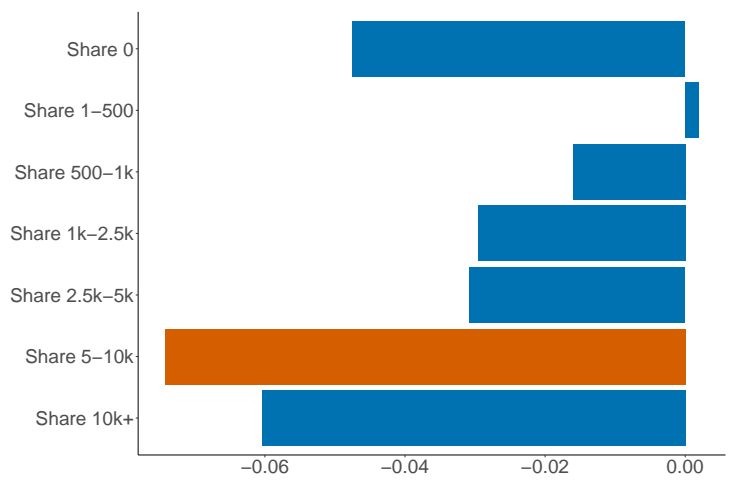

Note: This figure plots the effect of Medicare eligibility at age 65 on the distribution of new collections debts within the past year. The red bars indicate statistically significant results at the $5 \%$ level using methods from Kolesár and Rothe (2018). Panel A plots the effect of gaining Medicare eligibility at age 65 on the raw share of individuals in each mutually-exclusive bin defined by the amount of credit card debt 30 days past due. Panel B scales the effect on the raw shares by the total share within each bin at age 64 . The sample includes individuals who were age 55-75 between 2008 and 2017. See Section 2 for additional details on the outcomes and sample. Source: The financial health outcomes are based on 137,340,577 person-year observations from the New York Fed Consumer Credit Panel / Equifax, 2008-2017 


\section{Figure A8: Changes in financial health at age 65, pre- and post-ACA}

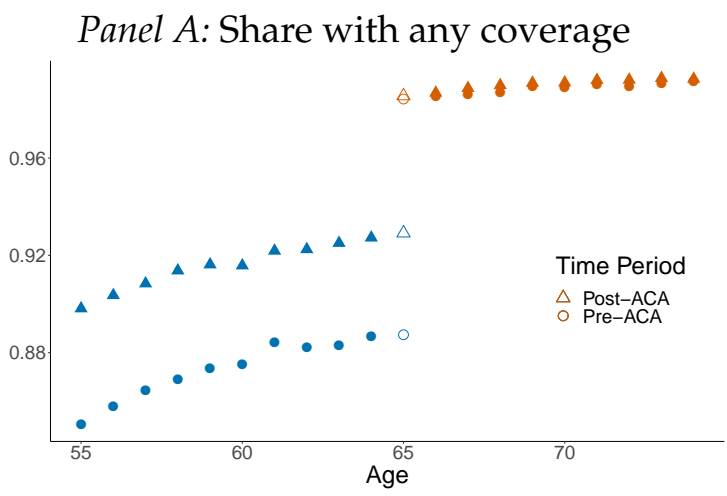

Panel C: Share with Medicare

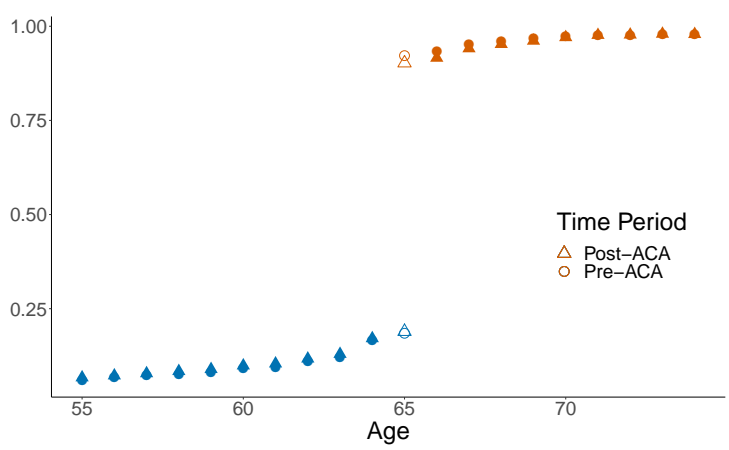

Panel B: Share with multiple forms of coverage

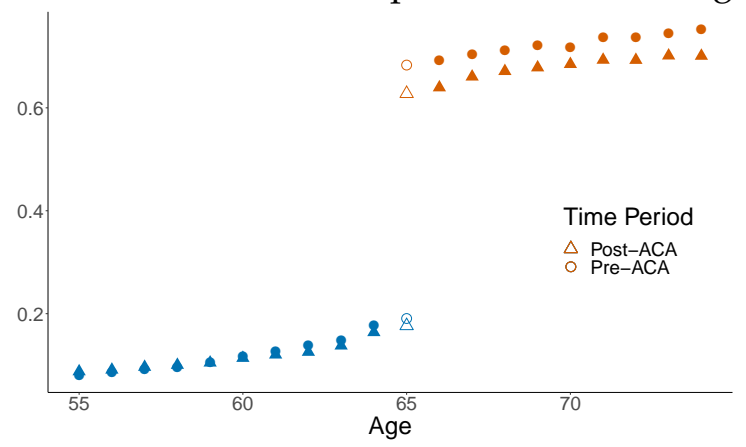

Panel D: Share with Medicaid

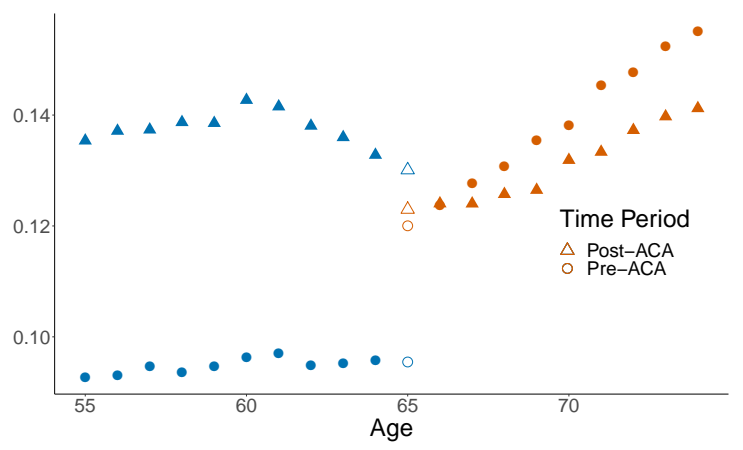

Note: This figure plots health insurance coverage by age before and after the implementation of the primary components of the Affordable Care Act in 2014. The circles correspond to the pre-ACA period. The triangles correspond to the post-ACA period. The horizontal axis denotes age in years. A local linear regression is fit on each side of the Medicare eligibility threshold using methods from Kolesár and Rothe (2018). Since we do not observe counterfactual coverage rates at age 65 without Medicare, we include hollow points that are the predicted counterfactual outcomes with and without Medicare at 65 . The blue hollow dot is the predicted coverage rate without Medicare and the red hollow dot is the predicted coverage rate with Medicare. Since we do observe actual coverage rates at age 65, a comparison of the hollow and solid red dots demonstrates the model fit on the right-hand side of the discontinuity at age 65. Panel A plots the share of individuals with any form of coverage. Panel B reports the share of individuals with multiple forms of coverage. Panel $\mathrm{C}$ plots the share with Medicare as their primary source of coverage. Panel D plots the share with Medicaid as their primary source of coverage. The sample includes individuals who were age 55-75 between 2008 and 2017. See Section 2 for additional details on the outcomes and sample. Source: American Community Survey, 2008-2017. 
Figure A9: Robustness of Age RD Estimates to Bound Scaling Factor

Panel A: Total Collections (\$)

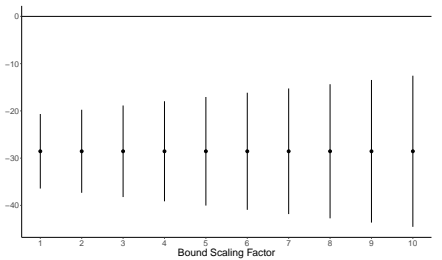

Panel D: Total Delinquency

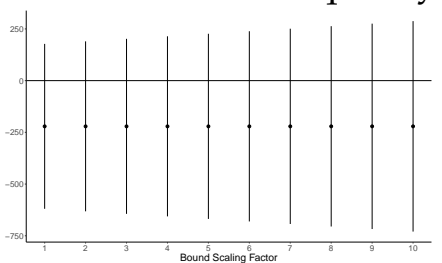

Panel G: Risk Score

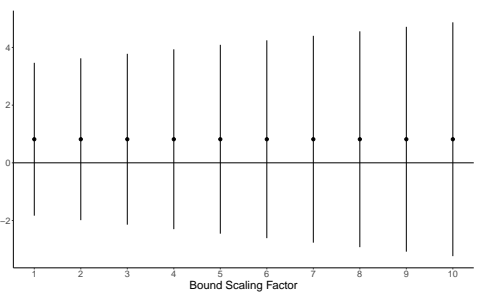

Panel B: \# of Collections

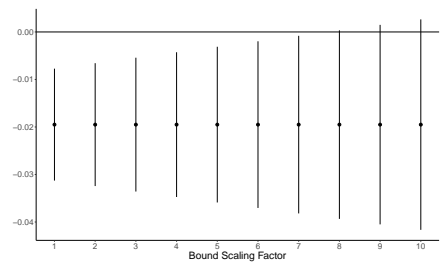

Panel E: Credit Card Delinq.

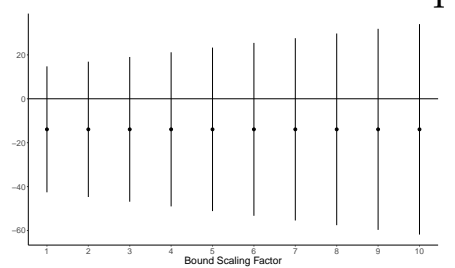

Panel H: Foreclosure

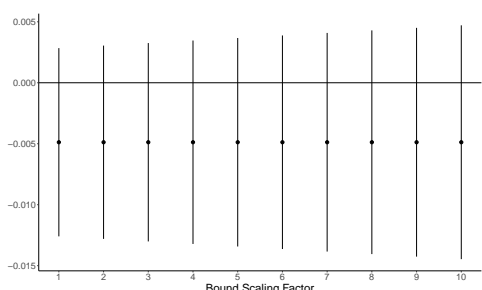

Panel C: Collections $>0$

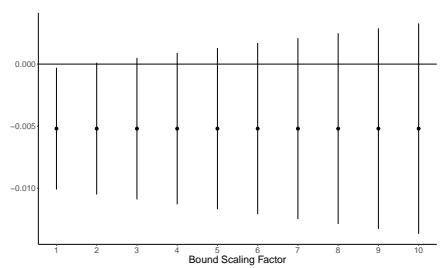

Panel F: Mortgage Delinq.

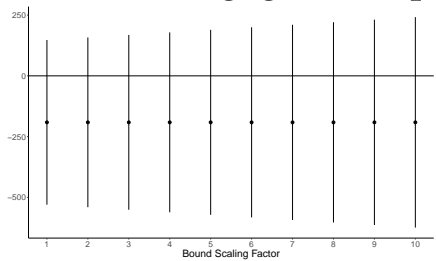

Panel I: Bankruptcy

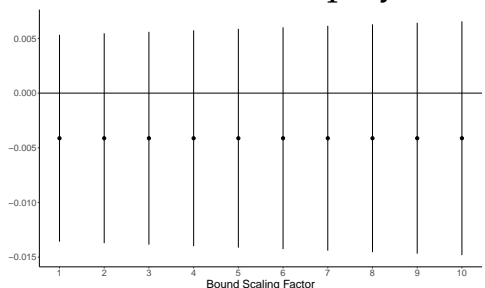

Note: This figure plots the robustness of our regression discontinuity estimates to the choice of the bound scaling factor used in the Kolesár and Rothe (2018) estimation procedure. Panel A plots the robustness of the average debt in collections in dollars RD estimates. Panel B plots the robustness of the number of debt in collections RD estimates. Panel C plots the robustness of the share of individuals with debt in collections RD estimates. Panel D plots the robustness of the average debt past due RD estimates. Panel E plots the robustness of the average credit card debt past due RD estimates. Panel F plots the robustness of the average mortgage debt past due RD estimates. Panel G plots the robustness of the risk score RD estimates based on the Equifax Riskscore 3.0. Panel H plots the robustness of the foreclosure RD estimates. Panel I plots the robustness of the bankruptcy RD estimates. The sample includes individuals who were age 55-75 between 2008 and 2017. See Section 2 for additional details on the outcomes and sample. Source: The financial health outcomes are based on 137,340,577 person-year observations from the New York Fed Consumer Credit Panel / Equifax, 2008-2017. 
Figure A10: Robustness of Age RD Estimates to Bandwidth Selection

Panel A: Total Collections (\$)

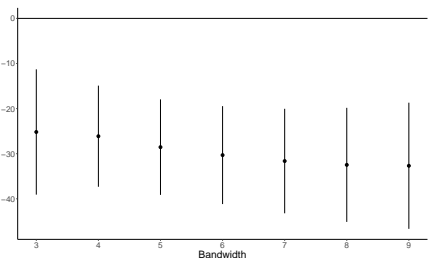

Panel D: Total Delinquency

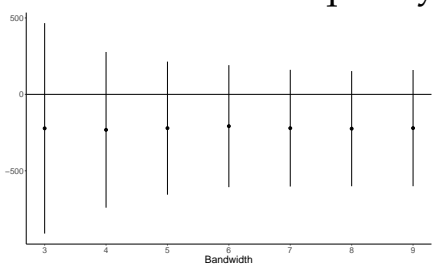

Panel G: Risk Score

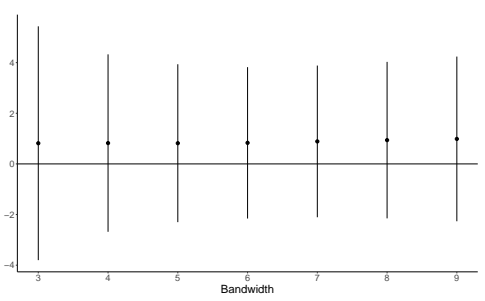

Panel B: \# of Collections

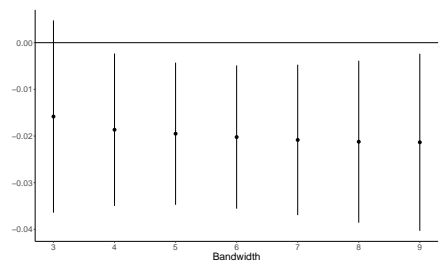

Panel E: Credit Card Delinq.

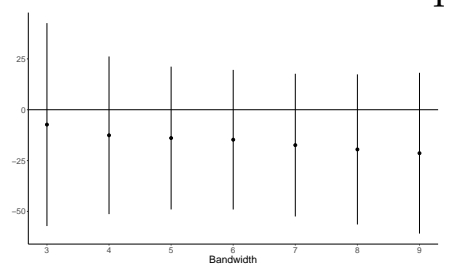

Panel H: Foreclosure

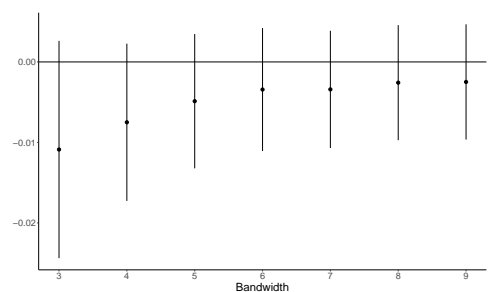

Panel C: Collections $>0$

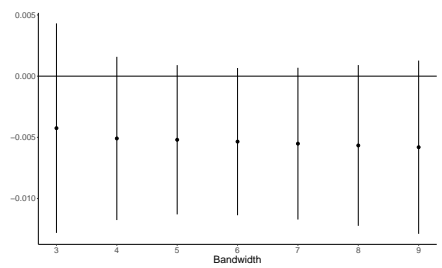

Panel F: Mortgage Delinq.

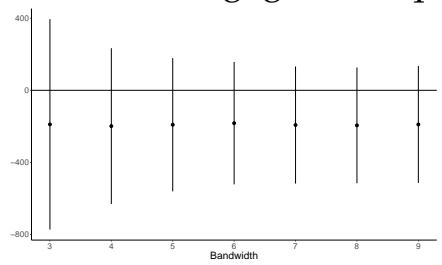

Panel I: Bankruptcy

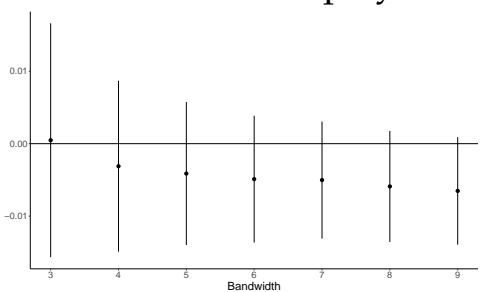

Note: This figure plots the robustness of our regression discontinuity estimates to the bandwidth selection used in the Kolesár and Rothe (2018) estimation procedure. Panel A plots the robustness of the average debt in collections in dollars RD estimates. Panel B plots the robustness of the number of debt in collections RD estimates. Panel C plots the robustness of the share of individuals with debt in collections RD estimates. Panel D plots the robustness of the average debt past due RD estimates. Panel E plots the robustness of the average credit card debt past due RD estimates. Panel F plots the robustness of the average mortgage debt past due RD estimates. Panel G plots the robustness of the risk score RD estimates based on the Equifax Riskscore 3.0. Panel $\mathrm{H}$ plots the robustness of the foreclosure RD estimates. Panel I plots the robustness of the bankruptcy RD estimates. The sample includes individuals who were age 55-75 between 2008 and 2017. The regressions include 26,120,830 person-year-quarter observations for 2,977,952 unique individuals. See Section 2 for additional details on the outcomes and sample. Source: New York Fed Consumer Credit Panel / Equifax. 


\section{Figure A11: Shrinkage Estimates for reduction in the uninsurance rate at 65}

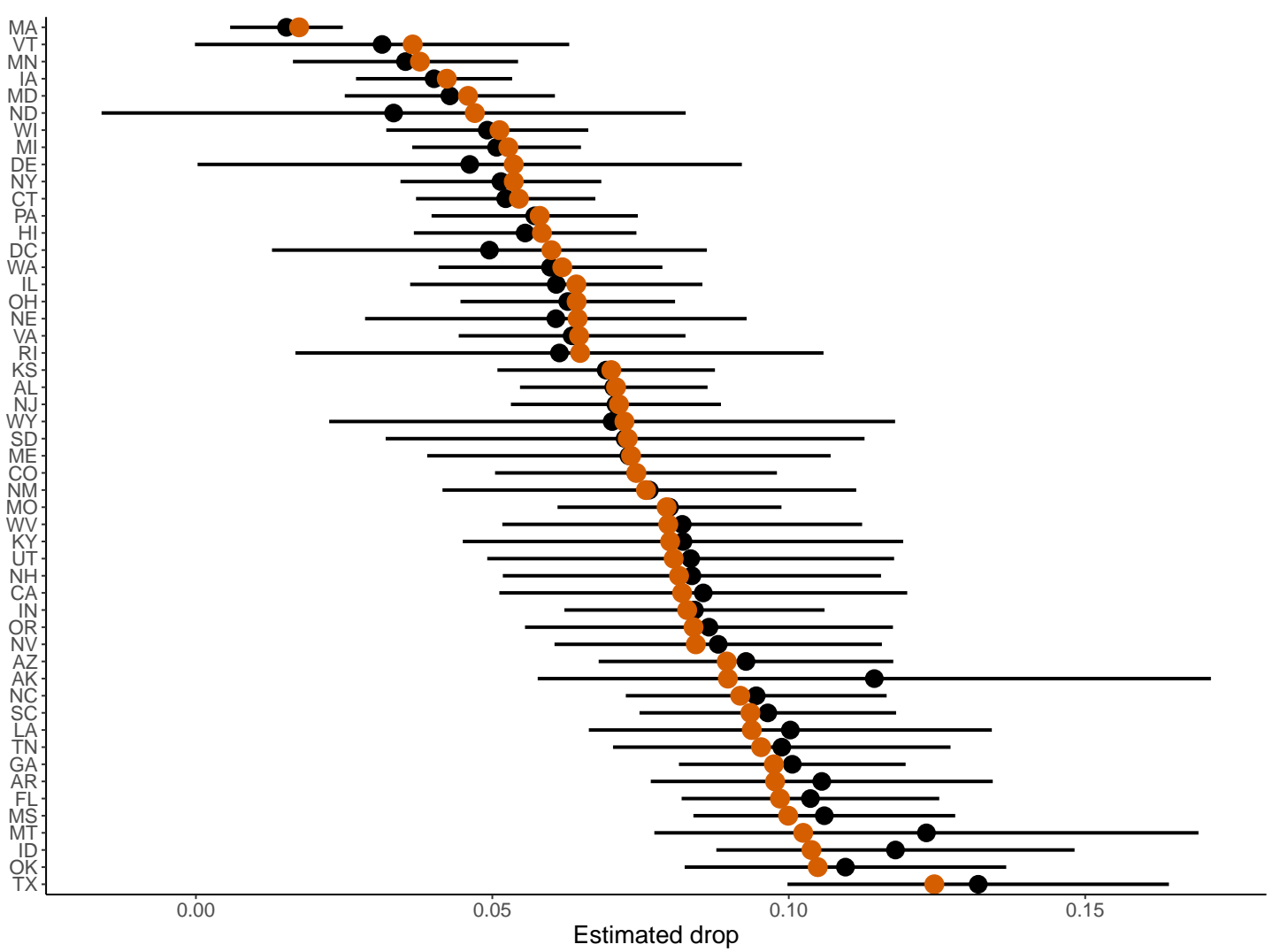

Note: This figure plots the estimate discontinuities at age 65 in the insurance rate by state. The black dots and confidence intervals are estimates based on a local linear regression fit to each side of the Medicare eligibility threshold using methods from Kolesár and Rothe (2018). The orange dots indicate the state-level estimates shrunk using empirical Bayes (See Section 4). The sample includes individuals who were age 55-75 between 2008 and 2017. See Section 2 for additional details on the outcomes and sample. Source: American Community Survey, 2008-2017. 
Figure A12: Shrinkage estimates for the impact on debt collections at age 65

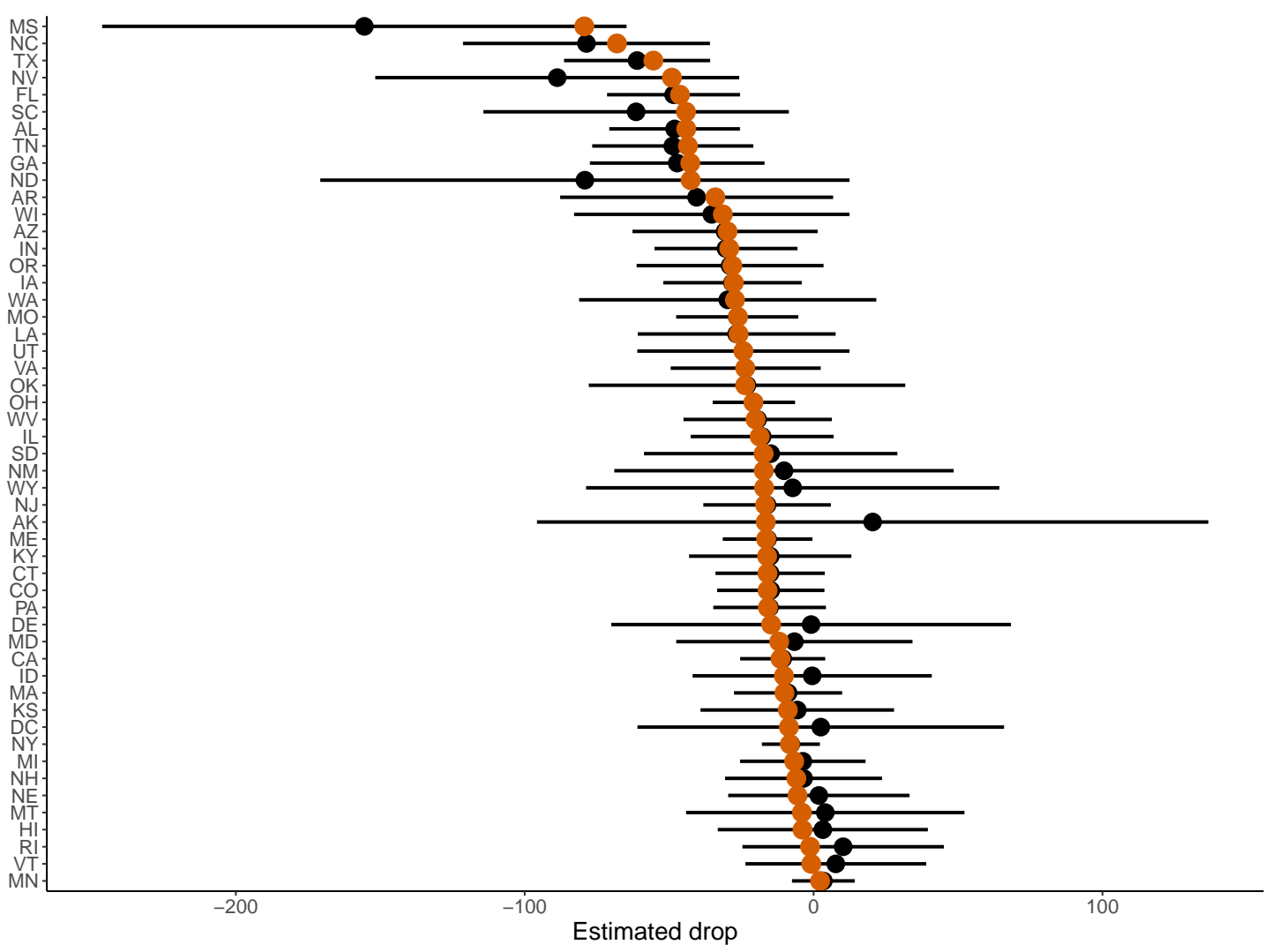

Note: This figure plots the estimate discontinuities at age 65 in the debt collections by state. The black dots and confidence intervals are estimates based on a local linear regression fit to each side of the Medicare eligibility threshold using methods from Kolesár and Rothe (2018). The orange dots indicate the state-level estimates shrunk using empirical Bayes (See Section 4). The sample includes individuals who were age 55-75 between 2008 and 2017. See Section 2 for additional details on the outcomes and sample. Source: The financial health outcomes are based on 137,340,577 person-year observations from the New York Fed Consumer Credit Panel / Equifax, 2008-2017 


\section{Figure A13: Covariate smoothness by state}

Panel A: Homeowner

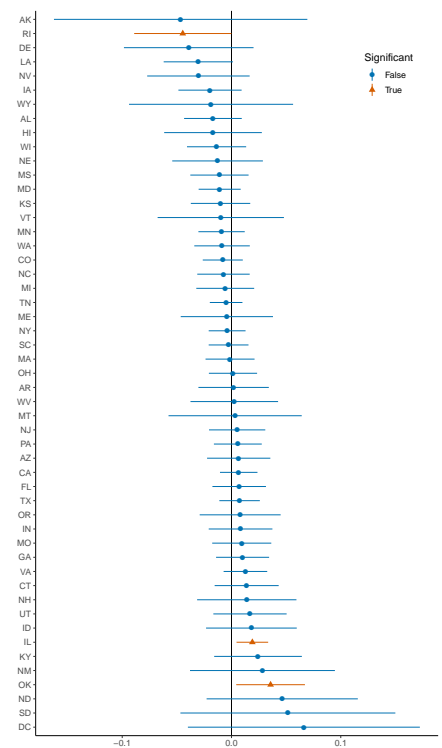

Panel D: Income

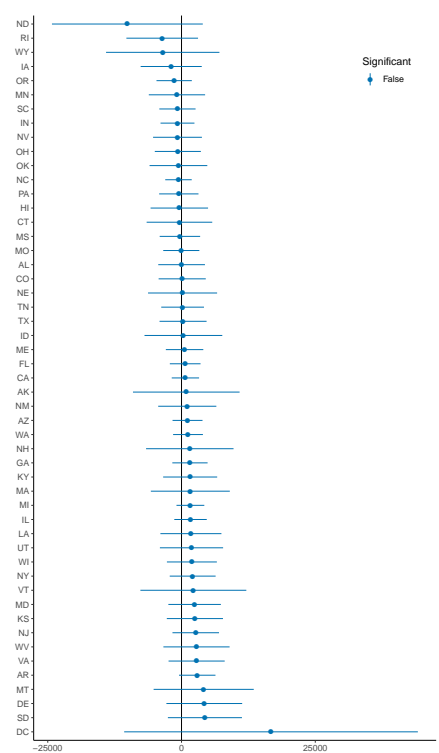

Panel B: Married

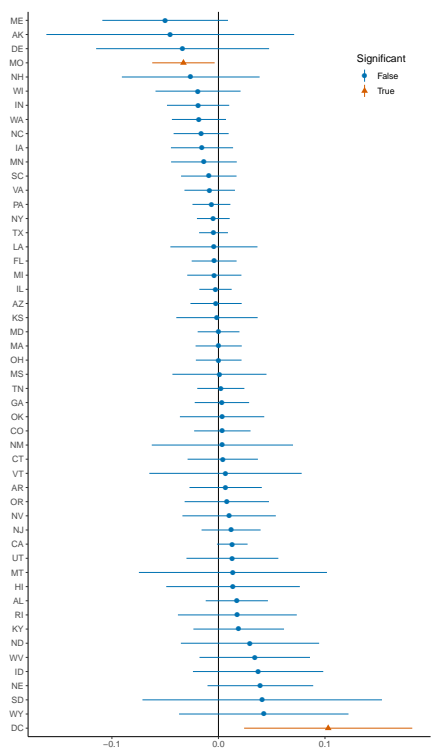

Panel E: Hours worked

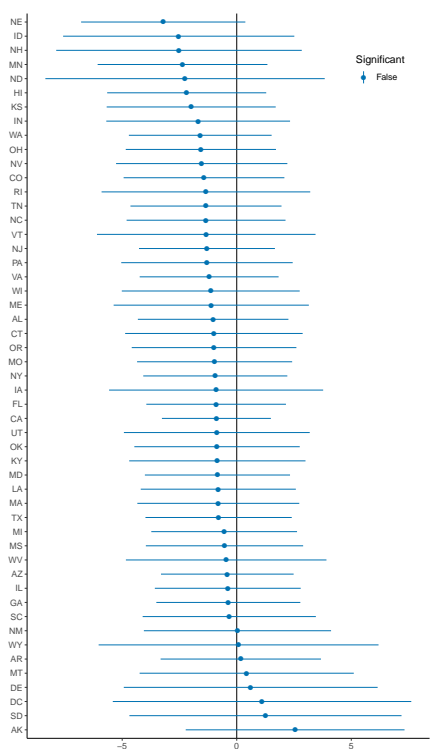

Panel C: Employed

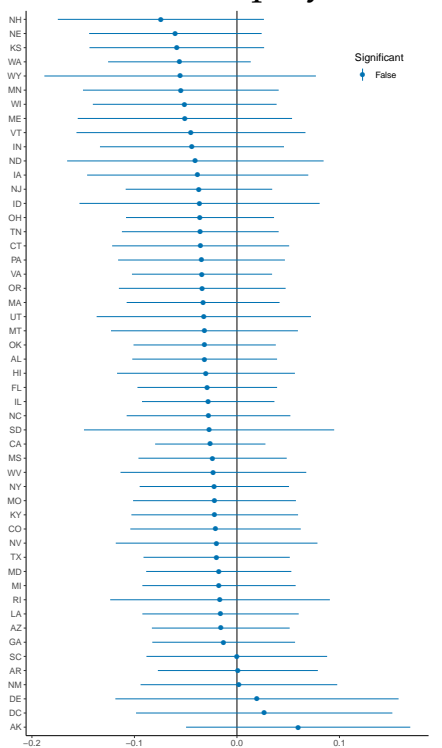

Panel F: Social Security Income

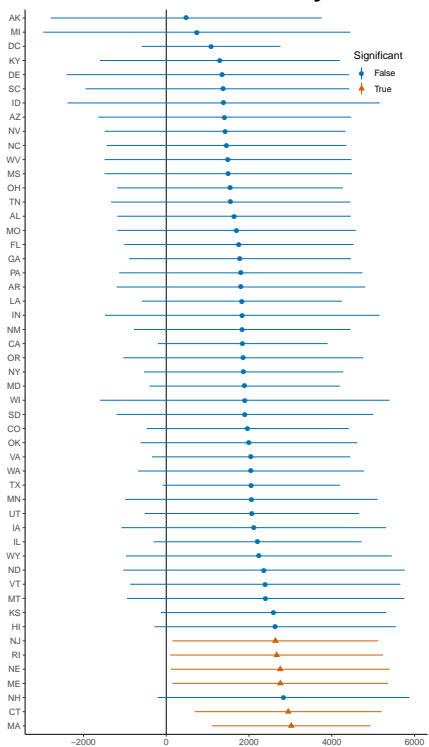

Note: This figure plots the estimated discontinuities at age 65 in individual covariates by state. A local linear regression is fit on each side of the Medicare eligibility threshold using methods from Kolesár and Rothe (2018). The red bars indicate statistically significant results at the 5\% level. Panel A plots the estimated discontinuities in homeownership rates by state. Panel B plots the estimated discontinuities in marriage rates by state. Panel $\mathrm{C}$ plots the estimated discontinuities in employment by state. Panel D plots the estimated discontinuities in income by state. Panel E plots the estimated discontinuities in hours worked by state. Panel F plots the estimate discontinuities in social security income by state. The sample includes individuals who were age 55-75 between 2008 and 2017. See Section 2 for additional details on the outcomes and sample. Source: American Community Survey, 2008-2017. 


\section{Figure A14: Covariate smoothness by commuting zone}
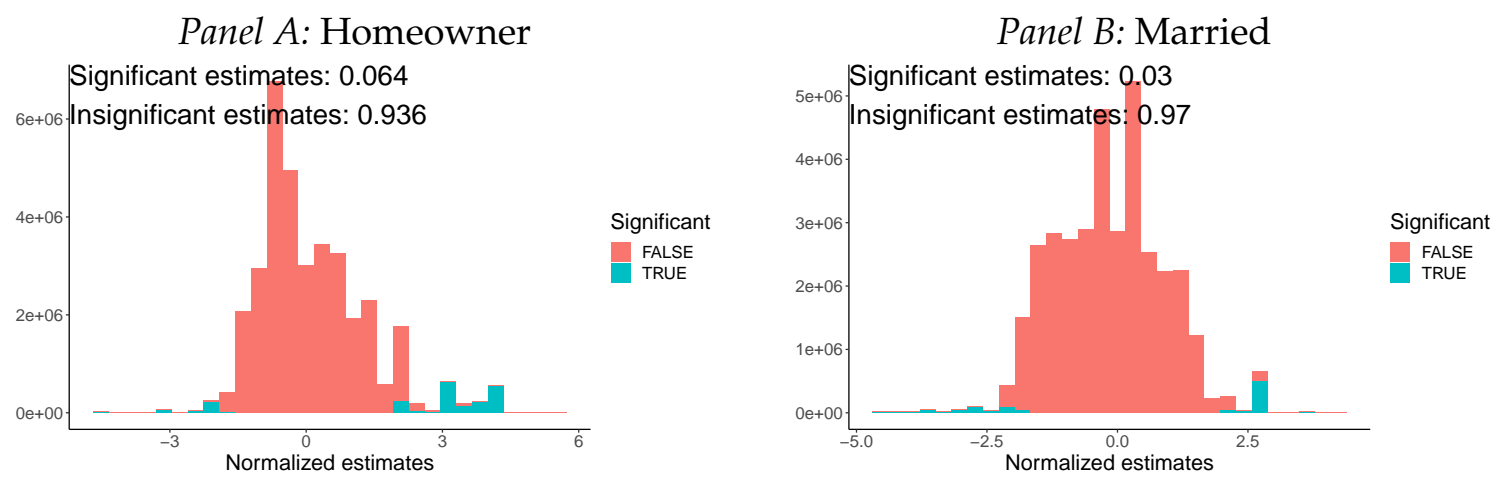

Panel C: Employed

Significant estimates: 0.003
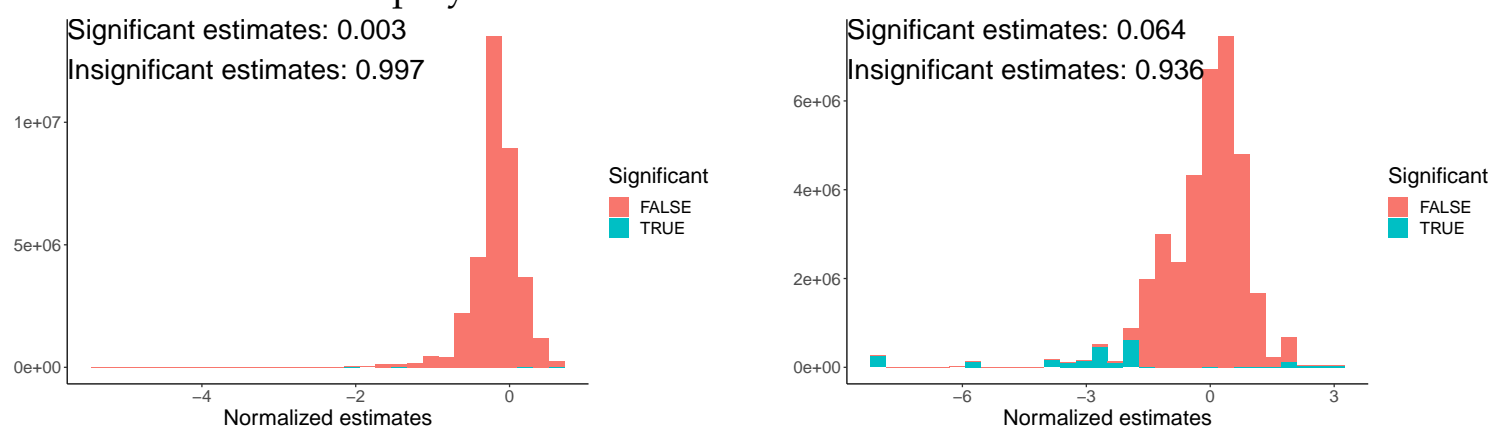

Panel E: Hours worked
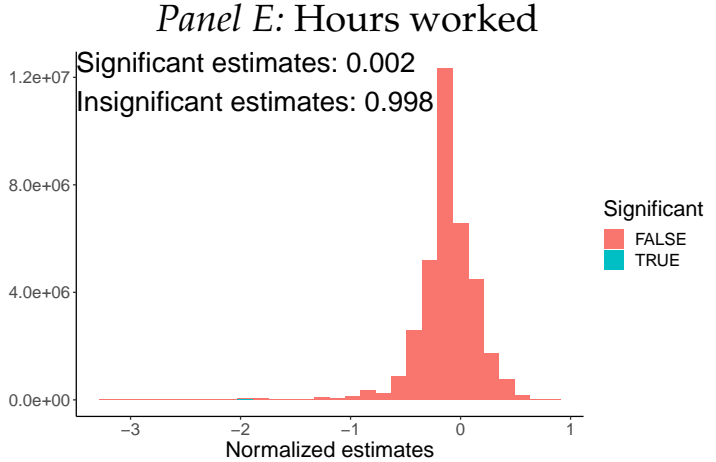

Panel F: Social Security Income

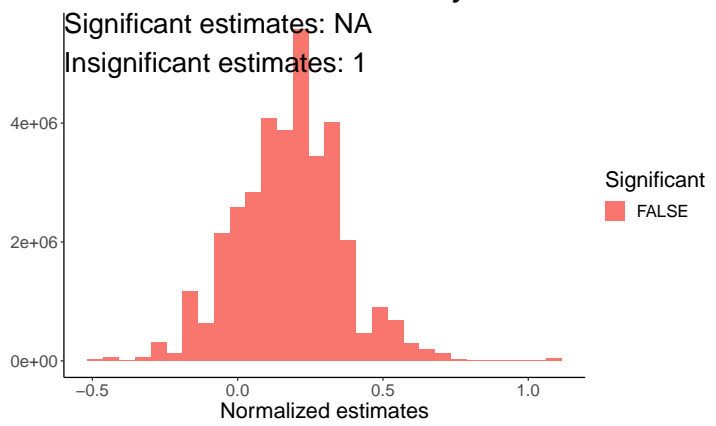

Note: This figure plots histograms of normalized estimated discontinuities at age 65 in individual covariates by commuting zone (CZ). A local linear regression is fit on each side of the Medicare eligibility threshold by $\mathrm{CZ}$ using methods from Kolesár and Rothe (2018). The red bars indicate statistically insignificant results at the 5\% level. The blue bars indicate indicate statistically significant results at the 5\% level. Panel A plots the estimated discontinuities in homeownership rates by state. Panel B plots the estimated discontinuities in marriage rates by state. Panel C plots the estimated discontinuities in employment by state. Panel D plots the estimated discontinuities in income by state. Panel E plots the estimated discontinuities in hours worked by state. Panel F plots the estimate discontinuities in social security income by state. The sample includes individuals who were age 55-75 between 2008 and 2017. See Section 2 for additional details on the outcomes and sample. Source: American Community Survey, 2008-2017. 


\section{Figure A15: Effect of Medicare eligibility on state health insurance outcomes}
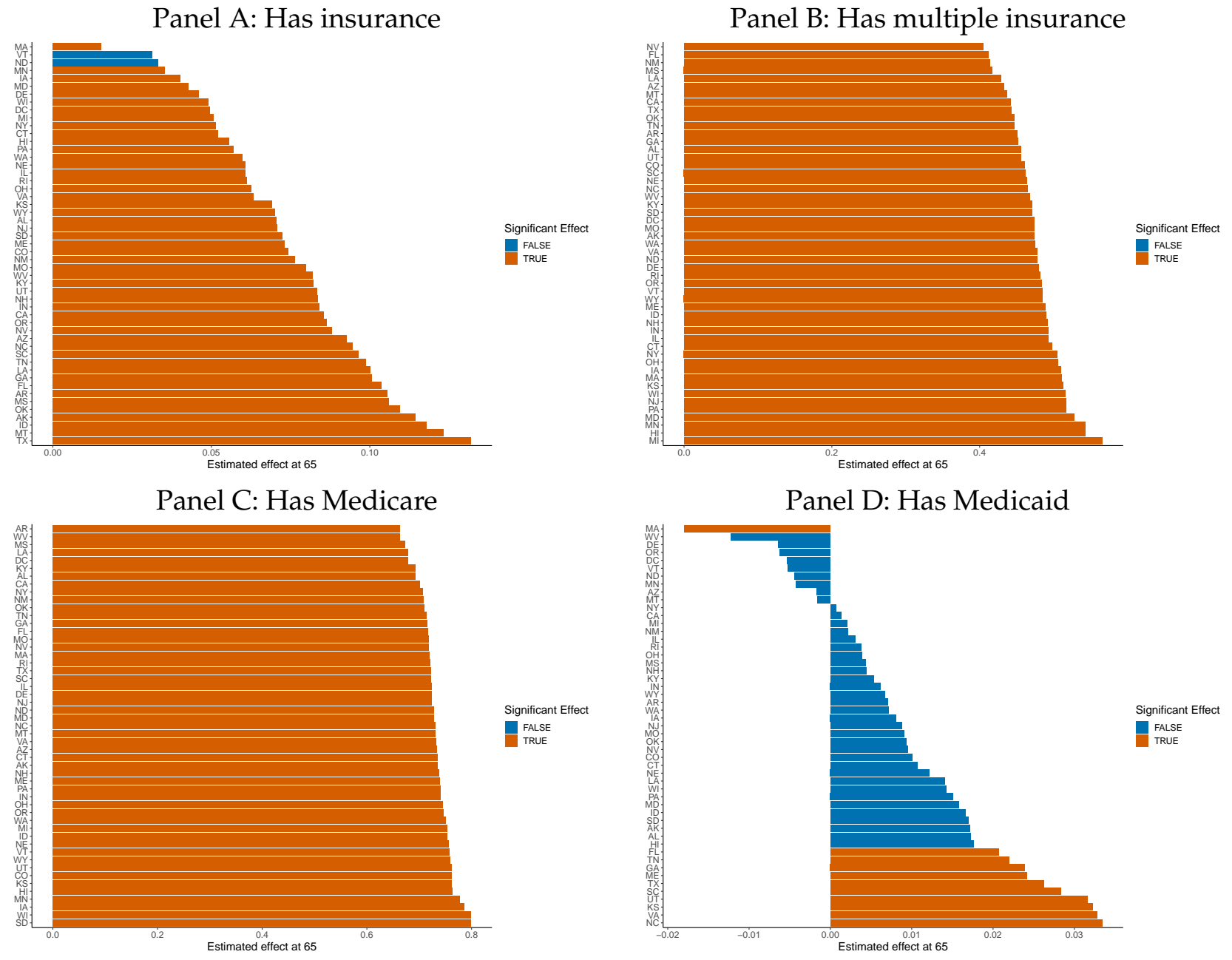

Note: This figure plots the effect of Medicare eligibility at age 65 on health insurance outcomes by state. The red bars indicate statistically significant results at the 5\% level using methods from Kolesár and Rothe (2018). Panel A plots the estimated change in the share of individuals with any form of coverage. Panel B plots the estimated changed in the share of individuals with multiple forms of coverage. Panel $\mathrm{C}$ reports the estimated change in the share of individuals with Medicare as their primary source of coverage. Panel D reports the estimated change in the share of individuals with Medicaid as their primary source of coverage. The sample includes individuals who were age 55-75 between 2008 and 2017. See Section 2 for additional details on the outcomes and sample. Source: American Community Survey, 2008-2017. 


\section{Figure A16: Effect of Medicare eligibility on state financial health outcomes}
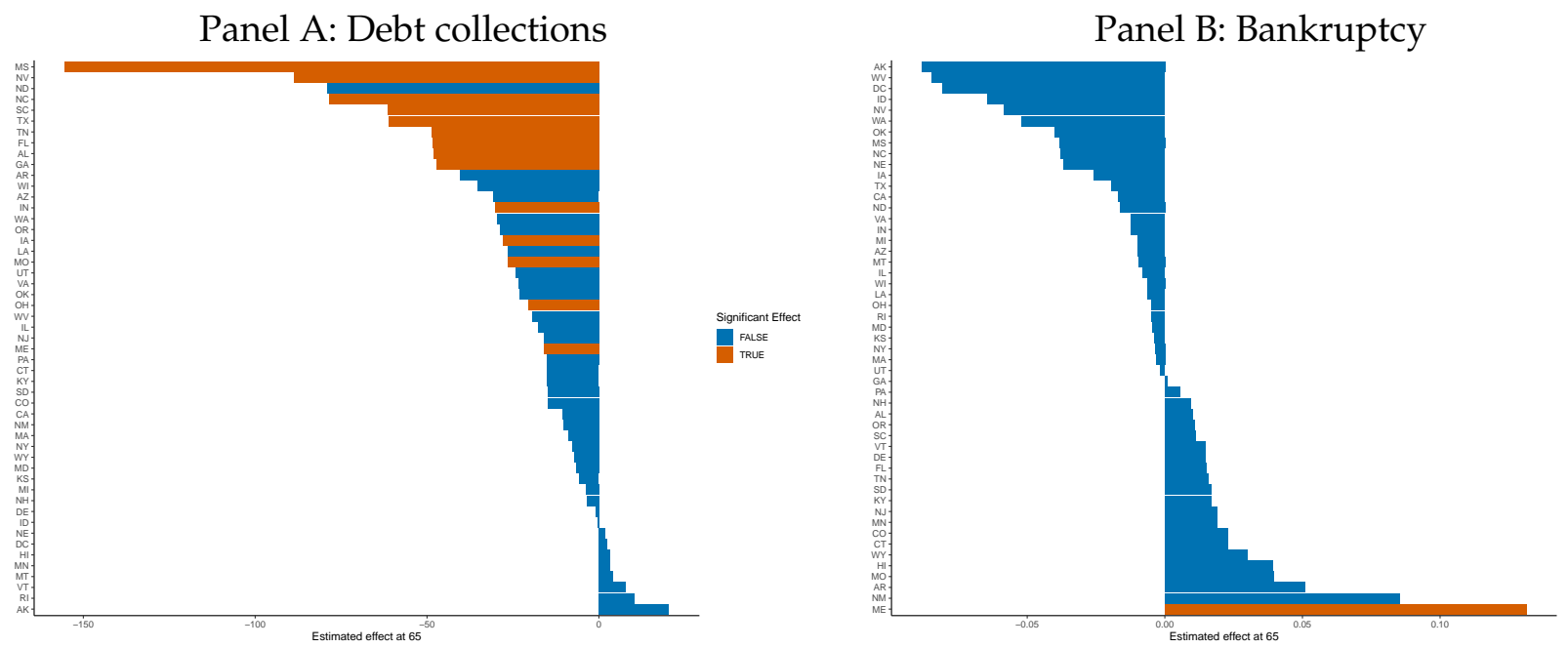

Panel C: Debt past due
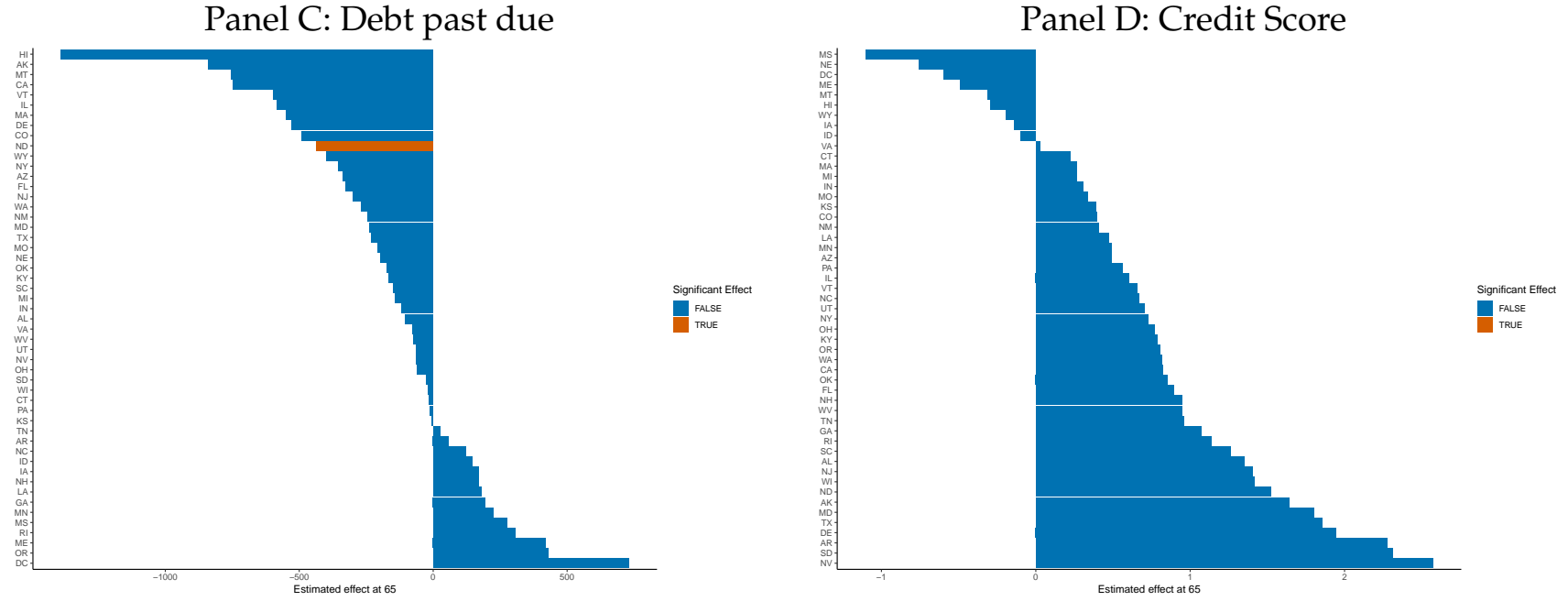

Note: This figure plots the effect of Medicare eligibility at age 65 on consumer credit outcomes by state. The red bars indicate statistically significant results at the 5\% level using methods from Kolesár and Rothe (2018). Panel A plots the estimated change in average balance for new debt in collections within the past year. Panel B plots the probability of a new bankruptcy filing within the past year. Panel $\mathrm{C}$ reports the average amount of debt that is more than 30 days past due. Panel D reports credit score data from the Equifax Riskscore 3.0. The sample includes individuals who were age 55-75 between 2008 and 2017. The regressions include 137,340,577 person-year observations. See Section 2 for additional details on the outcomes and sample. Source: New York Fed Consumer Credit Panel / Equifax, 2008-2017. 
Figure A17: Effect of Medicare eligibility on health insurance and collections debt at age 65, CZ vs. state-level effects

Panel A: Reduction in uninsurance at age 65

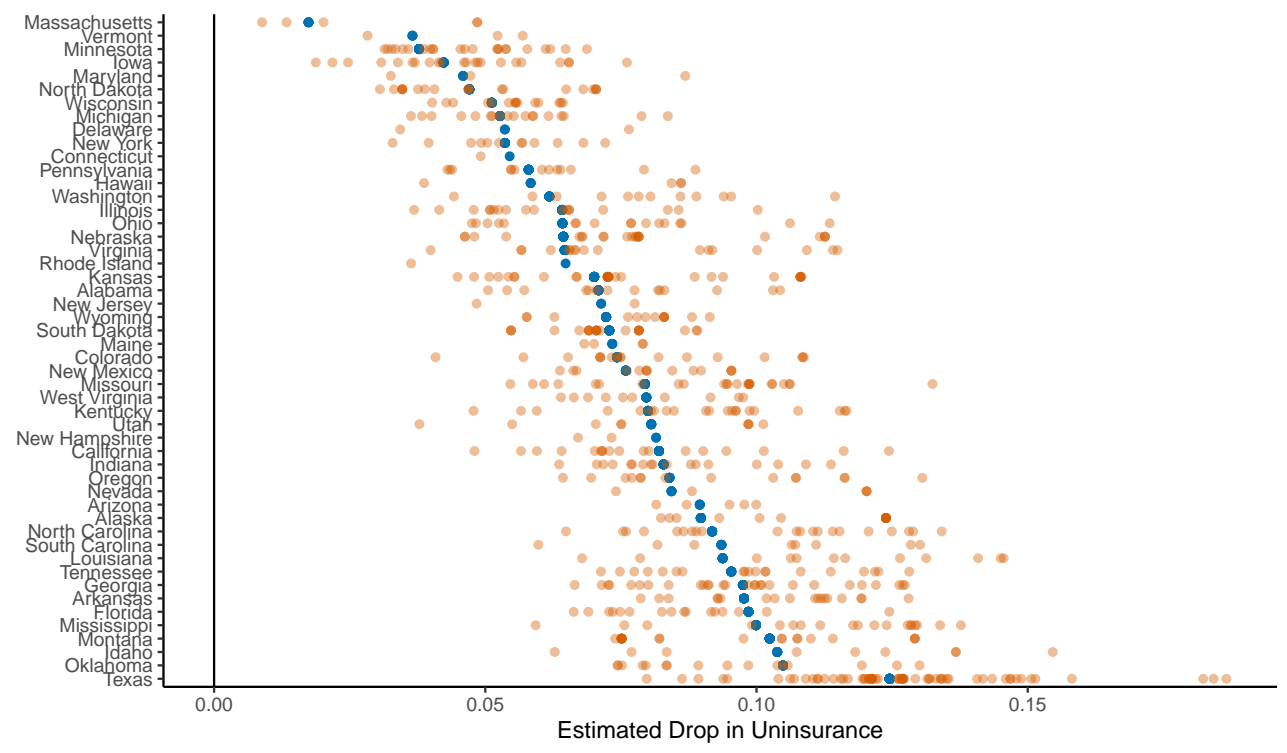

Panel B: Change in collections debt at age 65

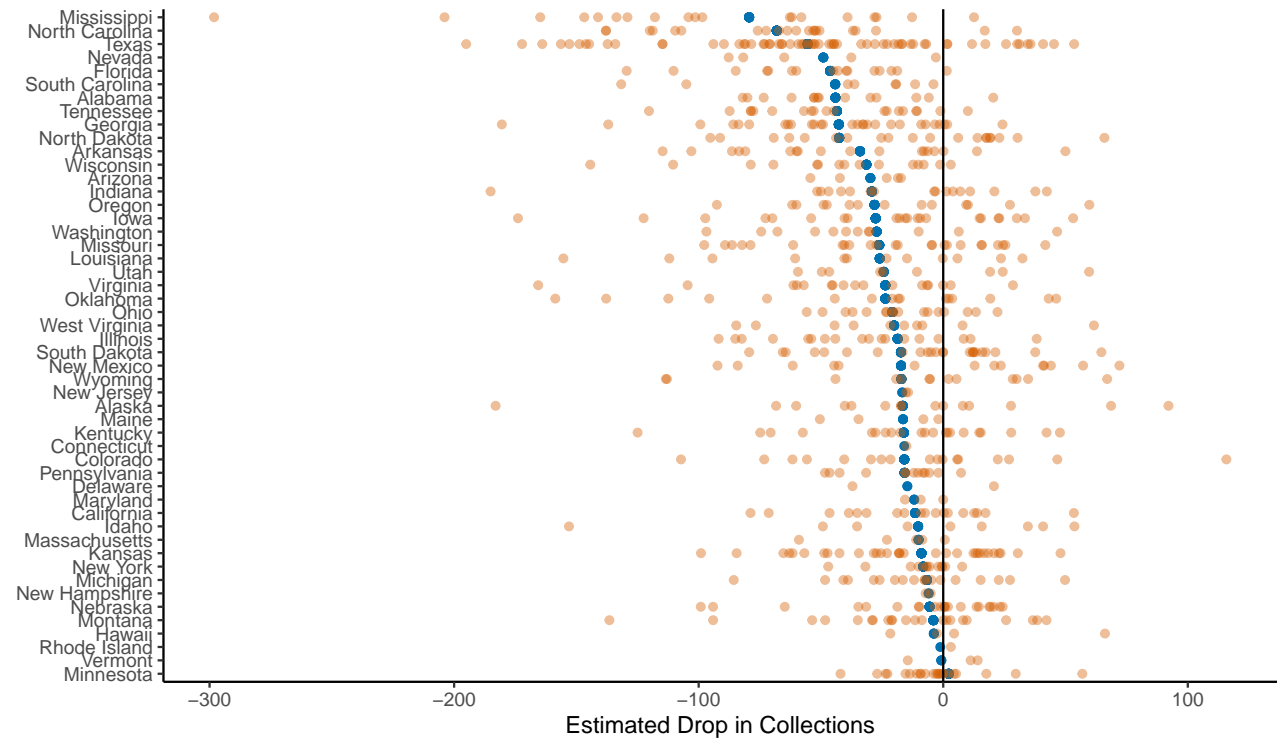

Note: This figure plots point estimates of the reduction in the flow of newly-reported collections debt (within the past year) and the increase in the insurance rate at age 65 based on local linear regressions, done separately by commuting zone, using the methods from Kolesár and Rothe (2018). The horizontal axis in Panel $\mathrm{A}$ is the estimated effect on the insurance rate at age 65 by commuting zone. The horizontal axis in Panel B is the estimated drop in collections at age 65. The vertical axis is order by state, in order from those with the smallest estimated effects to those with the largest estimated effects. The blue dot indicates the RD estimate for the corresponding state. The orange dots correspond to CZ-level estimates, arranged vertically to correspond to the state the $\mathrm{CZ}$ is primarily located in. The darker orange dots correspond to CZs with larger populations. Consumer credit outcomes are based on 137,340,577 person-year observations from the New York Fed Consumer Credit Panel / Equifax, 2008-2017. CZ-level uninsurance rates are from the American Community Survey, 2008-2017. 
Figure A18: Counterfactual levels of collections debt by state at age 65 with and without Medicare

Panel A: Without (Nearly) Universal Health Insurance

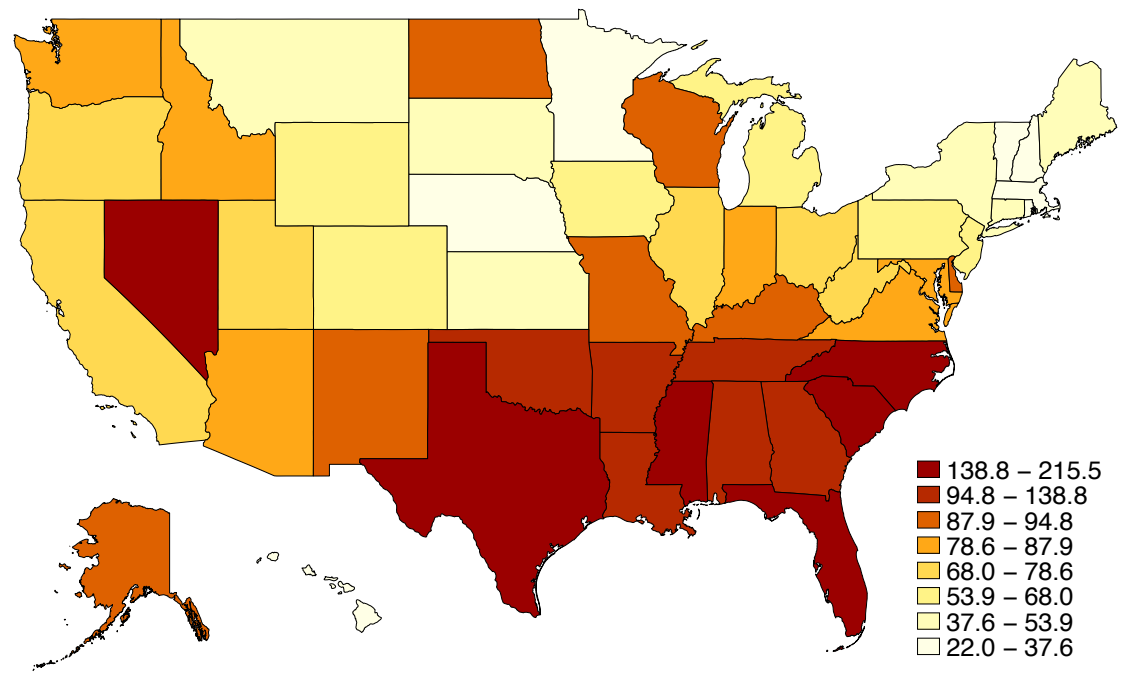

Panel B: With (Nearly) Universal Health Insurance

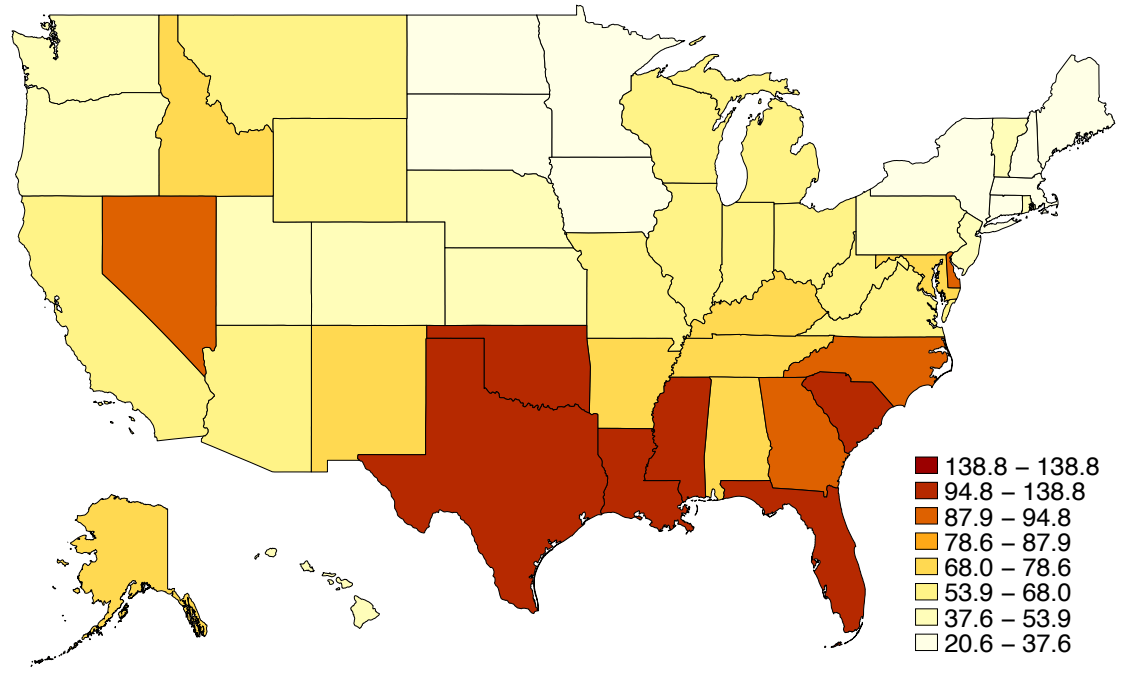

Note: This figure plots our counterfactual estimates of the flow of newly-reported collections debt (within the past year) per capita at age 65, with and without Medicare. The counterfactuals are based on local linear regressions, done separately by state, using the methods from Kolesár and Rothe (2018). Darker shading corresponds to states with higher counterfactual collections debt per capita. Source: Consumer credit outcomes are based on 137,340,577 person-year observations from the New York Fed Consumer Credit Panel / Equifax, 2008-2017. 
Figure A19: Counterfactual health insurance rates by commuting zone at age 65 with and without Medicare

Panel A: Without (Nearly) Universal Health Insurance

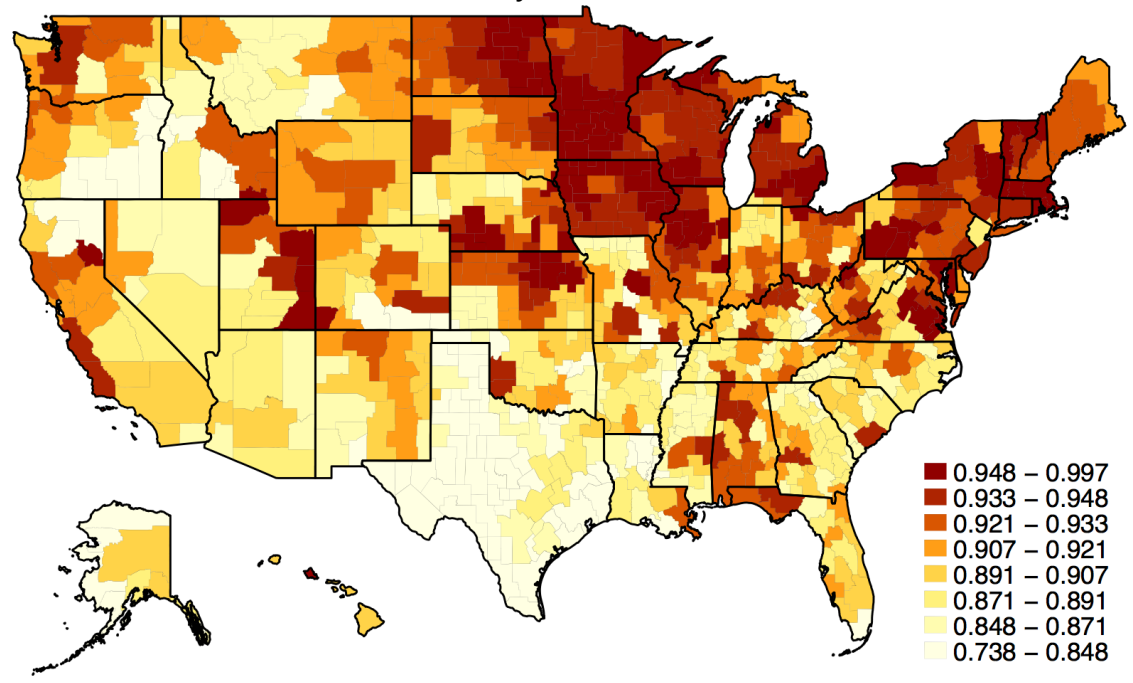

Panel B: With (Nearly) Universal Health Insurance

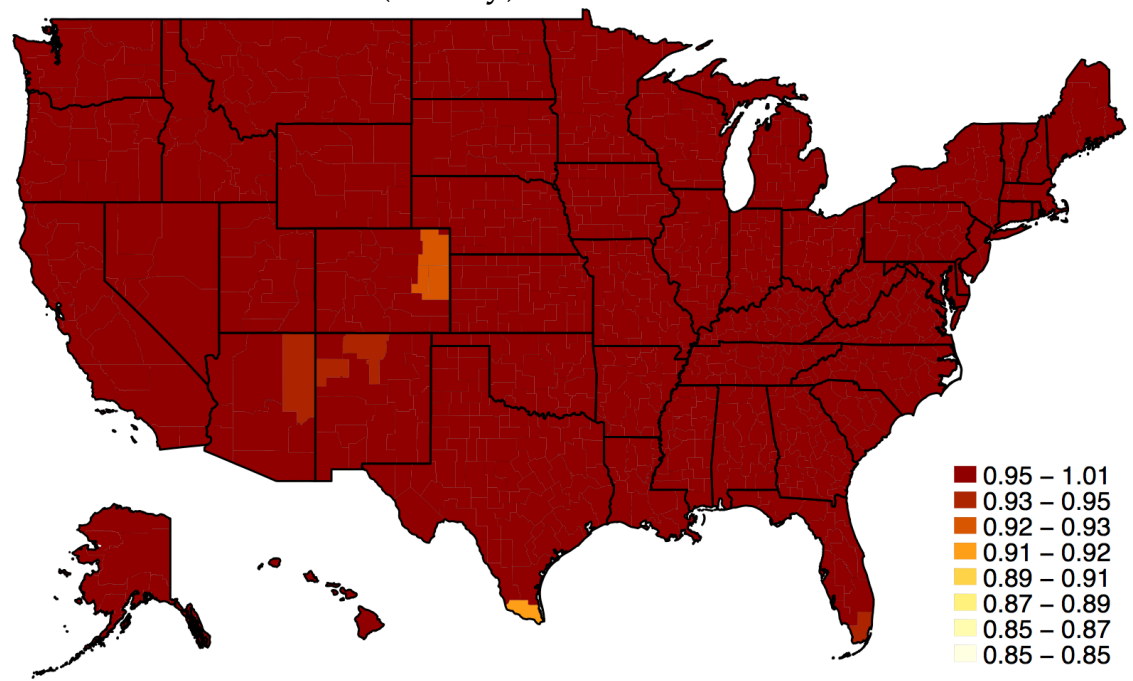

Note: This figure plots our counterfactual estimates of the share of the population with health insurance coverage at age 65, with and without Medicare. The counterfactuals are based on local linear regressions, done separately by commuting zone, using the methods from Kolesár and Rothe (2018). Darker shading corresponds to states with higher counterfactual health insurance rates. Source: CZ-level uninsurance rates are from the American Community Survey, 2008-2017. 
Figure A20: Counterfactual collections debt rates by commuting zone at age 65 with and without Medicare, pre- and post-ACA

I. Pre-ACA, 2008-2013

Panel A: Without Medicare

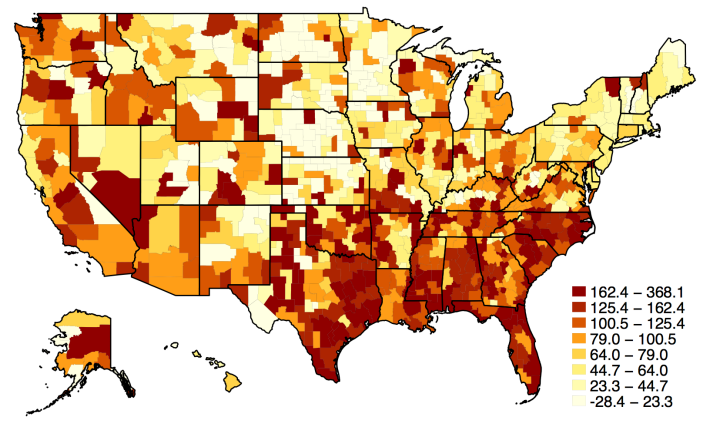

Panel B: With Medicare

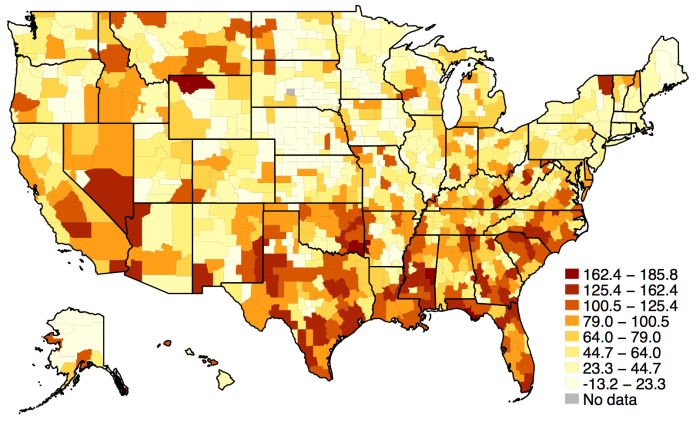

II. Post-ACA, 2014-2017

Panel A: Without Medicare

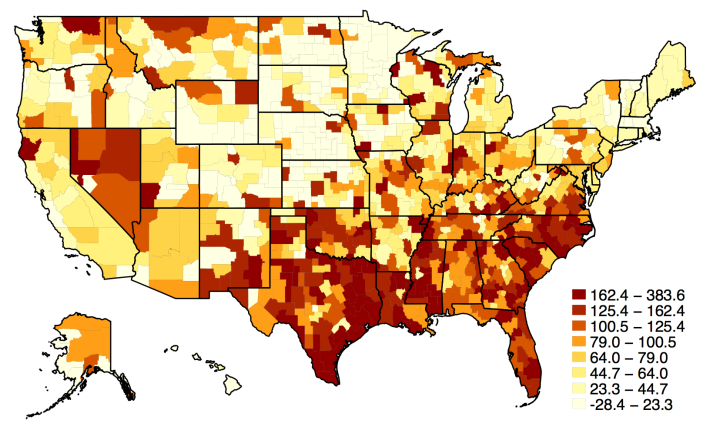

Panel B: With Medicare

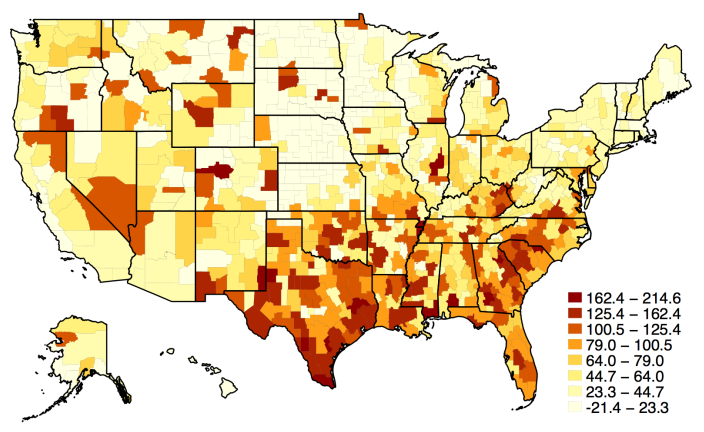

Note: This figure plots our counterfactual estimates of the flow of newly-reported collections debt (within the past year) per capita at age 65, with and without Medicare. The counterfactuals are based on local linear regressions, done separately by commuting zone, using the methods from Kolesár and Rothe (2018). The figures in Panel I. are constructed using data from the pre-ACA period, 2008-2013. The figures in Panel II. are constructed using data from the post-ACA period, 2014-2017. Darker shading corresponds to states with higher counterfactual collections debt per capita. Source: Consumer credit outcomes are based on 137,340,577 person-year observations from the New York Fed Consumer Credit Panel / Equifax, 2008-2017. 
Figure A21: Effect of Medicare eligibility on the level of collections debt at age 65 vs. effects on insurance, pre- and post-ACA
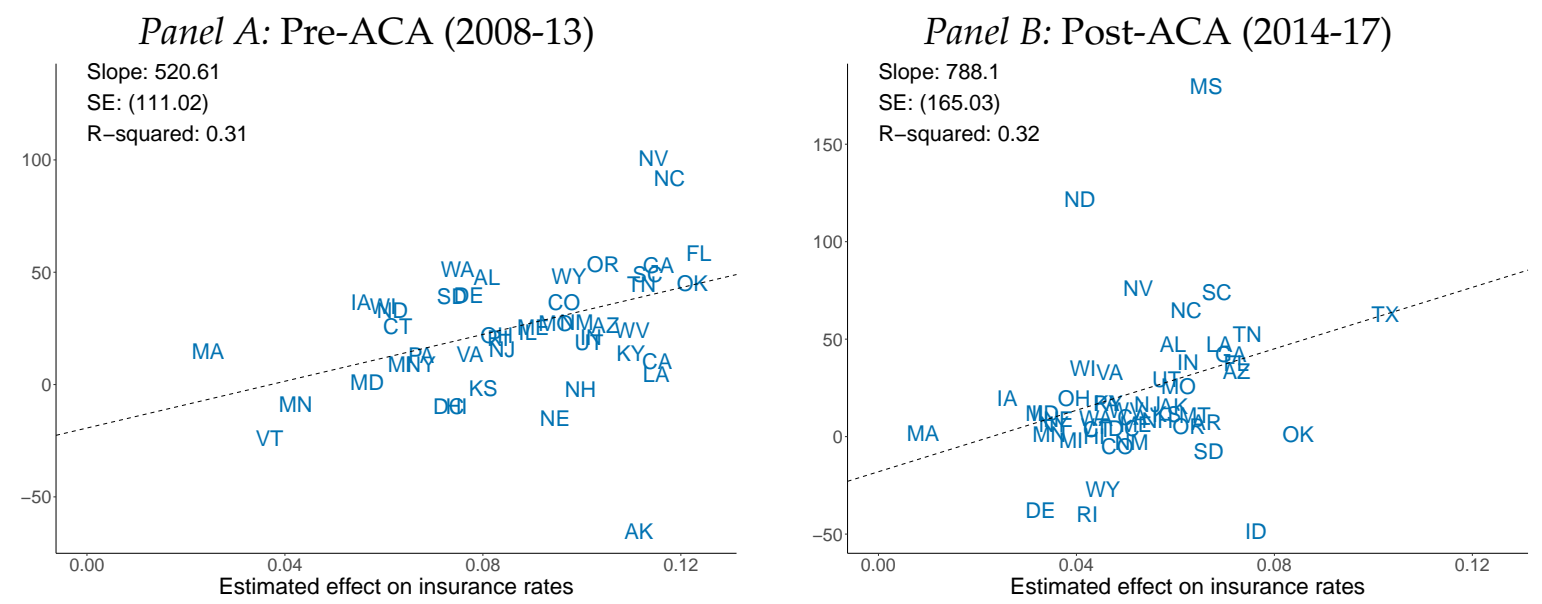

Note: This figure plots point estimates of the reduction in the flow of newly-reported collections debt (within the past year) against estimated increases in the insurance rate at age 65 based on local linear regressions, done separately by state, using the methods from Kolesár and Rothe (2018). Panel A restricts the data to the pre-ACA period (2008-2013) and Panel B restricts the data to the post-ACA period. The horizontal axis is the estimated effect on the insurance rate at age 65 by state. The vertical axis is the reduction in the flow of collections debt at age 65 by state. Source: Consumer credit outcomes are based on 137,340,577 person-year observations from the New York Fed Consumer Credit Panel / Equifax, 2008-2017. State-level uninsurance rates are from the American Community Survey, 2008-2017. 
Figure A22: Effect of Medicare eligibility on the level of collections debt at age 65 vs. effects on insurance

Panel A: Full study period, 2008-2017

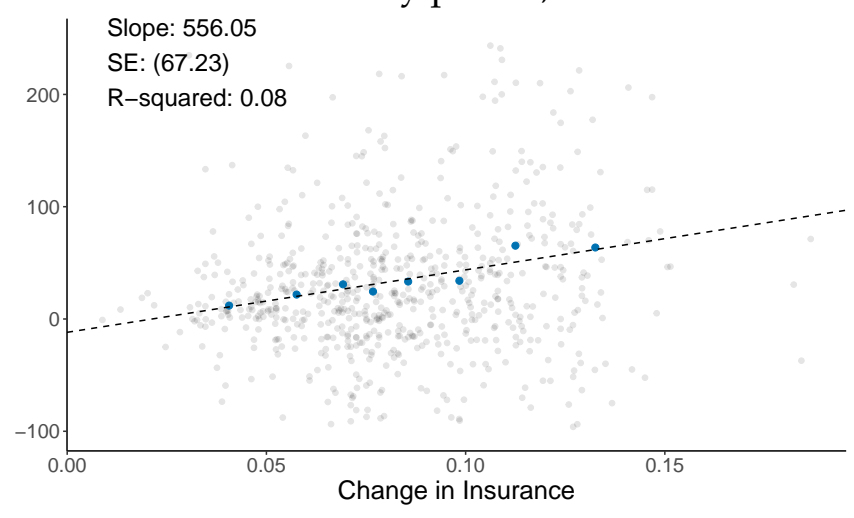

Panel B: Pre-ACA period, 2008-2013

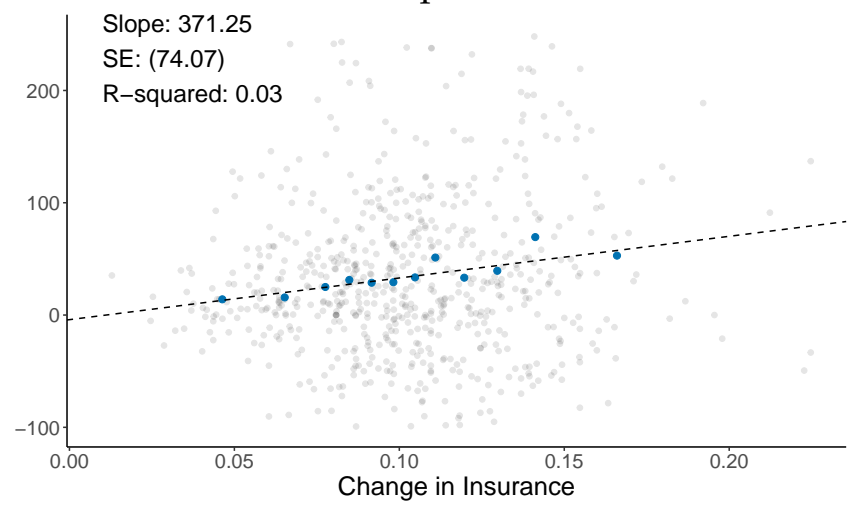

Panel C: Post-ACA period, 2014-2017

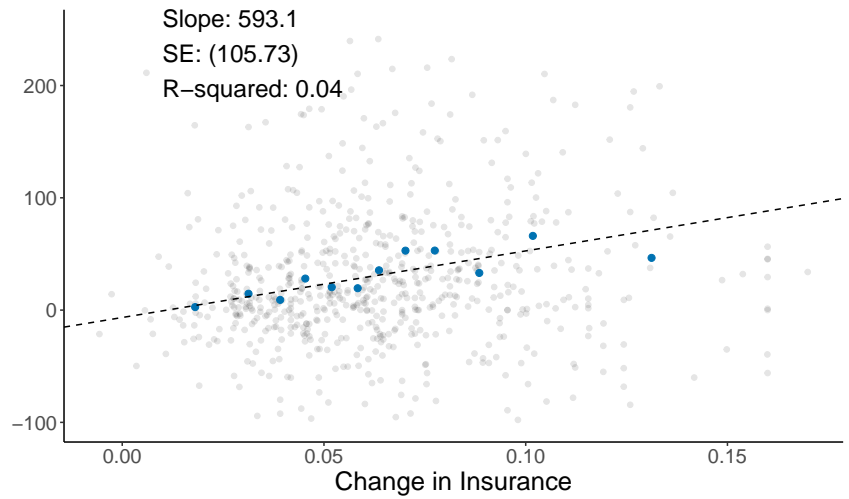

Note: This figure plots point estimates of the reduction in the flow of newly-reported collections debt (within the past year) and the increase in the insurance rate at age 65 based on local linear regressions, done separately by commuting zone, using the methods from Kolesár and Rothe (2018). The horizontal axis is the estimated effect on the insurance rate at age 65 by commuting zone. The vertical axis is the reduction in the flow of collections debt at age 65 by commuting zone. Panel A uses the full study period (2008-2017), Panel B restricts the data to the pre-ACA period (2008-2013), and Panel C restricts the data to the postACA period. Source: Consumer credit outcomes are based on 137,340,577 person-year observations from the New York Fed Consumer Credit Panel / Equifax, 2008-2017. CZ-level uninsurance rates are from the American Community Survey, 2008-2017. 
Figure A23: Counterfactual health insurance rates by commuting zone at age 65 without Medicare, pre- and post-ACA

Panel A: Pre-ACA, 2008-2013

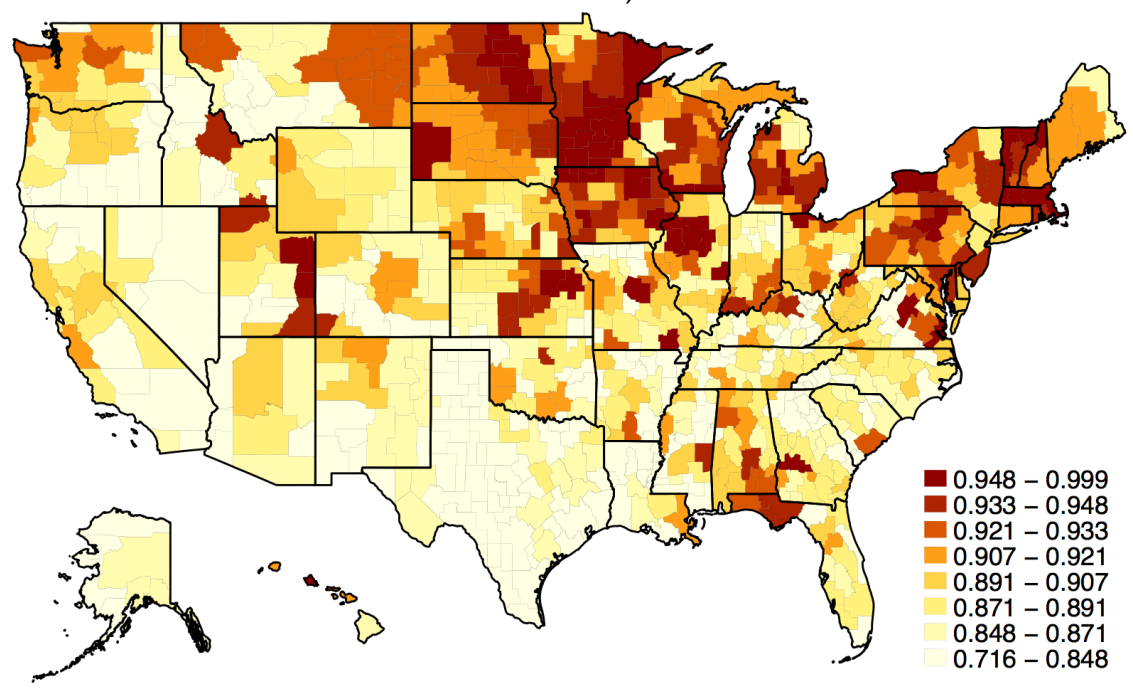

Panel B: Post-ACA, 2014-2017

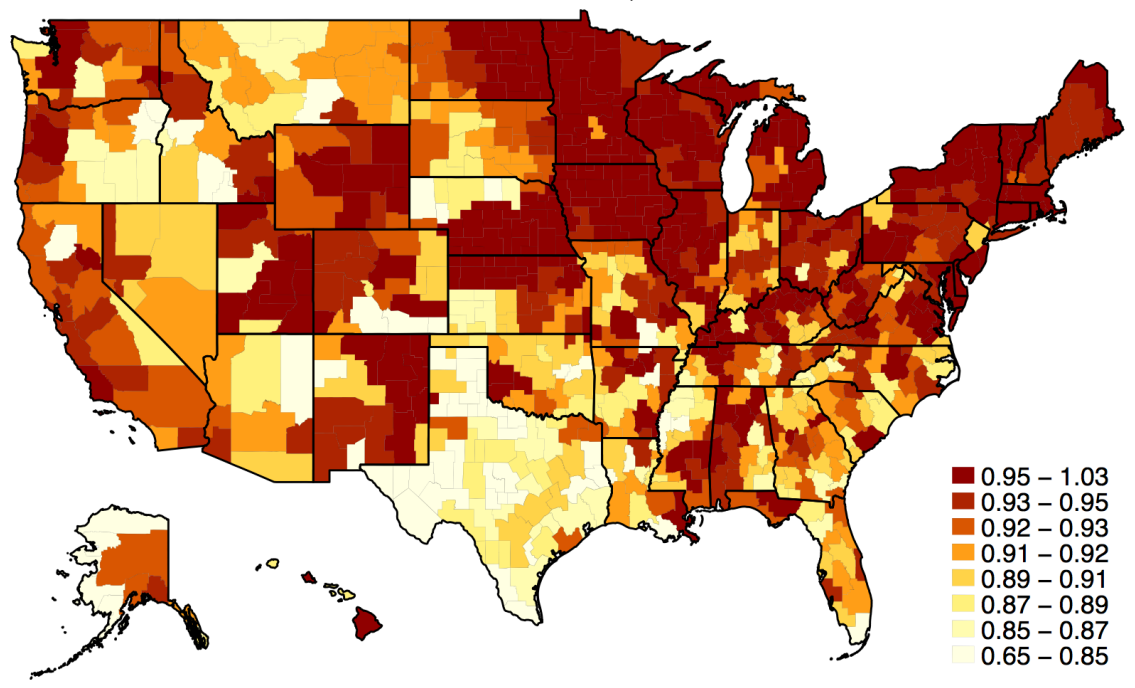

Note: This figure plots our counterfactual estimates of the share of the population with health insurance coverage at age 65, without Medicare, before and after the full implementation of the Affordable Care Act in 2014. The counterfactuals are based on local linear regressions, done separately by commuting zone, using the methods from Kolesár and Rothe (2018). Panel A. presents the counterfactuals from the pre-ACA period, 2008-2013. Panel B. presents the counterfactuals from the post-ACA period, 2014-2017. Darker shading corresponds to states with higher counterfactual health insurance rates. Source: CZ-level uninsurance rates are from the American Community Survey, 2008-2017. 
Figure A24: Difference-in-discontinuities estimates of increases in the near-elderly health insurance rate due to the ACA

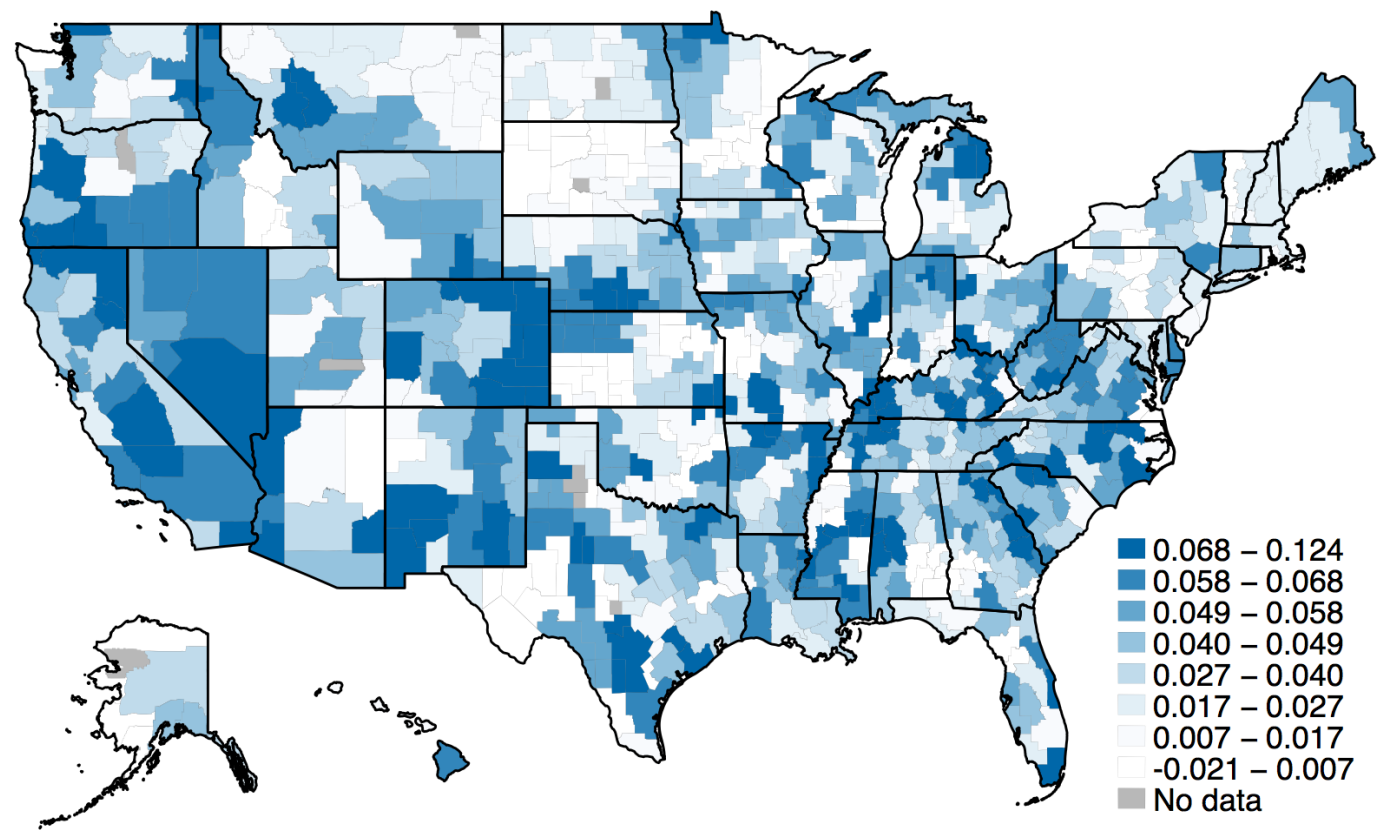

Note: This figure plots CZ-level estimates of the increase in health insurance coverage due to the Affordable Care Act using a difference-in-discontinuities design similar to Duggan, Gupta and Jackson (2019). We compare the discontinuity in health insurance at age 65 in the post-ACA period (2014-2017) to the discontinuity in health insurance at age 65 prior to its full implementation (2008-2013). CZ-level uninsurance rates are from the American Community Survey, 2008-2017. 
Figure A25: Difference-in-discontinuities estimates of increases in health insurance due to ACA vs. pre-ACA changes in coverage at 65

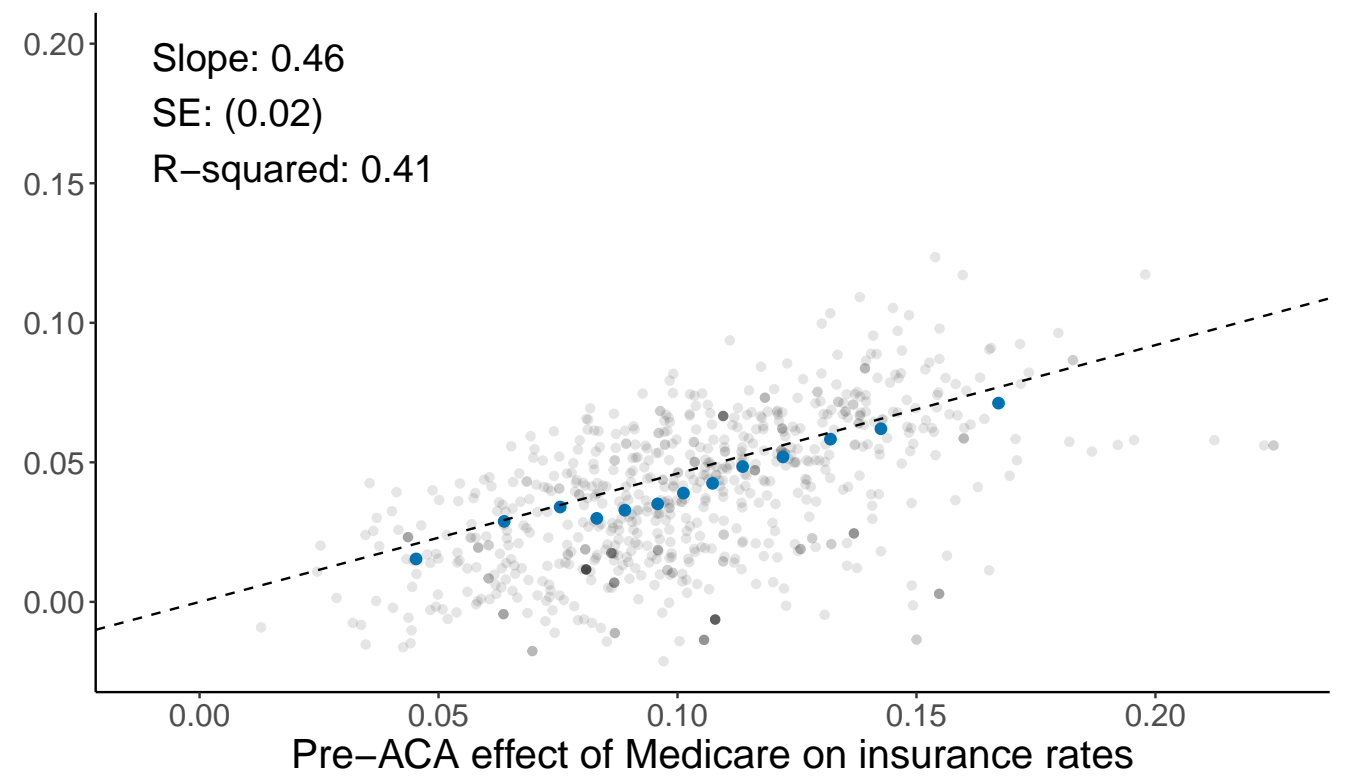

Note: This figure plots CZ-level estimates of the increase in health insurance coverage due to the Affordable Care Act using a difference-in-discontinuities design similar to Duggan, Gupta and Jackson (2019) against the pre-ACA increase in the insurance rate at age 65 based on local linear regressions, done separately by state, using the methods from Kolesár and Rothe (2018). The horizontal axis is the estimated effect on the insurance rate at age 65 by state in the pre-ACA period. The vertical axis is the stata-level diff-in-disc estimate of the increase in the insurance rate due to the ACA. Source: State-level uninsurance rates are from the American Community Survey, 2008-2017. 
Figure A26: Forecasts of causal reductions in collections debt per newly-insured nearelderly person by commuting zone, pre- and post-ACA

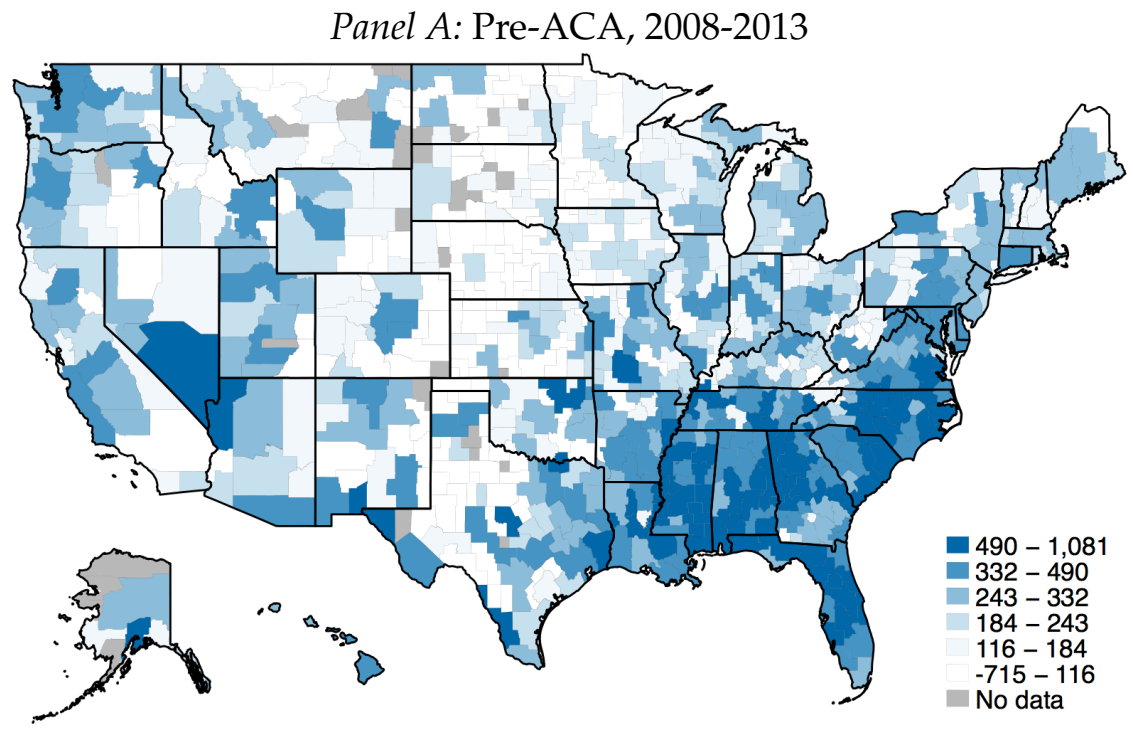

Panel B: Post-ACA, 2014-2017

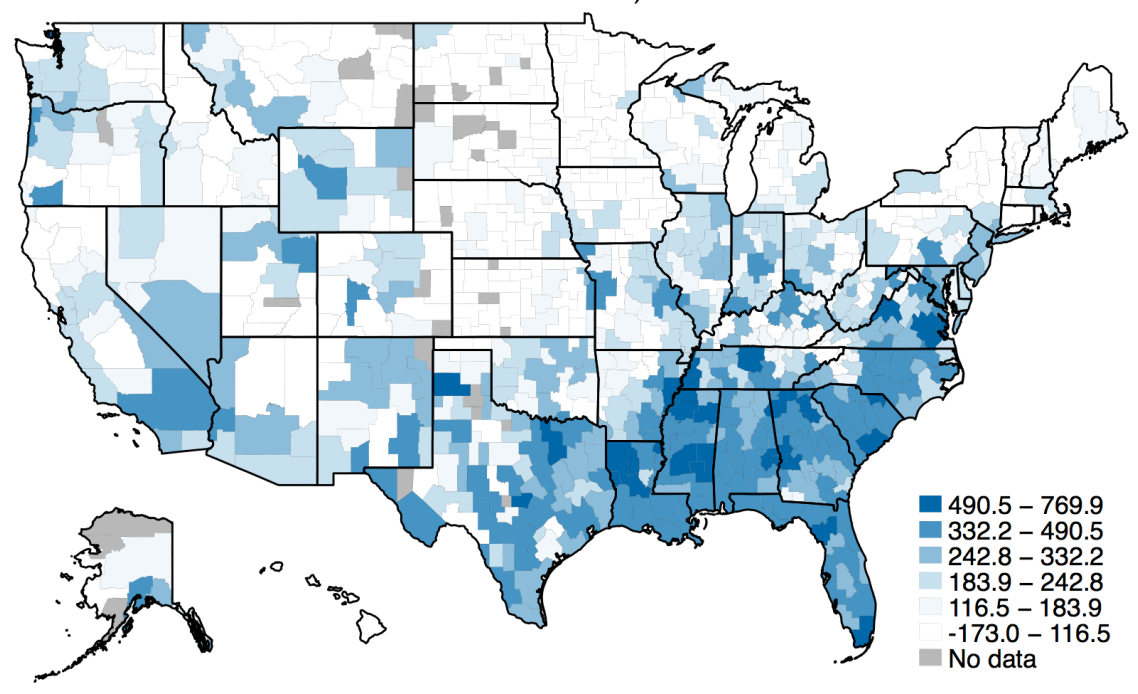

Note: This figure plots mean square error (MSE)-minimizing forecasts of the reductions in collections debt per newly-insured for the pre-ACA period (Panel A) and post-ACA period (Panel B). We construct the MSEminimizing forecasting by first running a Lasso regression to predict the CZ-level reductions in collections debt per newly-insured. This generates a prediction for each $\mathrm{CZ}$, which we call $\hat{\beta}_{l}$. Following Chetty and Hendren (2018) we then combine the $\hat{\beta}_{l}$ estimates with our estimates of $\beta_{l}$ to construct the mean square error-minimizing forecast for each commuting zone, $\beta_{l}^{f}$. Source: Consumer credit outcomes are based on 137,340,577 person-year observations from the New York Fed Consumer Credit Panel / Equifax, 2008-2017. State-level uninsurance rates are from the American Community Survey, 2008-2017. Healthcare market characteristics are from the Healthcare Cost Report Information System (HCRIS) and the Dartmouth Atlas. For additional details on the data see Section 2. 
Table A1: Description of the Federal Reserve Bank of New York's Equifax Consumer Credit Panel (CCP)

\begin{tabular}{|c|c|}
\hline Variable & Description \\
\hline Number of accounts sent to collection agencies & the number of 3 rd party collections within the past 12 months. \\
\hline Amount in collections & the total collection amount of these 3 rd party collection accounts. \\
\hline Number of delinquent accounts & the count of all non-current loans. \\
\hline Amount delinquent & the sum of all non-current loan balances. \\
\hline Total credit card balance past due & the difference of total bankcard balance and current bankcard balance. \\
\hline Total mortgage account balance past due & the difference of total mortgage account balance (incl. home equity installment) and current mortgage balance. \\
\hline Foreclosure & flag for if an individual recorded a foreclosure in the past 24 months. \\
\hline New Foreclosure & Number of people that recorded a foreclosure in the current quarter, but not the two previous quarters. \\
\hline Bankruptcy & flag for if an individual recorded a bankruptcy in the past 24 months. \\
\hline New Bankruptcy & Number of people that recorded a bankruptcy in the current quarter, but not the two previous quarters. \\
\hline Equifax Risk Score & always refers to Equifax Risk Score 3.0. \\
\hline
\end{tabular}

Note: This table reports definitions for the financial variables used from the New York Fed Consumer Credit Panel The dataset consists of 137,340,577 person-year observations from the New York Fed Consumer Credit Panel / Equifax, 2008-2017. 
Table A2: Additional Smoothness Tests

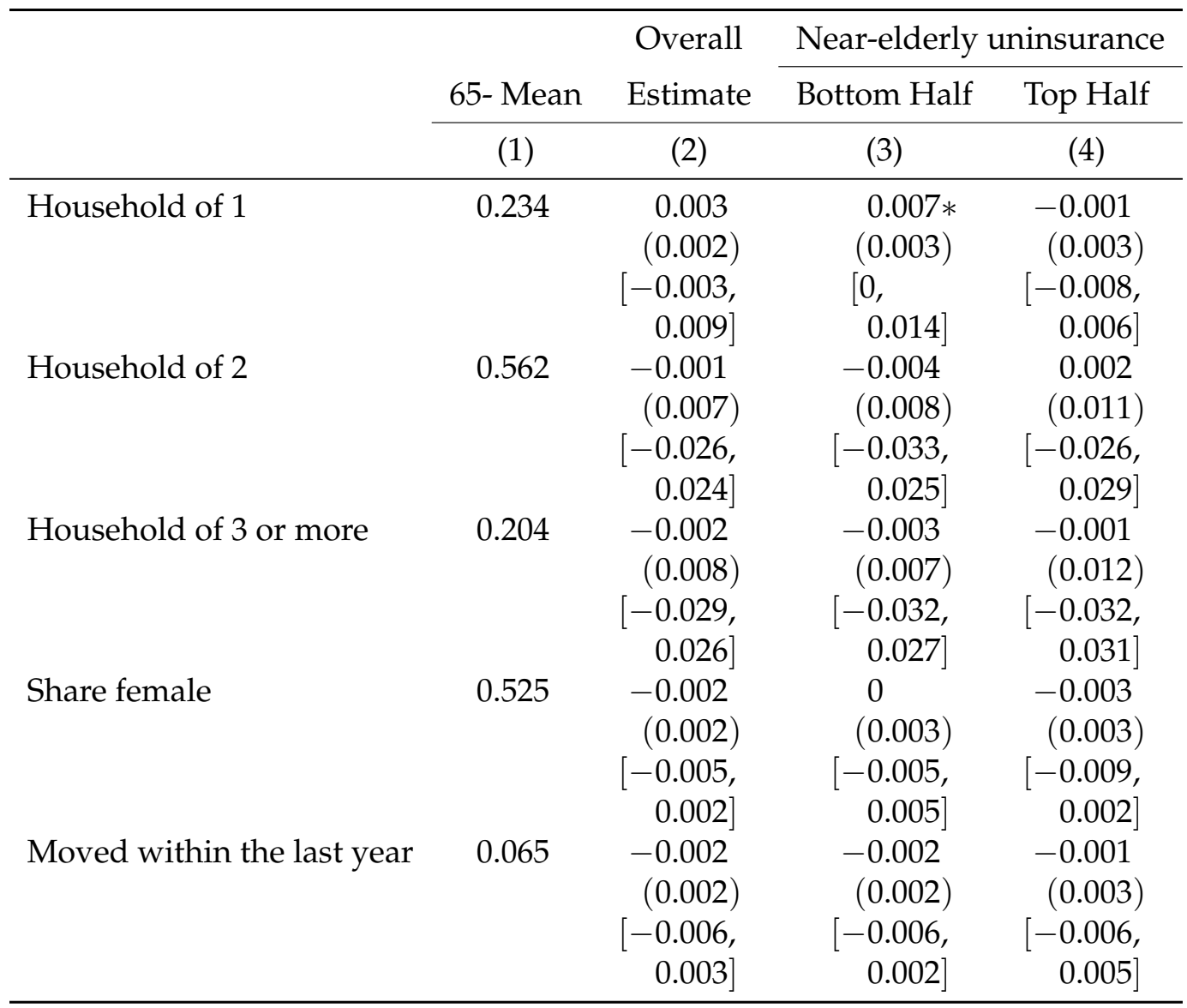

Note: This table reports regression discontinuity estimates of the effect of Medicare eligibility on additional covariates. Column 1 reports the predicted dependent variable mean at age 65 without Medicare. Column 2 reports the point estimate, standard error, and bias-adjusted 95\% confidence interval from a local linear regression using techniques from Kolesár and Rothe (2018). Columns 3 and 4 report the point estimate, standard error, and bias-adjusted 95\% confidence intervals from estimating our model on samples split by above- and below-median state near-elderly uninsurance rates. The sample includes individuals who were age 55-75 between 2008 and 2017. See Section 2 for additional details on the outcomes and sample. Source: American Community Survey, 2008-2017. 
Table A3: Additional Health Insurance Outcomes

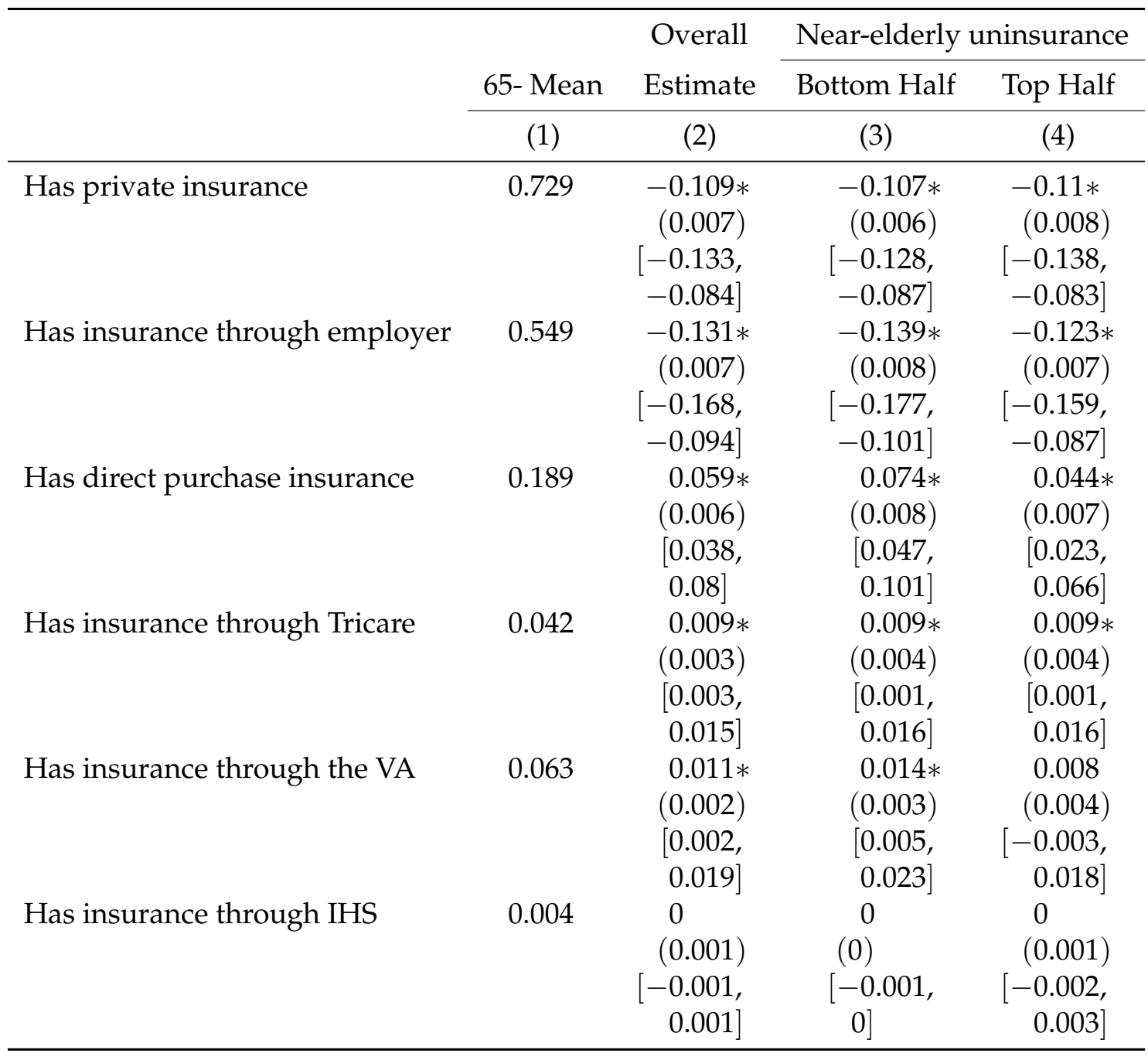

Note: This table reports regression discontinuity estimates of the effect of Medicare eligibility on additional health insurance outcomes. Column 1 reports the predicted dependent variable mean at age 65 without Medicare. Column 2 reports the point estimate, standard error, and bias-adjusted 95\% confidence interval from a local linear regression using techniques from Kolesár and Rothe (2018). Columns 3 and 4 report the point estimate, standard error, and bias-adjusted 95\% confidence intervals from estimating our model on samples split by above- and below-median state near-elderly uninsurance rates. The sample includes individuals who were age 55-75 between 2008 and 2017. See Section 2 for additional details on the outcomes and sample. Source: American Community Survey, 2008-2017. 
Table A4: Distributional treatment effects

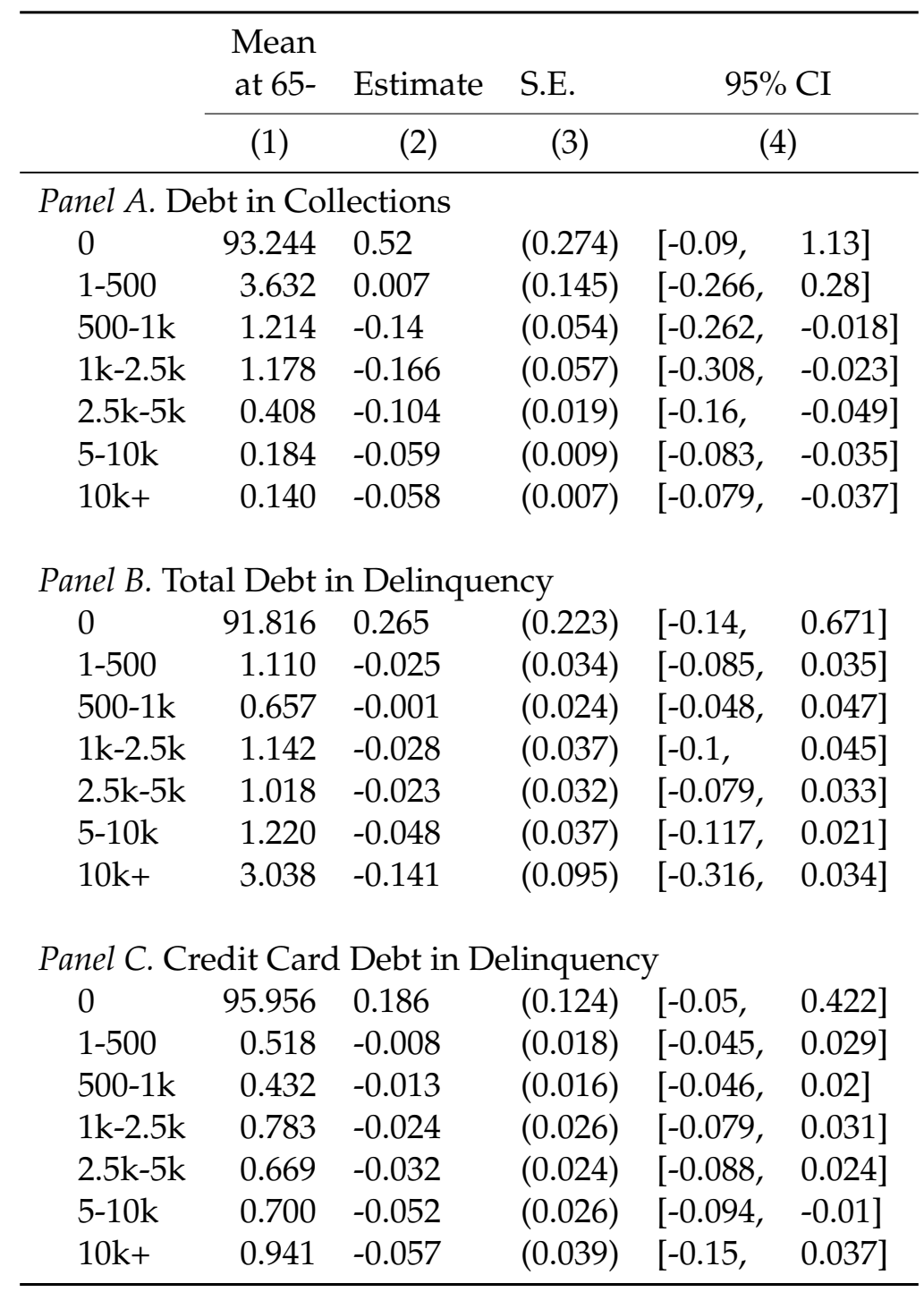

Note: This table reports regression discontinuity estimates of the effect of Medicare eligibility on the distribution of a select set of financial health outcomes. Each individual is binned into one of seven mutuallyexclusive bins for each financial health outcome and we estimate the discontinuity at age 65 in the share of individuals in each bin. Column 1 reports the predicted dependent variable mean at age 65 without Medicare. Column 2 reports the point estimate. Column 3 reports the standard error. Column 4 reports the bias-adjusted $95 \%$ confidence interval from a local linear regression using techniques from Kolesár and Rothe (2018). The sample includes individuals who were age 55-75 between 2008 and 2017. See Section 2 for additional details on the outcomes and sample. Source: American Community Survey, 2008-2017. 


\section{Table A5: Changes in insurance and financial outcomes at age 65, pre- and post-ACA}

\begin{tabular}{|c|c|c|c|c|c|c|c|c|}
\hline & \multicolumn{4}{|c|}{ Pre-Affordable Care Act (2008-2013) } & \multicolumn{4}{|c|}{ Post-Affordable Care Act (2014-2017) } \\
\hline & \multirow[b]{2}{*}{ 65- Mean } & \multirow{2}{*}{$\begin{array}{c}\text { Overall } \\
\text { Estimate }\end{array}$} & \multicolumn{2}{|c|}{ Near-elderly uninsurance } & \multirow[b]{2}{*}{ 65- Mean } & \multirow{2}{*}{$\begin{array}{c}\text { Overall } \\
\text { Estimate }\end{array}$} & \multicolumn{2}{|c|}{ Near-elderly uninsurance } \\
\hline & & & Bottom Half & Top Half & & & Bottom Half & Top Half \\
\hline & (1) & (2) & (3) & $(4)$ & (5) & (6) & $(7)$ & $(8)$ \\
\hline \multicolumn{9}{|l|}{ Panel A: Health insurance estimates: } \\
\hline Has health insurance coverage & 0.887 & $\begin{array}{c}0.097 * \\
(0.004) \\
{[0.084,} \\
0.11]\end{array}$ & $\begin{array}{c}0.072 * \\
(0.003) \\
{[0.063} \\
0.081]\end{array}$ & $\begin{array}{c}0.121 * \\
(0.004) \\
{[0.108} \\
0.134]\end{array}$ & 0.929 & $\begin{array}{c}0.056 * \\
(0.005) \\
{[0.046,} \\
0.067]\end{array}$ & $\begin{array}{c}0.042 * \\
(0.003) \\
{[0.037} \\
0.047]\end{array}$ & $\begin{array}{c}0.07 * \\
(0.007) \\
{[0.055} \\
0.086]\end{array}$ \\
\hline Has multiple forms of coverage & 0.191 & $\begin{array}{c}0.492 * \\
(0.007) \\
{[0.465,} \\
0.52]\end{array}$ & $\begin{array}{c}0.525 * \\
(0.007) \\
{[0.497} \\
0.553]\end{array}$ & $\begin{array}{c}0.461 * \\
(0.009) \\
{[0.431,} \\
0.49]\end{array}$ & 0.176 & $\begin{array}{c}0.451 * \\
(0.008) \\
{[0.422,} \\
0.48]\end{array}$ & $\begin{array}{c}0.488 * \\
(0.007) \\
{[0.46,} \\
0.517]\end{array}$ & $\begin{array}{l}0.415 * \\
(0.01) \\
{[0.384} \\
0.445]\end{array}$ \\
\hline Has insurance through Medicare & 0.185 & $\begin{array}{c}0.737 * \\
(0.004) \\
{[0.704,} \\
0.771]\end{array}$ & $\begin{array}{c}0.75 * \\
(0.005) \\
{[0.716} \\
0.784]\end{array}$ & $\begin{array}{r}0.725 * \\
(0.006) \\
{[0.687} \\
0.762]\end{array}$ & 0.189 & $\begin{array}{c}0.713 * \\
(0.005) \\
{[0.681} \\
0.746]\end{array}$ & $\begin{array}{c}0.727 * \\
(0.006) \\
{[0.694,} \\
0.76]\end{array}$ & $\begin{array}{c}0.699 * \\
(0.008) \\
{[0.661} \\
0.737]\end{array}$ \\
\hline Has insurance through Medicaid & 0.095 & $\begin{array}{c}0.025 * \\
(0.004) \\
{[0.017} \\
0.032]\end{array}$ & $\begin{array}{c}0.023 * \\
(0.006) \\
{[0.012} \\
0.034]\end{array}$ & $\begin{array}{c}0.026 * \\
(0.005) \\
{[0.017} \\
0.036]\end{array}$ & 0.130 & $\begin{array}{r}-0.007 \\
(0.008) \\
{[-0.027} \\
0.012]\end{array}$ & $\begin{array}{c}-0.01 \\
(0.009) \\
{[-0.032} \\
0.012]\end{array}$ & $\begin{array}{r}-0.004 \\
(0.012) \\
{[-0.031} \\
0.023]\end{array}$ \\
\hline \multicolumn{9}{|l|}{ Panel B: Debt in Collections: } \\
\hline Total Collections & 106.478 & $\begin{array}{r}-31.381 * \\
(4.647) \\
{[-42.538} \\
-20.224]\end{array}$ & $\begin{array}{r}-17.947 * \\
(3.878) \\
{[-28.242} \\
-7.652]\end{array}$ & $\begin{array}{r}-44.373 * \\
(7.913) \\
{[-60.422} \\
-28.324]\end{array}$ & 87.086 & $\begin{array}{r}-25.487 * \\
(4.727) \\
{[-37.301} \\
-13.673]\end{array}$ & $\begin{array}{r}-14.85 * \\
(3.582) \\
{[-23.259} \\
-6.441]\end{array}$ & $\begin{array}{r}-35.594 * \\
(9.326) \\
{[-56.122} \\
-15.067]\end{array}$ \\
\hline Number of Collections & 0.143 & $\begin{array}{c}-0.02 * \\
(0.006)\end{array}$ & $\begin{array}{c}-0.014 \\
(0.006)\end{array}$ & $\begin{array}{c}-0.026 \\
(0.012)\end{array}$ & 0.132 & $\begin{array}{c}-0.019 * \\
(0.007)\end{array}$ & $\begin{array}{c}-0.015 * \\
(0.007)\end{array}$ & $\begin{array}{c}-0.022 \\
(0.013)\end{array}$ \\
\hline & & $\begin{array}{r}{[-0.037} \\
-0.003]\end{array}$ & $\begin{array}{r}{[-0.031} \\
0.003]\end{array}$ & $\begin{array}{r}{[-0.053} \\
0.002]\end{array}$ & & $\begin{array}{r}{[-0.033} \\
-0.005]\end{array}$ & $\begin{array}{r}{[-0.028} \\
-0.002]\end{array}$ & $\begin{array}{r}{[-0.047} \\
0.002]\end{array}$ \\
\hline Collections $>0$ & 0.070 & $\begin{array}{c}-0.005 \\
(0.003)\end{array}$ & $\begin{array}{c}-0.004 \\
(0.003)\end{array}$ & $\begin{array}{c}-0.007 \\
(0.005)\end{array}$ & 0.066 & $\begin{array}{c}-0.005 \\
(0.003)\end{array}$ & $\begin{array}{c}-0.004 \\
(0.003)\end{array}$ & $\begin{array}{c}-0.006 \\
(0.006)\end{array}$ \\
\hline & & $\begin{array}{r}{[-0.012} \\
0.002]\end{array}$ & $\begin{array}{r}{[-0.011} \\
0.003]\end{array}$ & $\begin{array}{r}{[-0.017} \\
0.004]\end{array}$ & & $\begin{array}{c}{[-0.01} \\
0]\end{array}$ & $\begin{array}{r}{[-0.009} \\
0.001]\end{array}$ & $\begin{array}{r}{[-0.016} \\
0.003]\end{array}$ \\
\hline
\end{tabular}

Note: This table reports regression discontinuity estimates of the effect of Medicare eligibility on health insurance coverage and financial health before and after the implementation of the Affordable Care Act in 2014. Columns 1 and 5 report the predicted dependent variable mean at age 65 without Medicare pre- and post-ACA, respectively. Columns 2 and 5 report the point estimate, standard error, and bias-adjusted $95 \%$ confidence interval from local linear regression using techniques from Kolesár and Rothe (2018) estimating pre- and post-ACA, respectively. Columns 3 and 4 and 7 and 8 report the point estimate, standard error, and bias-adjusted $95 \%$ confidence intervals from estimating our model on samples split by above- and below-median state near-elderly uninsurance rates preand post-ACA, respectively. The sample includes individuals who were age 55-75 between 2008 and 2017. See Section 2 for additional details on the outcomes and sample. Sources: American Community Survey, 2008-2017. The financial health outcomes are based on 137,340,577 person-year observations from the New York Fed Consumer Credit Panel / Equifax, 2008-2017. 
Table A6: Change post-ACA in effect of Medicare on insurance outcomes at age 65, split by expansion states

\begin{tabular}{|c|c|c|c|c|}
\hline & \multirow{2}{*}{$\begin{array}{c}\text { RD Estimate } \\
\text { Pre-ACA }\end{array}$} & \multicolumn{3}{|c|}{ Diff-in-Disc Estimate } \\
\hline & & Main & Expansion & Non-Expansion \\
\hline & $(1)$ & (2) & (3) & (4) \\
\hline \multicolumn{5}{|l|}{ Panel A: Health insurance estimates } \\
\hline Has health insurance coverage & 0.097 & $\begin{array}{c}-0.04 * \\
(0.002)\end{array}$ & $\begin{array}{c}-0.04 * \\
(0.003)\end{array}$ & $\begin{array}{c}-0.039 * \\
(0.002)\end{array}$ \\
\hline & & $\begin{array}{r}{[-0.043} \\
-0.036]\end{array}$ & $\begin{array}{r}{[-0.045} \\
-0.035]\end{array}$ & $\begin{array}{r}{[-0.045} \\
-0.033]\end{array}$ \\
\hline Has private insurance & -0.085 & $\begin{array}{r}-0.042 * \\
(0.003)\end{array}$ & $\begin{array}{c}-0.032 * \\
(0.003)\end{array}$ & $\begin{array}{r}-0.058 * \\
(0.004)\end{array}$ \\
\hline & & $\begin{array}{r}{[-0.049} \\
-0.035]\end{array}$ & $\begin{array}{c}{[-0.04} \\
-0.024]\end{array}$ & $\begin{array}{r}{[-0.068} \\
-0.049]\end{array}$ \\
\hline Has insurance through Medicaid & 0.025 & $\begin{array}{r}-0.033 * \\
(0.003)\end{array}$ & $\begin{array}{r}-0.045 * \\
(0.003)\end{array}$ & $\begin{array}{r}-0.013 * \\
(0.002)\end{array}$ \\
\hline & & $\begin{array}{c}{[-0.04} \\
-0.026]\end{array}$ & $\begin{array}{r}{[-0.052} \\
-0.038]\end{array}$ & $\begin{array}{c}{[-0.02} \\
-0.005]\end{array}$ \\
\hline Has insurance through Medicare & 0.737 & $\begin{array}{r}-0.022 * \\
(0.001)\end{array}$ & $\begin{array}{r}-0.021 * \\
(0.002)\end{array}$ & $\begin{array}{r}-0.023 * \\
(0.002)\end{array}$ \\
\hline & & $\begin{array}{r}{[-0.026} \\
-0.017]\end{array}$ & $\begin{array}{r}{[-0.027} \\
-0.015]\end{array}$ & $\begin{array}{r}{[-0.028} \\
-0.019]\end{array}$ \\
\hline Has multiple insurance coverages & 0.492 & $\begin{array}{r}-0.028 * \\
(0.002)\end{array}$ & $\begin{array}{r}-0.028 * \\
(0.003)\end{array}$ & $\begin{array}{r}-0.028 * \\
(0.004)\end{array}$ \\
\hline & & $\begin{array}{c}{[-0.036} \\
-0.02]\end{array}$ & $\begin{array}{c}{[-0.035} \\
-0.02]\end{array}$ & $\begin{array}{c}{[-0.04} \\
-0.016]\end{array}$ \\
\hline \multicolumn{5}{|l|}{ Panel B: Debt in Collections } \\
\hline Total Collections & -31.381 & $\begin{array}{c}7.355 \\
(4.034)\end{array}$ & $\begin{array}{c}10.879 * \\
(4.748)\end{array}$ & $\begin{array}{c}1.426 \\
(7.232)\end{array}$ \\
\hline & & $\begin{array}{r}{[-5.463} \\
20.173]\end{array}$ & $\begin{array}{r}{[0.244} \\
21.514]\end{array}$ & $\begin{array}{r}{[-22.254} \\
25.106]\end{array}$ \\
\hline Number of Collections & -0.02 & $\begin{array}{c}0.006 \\
(0.003)\end{array}$ & $\begin{array}{r}0.009 * \\
(0.003)\end{array}$ & $\begin{array}{c}0.002 \\
(0.005)\end{array}$ \\
\hline & & {$\left[\begin{array}{l}{[0,} \\
0.013]\end{array}\right.$} & $\begin{array}{r}{[0.001} \\
0.017]\end{array}$ & $\begin{array}{r}-0.007 \\
0.011]\end{array}$ \\
\hline Collections $>0$ & -0.005 & $\begin{array}{l}0 \\
(0.001)\end{array}$ & $\begin{array}{c}-0.001 \\
(0.001)\end{array}$ & $\begin{array}{c}0.002 \\
(0.002)\end{array}$ \\
\hline & & {$\left[\begin{array}{r}-0.001 \\
0.002]\end{array}\right.$} & {$\left[\begin{array}{r}-0.003 \\
0.001]\end{array}\right.$} & {$\left[\begin{array}{r}-0.001 \\
0.005]\end{array}\right.$} \\
\hline
\end{tabular}

Note: This table reports regression discontinuity-in-differences estimates that measures the average change in the discontinuity at age 65 from the pre-ACA to post-ACA period. Column 1 reports the pre-ACA regression discontinuity estimate for each dependent variable. Column 2 reports the point estimate, standard error, and biasadjusted 95\% confidence interval from our discontinuity-in-differences estimates using techniques from Kolesár and Rothe (2018). Columns 3 and 4 report the point estimate, standard error, and bias-adjusted 95\% confidence intervals separately for Medicaid expansion and non-expansion states, respectively. The sample includes individuals who were age 55-75 between 2008 and 2017. The regressions include 15,046,670 person-year observations. See Section 2 for additional details on the outcomes and sample. Sources: American Community Survey, 20082017. The financial health outcomes are based on 137,340,577 person-year observations from the New York Fed Consumer Credit Panel / Equifax, 2008-2017. 
Table A7: Changes in other financial outcomes at age 65, pre- and post-ACA

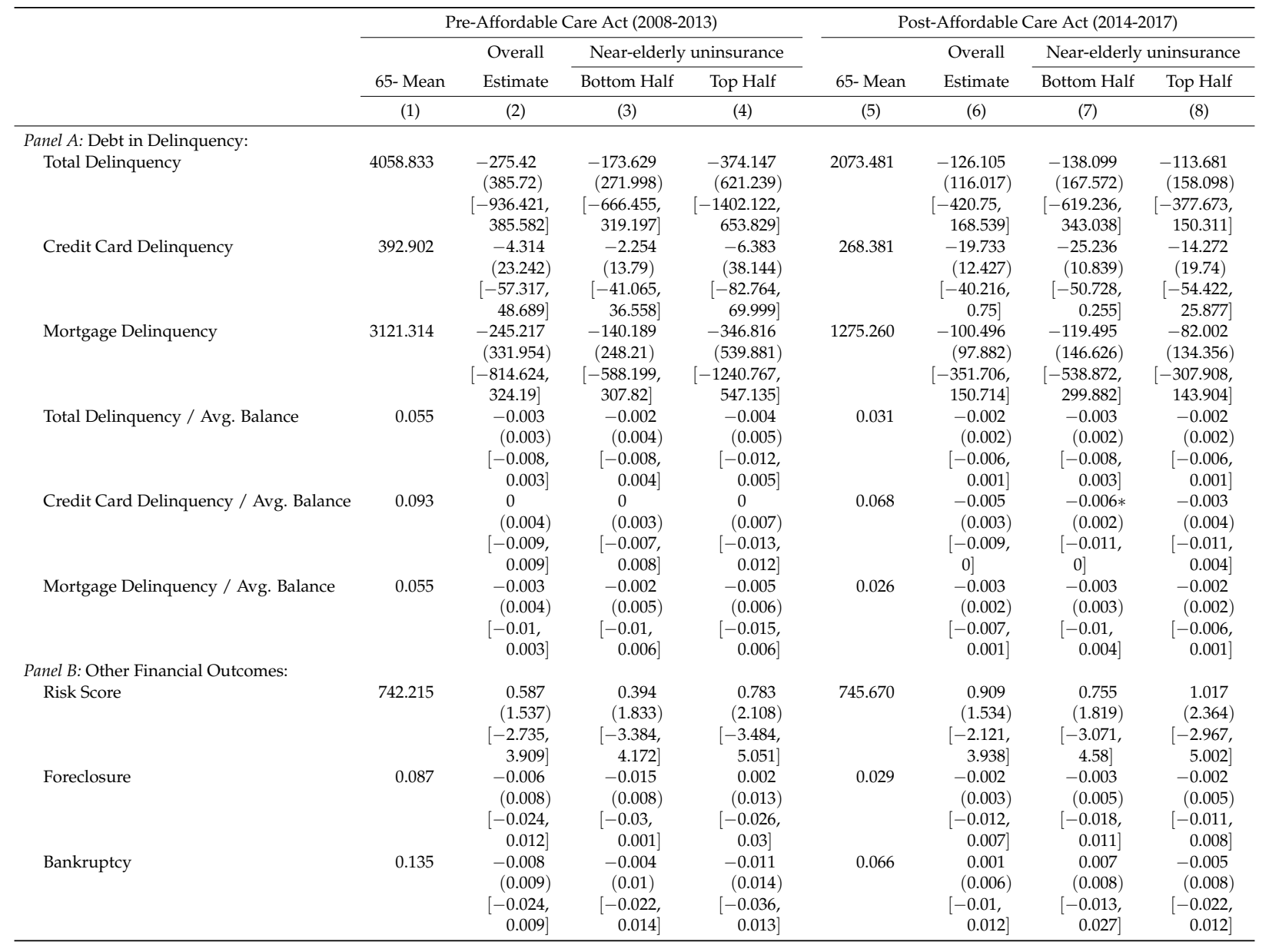

Note: This table reports regression discontinuity estimates of the effect of Medicare eligibility on additional financial health outcomes before and after the implementation of the Affordable Care Act in 2014. Columns 1 and 5 report the predicted dependent variable mean at age 65 without Medicare pre- and post-ACA, respectively. Columns 2 and 5 report the point estimate, standard error, and bias-adjusted 95\% confidence interval from local linear regression using techniques from Kolesár and Rothe (2018) pre- and post-ACA, respectively. Columns 3 and 4 and 7 and 8 report the point estimate, standard error, and bias-adjusted 95\% confidence intervals from estimating our model on samples split by above- and below-median state near-elderly uninsurance rates pre- and post-ACA. The sample includes individuals who were age 55-75 between 2008 and 2017. See Section 2 for additional details on the outcomes and sample. Source: The financial health outcomes are based on 137,340,577 person-year observations from the New York Fed Consumer Credit Panel / Equifax, 2008-2017. 
Table A8: Robustness of estimated changes in financial outcomes at age 65

\begin{tabular}{|c|c|c|c|c|c|c|c|c|}
\hline & $\begin{array}{c}\text { Main } \\
\text { Estimate }\end{array}$ & $\begin{array}{l}\text { Linear with } \\
\text { robust SEs }\end{array}$ & $\begin{array}{l}\text { Quad. with } \\
\text { robust SEs }\end{array}$ & $\begin{array}{l}\text { Cubic. with } \\
\text { robust SEs }\end{array}$ & $\begin{array}{l}\text { Linear with } \\
\text { clustered SEs }\end{array}$ & $\begin{array}{l}\text { Quad. with } \\
\text { clustered SEs }\end{array}$ & $\begin{array}{l}\text { Cubic. with } \\
\text { clustered SEs }\end{array}$ & $\begin{array}{l}\text { Local linear } \\
\text { with rdrobust }\end{array}$ \\
\hline & (1) & (2) & (3) & (4) & (5) & (6) & (7) & (8) \\
\hline \multicolumn{9}{|l|}{ Panel A: Debt in collections } \\
\hline \multirow[t]{2}{*}{ Total Collections } & $\begin{array}{c}-28.546 * \\
(4.247)\end{array}$ & $\begin{array}{c}-32.981 * \\
(2.578)\end{array}$ & $\begin{array}{c}-32.121 * \\
(4.407)\end{array}$ & $\begin{array}{r}-23.58 * \\
(7.467)\end{array}$ & $\begin{array}{c}-32.981 * \\
(2.212)\end{array}$ & $\begin{array}{c}-32.121 * \\
(2.498)\end{array}$ & $\begin{array}{r}-23.58 * \\
(2.549)\end{array}$ & $\begin{array}{c}-20.763 * \\
(9.906)\end{array}$ \\
\hline & $\begin{array}{r}{[-39.135} \\
-17.957]\end{array}$ & $\begin{array}{r}{[-38.034} \\
-27.928]\end{array}$ & $\begin{array}{c}{[-40.76} \\
-23.483]\end{array}$ & $\begin{array}{r}{[-38.216} \\
-8.945]\end{array}$ & $\begin{array}{r}{[-37.317} \\
-28.645]\end{array}$ & $\begin{array}{r}{[-37.018} \\
-27.224]\end{array}$ & $\begin{array}{r}{[-28.577} \\
-18.584]\end{array}$ & $\begin{array}{r}{[-40.178} \\
-1.348]\end{array}$ \\
\hline \multirow[t]{2}{*}{ Number of Collections } & $\begin{array}{c}-0.02 * \\
(0.006)\end{array}$ & $\begin{array}{r}-0.021 * \\
(0.004)\end{array}$ & $\begin{array}{r}-0.021 * \\
(0.007)\end{array}$ & $\begin{array}{c}-0.016 \\
(0.011)\end{array}$ & $\begin{array}{c}-0.021 * \\
(0.003)\end{array}$ & $\begin{array}{r}-0.021 * \\
(0.002)\end{array}$ & $\begin{array}{c}-0.016 * \\
(0.001)\end{array}$ & $\begin{array}{c}-0.015 \\
(0.016)\end{array}$ \\
\hline & $\begin{array}{r}{[-0.035} \\
-0.004]\end{array}$ & $\begin{array}{l}{[-0.029} \\
-0.014]\end{array}$ & $\begin{array}{r}{[-0.034} \\
-0.008]\end{array}$ & {$\left[\begin{array}{r}-0.039 \\
0.006\end{array}\right.$} & $\begin{array}{r}{[-0.026} \\
-0.016]\end{array}$ & $\begin{array}{r}{[-0.025} \\
-0.018]\end{array}$ & $\begin{array}{r}{[-0.018} \\
-0.014]\end{array}$ & $\begin{array}{r}{[-0.047} \\
0.016]\end{array}$ \\
\hline \multirow[t]{2}{*}{ Collections $>0$} & $\begin{array}{c}-0.005 \\
(0.003)\end{array}$ & $\begin{array}{r}-0.006 * \\
(0.002)\end{array}$ & $\begin{array}{c}-0.005 \\
(0.003)\end{array}$ & $\begin{array}{c}-0.004 \\
(0.005)\end{array}$ & $\begin{array}{r}-0.006 * \\
(0.001)\end{array}$ & $\begin{array}{c}-0.005 * \\
(0.001)\end{array}$ & $\begin{array}{l}-0.004 * \\
(0)\end{array}$ & $\begin{array}{c}-0.004 \\
(0.006)\end{array}$ \\
\hline & {$\left[\begin{array}{r}-0.011 \\
0.001]\end{array}\right.$} & $\begin{array}{r}{[-0.009} \\
-0.003]\end{array}$ & $\begin{array}{c}{[-0.011,} \\
0]\end{array}$ & $\begin{array}{r}{[-0.013} \\
0.005]\end{array}$ & $\begin{array}{r}{[-0.008} \\
-0.004]\end{array}$ & $\begin{array}{r}{[-0.006} \\
-0.004]\end{array}$ & $\begin{array}{r}{[-0.005} \\
-0.003]\end{array}$ & {$\left[\begin{array}{r}-0.017 \\
0.008]\end{array}\right.$} \\
\hline \multicolumn{9}{|l|}{ Panel B: Debt past due } \\
\hline \multirow[t]{2}{*}{ Total Delinquency } & $\begin{array}{c}-220.973 \\
(234.903)\end{array}$ & $\begin{array}{r}-213.784 \\
(139.794)\end{array}$ & $\begin{array}{c}-230.164 \\
(240.424)\end{array}$ & $\begin{array}{c}-200.976 \\
(412.141)\end{array}$ & $\begin{array}{r}-213.784 * \\
(38.637)\end{array}$ & $\begin{array}{r}-230.164 * \\
(53.615)\end{array}$ & $\begin{array}{r}-200.976 * \\
(52.082)\end{array}$ & $\begin{array}{c}-243.446 \\
(748.521)\end{array}$ \\
\hline & $\begin{array}{c}{[-656.27} \\
214.323]\end{array}$ & $\begin{array}{c}{[-487.78} \\
60.212]\end{array}$ & $\begin{array}{r}{[-701.396,} \\
241.067]\end{array}$ & $\begin{array}{c}{[-1008.772,} \\
606.82]\end{array}$ & $\begin{array}{l}{[-289.513} \\
-138.055]\end{array}$ & $\begin{array}{l}{[-335.25} \\
-125.079]\end{array}$ & $\begin{array}{r}{[-303.057} \\
-98.895]\end{array}$ & $\begin{array}{r}{[-1710.521} \\
1223.629]\end{array}$ \\
\hline \multirow[t]{2}{*}{ Credit Card Delinquency } & $\begin{array}{c}-13.922 \\
(16.14)\end{array}$ & $\begin{array}{c}-27.734 * \\
(9.16)\end{array}$ & $\begin{array}{c}-11.793 \\
(16.058)\end{array}$ & $\begin{array}{l}-6.079 \\
(27.349)\end{array}$ & $\begin{array}{c}-27.734 * \\
(4.22)\end{array}$ & $\begin{array}{c}-11.793 * \\
(3.959)\end{array}$ & $\begin{array}{c}-6.079 \\
(4.492)\end{array}$ & $\begin{array}{l}-6.349 \\
(49.628)\end{array}$ \\
\hline & $\begin{array}{r}{[-49.023} \\
21.178]\end{array}$ & $\begin{array}{r}{[-45.688} \\
-9.781]\end{array}$ & $\begin{array}{c}{[-43.265} \\
19.68]\end{array}$ & $\begin{array}{r}{[-59.683} \\
47.524]\end{array}$ & $\begin{array}{r}{[-36.005} \\
-19.464]\end{array}$ & $\begin{array}{r}{[-19.552} \\
-4.033]\end{array}$ & $\begin{array}{r}{[-14.883} \\
2.724]\end{array}$ & $\begin{array}{c}{[-103.617,} \\
90.92]\end{array}$ \\
\hline \multirow[t]{2}{*}{ Mortgage Delinquency } & $\begin{array}{c}-191.289 \\
(199.575)\end{array}$ & $\begin{array}{c}-176.85 \\
(120.781)\end{array}$ & $\begin{array}{c}-207.937 \\
(206.156)\end{array}$ & $\begin{array}{c}-177.245 \\
(354.14)\end{array}$ & $\begin{array}{c}-176.85 * \\
(30.91)\end{array}$ & $\begin{array}{c}-207.937 * \\
(44.385)\end{array}$ & $\begin{array}{r}-177.245 * \\
(46.654)\end{array}$ & $\begin{array}{c}-203.656 \\
(637.61)\end{array}$ \\
\hline & $\begin{array}{r}{[-561.431,} \\
178.853]\end{array}$ & $\begin{array}{c}{[-413.58,} \\
59.881]\end{array}$ & {$\left[\begin{array}{r}-612.002 \\
196.128]\end{array}\right.$} & $\begin{array}{c}{[-871.359,} \\
516.87]\end{array}$ & $\begin{array}{r}{[-237.433} \\
-116.266]\end{array}$ & $\begin{array}{r}{[-294.932} \\
-120.942]\end{array}$ & $\begin{array}{r}{[-268.687} \\
-85.803]\end{array}$ & $\begin{array}{r}{[-1453.348} \\
1046.036]\end{array}$ \\
\hline \multirow[t]{2}{*}{ Total Delinquency / Avg. Balance } & $\begin{array}{c}-0.003 \\
(0.002)\end{array}$ & $\begin{array}{r}-0.004 * \\
(0.001)\end{array}$ & $\begin{array}{c}-0.002 \\
(0.002)\end{array}$ & $\begin{array}{c}-0.002 \\
(0.004)\end{array}$ & $\begin{array}{c}-0.004 * \\
(0.001)\end{array}$ & $\begin{array}{c}-0.002 * \\
(0.001)\end{array}$ & $\begin{array}{r}-0.002 * \\
(0.001)\end{array}$ & $\begin{array}{c}-0.003 \\
(0.007)\end{array}$ \\
\hline & $\begin{array}{r}{[-0.007} \\
0.001]\end{array}$ & $\begin{array}{r}{[-0.007} \\
-0.002]\end{array}$ & {$\left[\begin{array}{r}-0.007 \\
0.002]\end{array}\right.$} & {$\left[\begin{array}{c}{[-0.01} \\
0.005\end{array}\right]$} & $\begin{array}{l}{[-0.006} \\
-0.003]\end{array}$ & $\begin{array}{r}{[-0.004} \\
-0.001]\end{array}$ & $\begin{array}{r}{[-0.004,} \\
-0.001]\end{array}$ & $\begin{array}{c}{[-0.017,} \\
0.01]\end{array}$ \\
\hline \multirow[t]{2}{*}{ Credit Card Delinquency / Avg. Balance } & $\begin{array}{c}-0.003 \\
(0.003)\end{array}$ & $\begin{array}{c}-0.008 * \\
(0.002)\end{array}$ & $\begin{array}{c}-0.001 \\
(0.003)\end{array}$ & $\begin{array}{c}-0.001 \\
(0.005)\end{array}$ & $\begin{array}{c}-0.008 * \\
(0.002)\end{array}$ & $\begin{array}{c}-0.001 * \\
(0.001)\end{array}$ & $\begin{array}{c}-0.001 \\
(0.001)\end{array}$ & $\begin{array}{c}-0.001 \\
(0.009)\end{array}$ \\
\hline & {$\left[\begin{array}{r}-0.009 \\
0.003]\end{array}\right.$} & $\begin{array}{l}{[-0.011} \\
-0.004]\end{array}$ & {$\left[\begin{array}{r}-0.007 \\
0.005]\end{array}\right.$} & $\begin{array}{r}{[-0.011} \\
0.009]\end{array}$ & $\begin{array}{l}{[-0.011} \\
-0.004]\end{array}$ & $\begin{array}{c}{[-0.002,} \\
0]\end{array}$ & {$\left[\begin{array}{r}-0.002 \\
0.001]\end{array}\right.$} & {$\left[\begin{array}{c}-0.02 \\
0.017]\end{array}\right.$} \\
\hline \multirow[t]{2}{*}{ Mortgage Delinquency / Avg. Balance } & $\begin{array}{c}-0.003 \\
(0.003)\end{array}$ & $\begin{array}{c}-0.005 * \\
(0.002)\end{array}$ & $\begin{array}{c}-0.003 \\
(0.003)\end{array}$ & $\begin{array}{c}-0.003 \\
(0.005)\end{array}$ & $\begin{array}{c}-0.005 * \\
(0.001)\end{array}$ & $\begin{array}{c}-0.003 * \\
(0.001)\end{array}$ & $\begin{array}{c}-0.003 * \\
(0.001)\end{array}$ & $\begin{array}{c}-0.004 \\
(0.008)\end{array}$ \\
\hline & {$\left[\begin{array}{r}{[-0.008} \\
0.001]\end{array}\right.$} & $\begin{array}{r}{[-0.008} \\
-0.002]\end{array}$ & {$\left[\begin{array}{r}-0.008 \\
0.002]\end{array}\right.$} & $\begin{array}{r}{[-0.012} \\
0.006]\end{array}$ & $\begin{array}{r}{[-0.006} \\
-0.003]\end{array}$ & $\begin{array}{r}{[-0.005} \\
-0.001]\end{array}$ & $\begin{array}{r}{[-0.005} \\
-0.001]\end{array}$ & {$\left[\begin{array}{c}{[-0.02} \\
0.012\end{array}\right]$} \\
\hline \multicolumn{9}{|l|}{ Panel C: Other financial outcomes } \\
\hline \multirow[t]{2}{*}{ Risk Score } & $\begin{array}{c}0.818 \\
(1.516)\end{array}$ & $\begin{array}{r}1.199 \\
(0.87)\end{array}$ & $\begin{array}{c}0.645 \\
(1.515)\end{array}$ & $\begin{array}{c}0.682 \\
(2.57)\end{array}$ & $\begin{array}{c}1.199 * \\
(0.437)\end{array}$ & $\begin{array}{c}0.645 * \\
(0.135)\end{array}$ & $\begin{array}{r}0.682 * \\
(0.108)\end{array}$ & $\begin{array}{c}0.812 \\
(3.624)\end{array}$ \\
\hline & {$\left[\begin{array}{c}{[-2.3} \\
3.936]\end{array}\right.$} & $\begin{array}{r}{[-0.506,} \\
2.905]\end{array}$ & {$\left[\begin{array}{r}-2.324 \\
3.614\end{array}\right]$} & $\begin{array}{c}{[-4.357} \\
5.72]\end{array}$ & $\begin{array}{c}{[0.342,} \\
2.057]\end{array}$ & $\begin{array}{r}{[0.381} \\
0.909]\end{array}$ & $\begin{array}{c}{[0.471} \\
0.892]\end{array}$ & $\begin{array}{r}{[-6.291} \\
7.914]\end{array}$ \\
\hline \multirow[t]{2}{*}{ Foreclosure } & $\begin{array}{c}-0.005 \\
(0.005)\end{array}$ & $\begin{array}{c}-0.003 \\
(0.003)\end{array}$ & $\begin{array}{c}-0.001 \\
(0.005)\end{array}$ & $\begin{array}{l}-0.01 \\
(0.008)\end{array}$ & $\begin{array}{c}-0.003 \\
(0.002)\end{array}$ & $\begin{array}{c}-0.001 \\
(0.004)\end{array}$ & $\begin{array}{c}-0.01 * \\
(0.004)\end{array}$ & $\begin{array}{c}-0.015 \\
(0.012)\end{array}$ \\
\hline & $\begin{array}{r}{[-0.013} \\
0.003]\end{array}$ & $\begin{array}{r}{[-0.009} \\
0.002]\end{array}$ & {$\left[\begin{array}{r}{[-0.011,} \\
0.008]\end{array}\right.$} & $\begin{array}{r}{[-0.026} \\
0.006]\end{array}$ & $\begin{array}{c}{[-0.007} \\
0]\end{array}$ & $\begin{array}{r}{[-0.008} \\
0.006]\end{array}$ & $\begin{array}{r}{[-0.017} \\
-0.003]\end{array}$ & $\begin{array}{r}{[-0.039} \\
0.009]\end{array}$ \\
\hline \multirow[t]{2}{*}{ Bankruptcy } & $\begin{array}{c}-0.004 \\
(0.006)\end{array}$ & $\begin{array}{c}-0.006 \\
(0.003)\end{array}$ & $\begin{array}{c}-0.008 \\
(0.006)\end{array}$ & $\begin{array}{c}0.005 \\
(0.01)\end{array}$ & $\begin{array}{c}-0.006 * \\
(0.003)\end{array}$ & $\begin{array}{c}-0.008 \\
(0.005)\end{array}$ & $\begin{array}{c}0.005 \\
(0.006)\end{array}$ & $\begin{array}{c}0.002 \\
(0.013)\end{array}$ \\
\hline & {$\left[\begin{array}{r}-0.014 \\
0.006\end{array}\right.$} & {$\left[\begin{array}{r}{[-0.012} \\
0.001]\end{array}\right.$} & {$\left[\begin{array}{r}{[-0.019} \\
0.003]\end{array}\right.$} & $\begin{array}{r}{[-0.014} \\
0.024]\end{array}$ & {$\left[\begin{array}{c}{[-0.011,} \\
0]\end{array}\right.$} & {$\left[\begin{array}{r}-0.017 \\
0.001]\end{array}\right.$} & {$\left[\begin{array}{r}-0.006 \\
0.016]\end{array}\right.$} & {$\left[\begin{array}{r}{[0.025,} \\
0.028]\end{array}\right.$} \\
\hline
\end{tabular}

Note: This table reports the sensitivity of our main regression discontinuity estimates to alternative specifications. Column 1 reports the point estimate, standard error, and bias-adjusted 95\% confidence interval from a local linear regression using techniques from Kolesár and Rothe (2018). Columns 2-4 report the results of estimating the discontinuity at 65 using three parametric models and robust standard errors with linear, quadratic, and cubic age trends, respectively. Columns 2-4 report the results of estimating the discontinuity at 65 using three parametric models and clustering standard errors by age (the running variable) as in Lee and Card (2008) with linear, quadratic, and cubic age trends, respectively. Column 8 reports the results of estimating the discontinuity using the local linear regression model as in Calonico, Cattaneo and Titiunik (2015). The sample includes individuals who were age 55-75 between 2008 and 2017. Credit score data used is from Equifax Riskscore 3.0. See Section 2 for additional details on the outcomes and sample. Source: The financial health outcomes are based on 137,340,577 person-year observations from the New York Fed Consumer Credit Panel / Equifax, 2008-2017. 
Table A9: Geographic variation in counterfactual outcomes at age 65, with and without Medicare

\begin{tabular}{|c|c|c|c|c|c|c|c|c|c|}
\hline \multirow[b]{3}{*}{ Outcome } & \multicolumn{3}{|c|}{ Full sample, 2008-2017 } & \multicolumn{3}{|c|}{ Pre-ACA, 2008-2013 } & \multicolumn{3}{|c|}{ Post-ACA, 2014-2017 } \\
\hline & $\sigma_{65^{-}}$ & $\sigma_{65^{+}}$ & $\sigma_{65^{+}}^{2} / \sigma_{65^{-}}^{2}$ & $\sigma_{65^{-}}$ & $\sigma_{65^{+}}$ & $\sigma_{65^{+}}^{2} / \sigma_{65^{-}}^{2}$ & $\sigma_{65^{-}}$ & $\sigma_{65^{+}}$ & $\sigma_{65^{+}}^{2} / \sigma_{65^{-}}^{2}$ \\
\hline & $(1)$ & $(2)$ & (3) & $(4)$ & $(5)$ & (6) & (7) & $(8)$ & (9) \\
\hline $\begin{array}{l}\text { Panel A: Health insurance } \\
\text { Has health insurance coverage }\end{array}$ & 0.033 & 0.008 & 0.065 & 0.038 & 0.010 & 0.072 & 0.030 & 0.009 & 0.081 \\
\hline $\begin{array}{l}\text { Panel B: Debt in collections } \\
\text { Total Collections } \\
\text { Number of Collections } \\
\text { Collections }>0\end{array}$ & $\begin{array}{r}57.308 \\
0.082 \\
0.032\end{array}$ & $\begin{array}{r}31.160 \\
0.062 \\
0.027\end{array}$ & $\begin{array}{l}0.296 \\
0.585 \\
0.699\end{array}$ & $\begin{array}{r}60.317 \\
0.080 \\
0.031\end{array}$ & $\begin{array}{r}33.994 \\
0.071 \\
0.028\end{array}$ & $\begin{array}{l}0.318 \\
0.785 \\
0.801\end{array}$ & $\begin{array}{r}67.470 \\
0.088 \\
0.034\end{array}$ & $\begin{array}{r}36.568 \\
0.064 \\
0.028\end{array}$ & $\begin{array}{l}0.294 \\
0.531 \\
0.655\end{array}$ \\
\hline $\begin{array}{l}\text { Panel C: Debt in delinquency } \\
\text { Total Delinquency } \\
\text { Credit Card Delinquency } \\
\text { Mortgage Delinquency } \\
\text { Total Delinquency / Avg. Balance } \\
\text { Credit Card Delinquency / Avg. Balance } \\
\text { Mortgage Delinquency / Avg. Balance }\end{array}$ & $\begin{array}{r}1502.923 \\
111.725 \\
1283.376 \\
0.020 \\
0.024 \\
0.024\end{array}$ & $\begin{array}{r}1276.553 \\
102.992 \\
1095.950 \\
0.016 \\
0.024 \\
0.019\end{array}$ & $\begin{array}{l}0.721 \\
0.850 \\
0.729 \\
0.609 \\
0.975 \\
0.611\end{array}$ & $\begin{array}{r}2171.064 \\
158.566 \\
1992.038 \\
0.025 \\
0.033 \\
0.031\end{array}$ & $\begin{array}{r}2123.737 \\
152.141 \\
1807.377 \\
0.024 \\
0.037 \\
0.029\end{array}$ & $\begin{array}{l}0.957 \\
0.921 \\
0.823 \\
0.973 \\
1.232 \\
0.850\end{array}$ & $\begin{array}{r}1033.778 \\
110.415 \\
839.944 \\
0.015 \\
0.025 \\
0.017\end{array}$ & $\begin{array}{r}810.383 \\
101.932 \\
678.653 \\
0.012 \\
0.025 \\
0.014\end{array}$ & $\begin{array}{l}0.615 \\
0.852 \\
0.653 \\
0.603 \\
0.957 \\
0.610\end{array}$ \\
\hline $\begin{array}{l}\text { Panel D: Other financial outcomes } \\
\text { Risk Score } \\
\text { Foreclosure } \\
\text { Bankruptcy }\end{array}$ & $\begin{array}{r}16.715 \\
0.037 \\
0.063\end{array}$ & $\begin{array}{r}16.505 \\
0.034 \\
0.063\end{array}$ & $\begin{array}{l}0.975 \\
0.859 \\
0.985\end{array}$ & $\begin{array}{r}16.421 \\
0.067 \\
0.093\end{array}$ & $\begin{array}{r}17.323 \\
0.058 \\
0.098\end{array}$ & $\begin{array}{l}1.113 \\
0.759 \\
1.096\end{array}$ & $\begin{array}{r}18.423 \\
0.033 \\
0.061\end{array}$ & $\begin{array}{r}17.715 \\
0.038 \\
0.062\end{array}$ & $\begin{array}{l}0.925 \\
1.353 \\
1.051\end{array}$ \\
\hline
\end{tabular}

Note: This table reports the CZ-level standard deviations in our counterfactual estimates of health insurance and financial health outcomes at age 65, with and without Medicare, and the reduction in CZ-level variance at age 65 . Columns 1 and 2 contain the standard deviation of the CZ-level counterfactual estimates of health insurance and financial health outcomes at age 65, without and with Medicare respectively, over the course of the full study period (2008-2017). Column 3 measures the reduction in variance at age 65 due to eligibility for Medicare as $\sigma_{65^{+}}^{2} / \sigma_{65^{-}}^{2}$ in the full study period. Columns 4 and 5 contain the standard deviation of the CZ-level counterfactual estimates of health insurance and financial health outcomes at age 65, without and with Medicare respectively, in the pre-ACA period (2008-2013). Column 6 measures the reduction in variance at age 65 due to eligibility for Medicare as $\sigma_{65^{+}}^{2} / \sigma_{65^{-}}^{2}$ in the pre-ACA period. Columns 7 and 8 contain the standard deviation of the CZ-level counterfactual estimates of health insurance and financial health outcomes at age 65, without and with Medicare respectively, in the post-ACA period (2014-2017). Column 9 measures the reduction in variance at age 65 due to eligibility for Medicare as $\sigma_{65^{+}}^{2} / \sigma_{65^{-}}^{2}$ in the pre-ACA period. The sample includes individuals who were age 55-75 between 2008 and 2017. See Section 2 for additional details on the outcomes and sample. Source: CZ-level health insurance rates are from the American Community Survey, $2008-2017$. The financial health outcomes are based on 137,340,577 person-year observations from the New York Fed Consumer Credit Panel / Equifax, 2008-2017. 
Table A10: CZ-level correlates with counterfactual collections debt estimates at age 65, with and without Medicare

\begin{tabular}{|c|c|c|c|c|c|c|c|c|c|c|c|c|}
\hline \multirow[b]{3}{*}{ Correlate } & \multicolumn{4}{|c|}{ Full sample, 2008-2017 } & \multicolumn{4}{|c|}{ Pre-ACA, 2008-2013 } & \multicolumn{4}{|c|}{ Post-ACA, 2014-2017 } \\
\hline & $65^{-}$ & $65+$ & $\Delta$ & $65^{+} / 65^{-}$ & $65^{-}$ & $65+$ & $\Delta$ & $65^{+} / 65^{-}$ & $65^{-}$ & $65+$ & $\Delta$ & $65^{+} / 65^{-}$ \\
\hline & (1) & (2) & (3) & (4) & (5) & (6) & (7) & (8) & (9) & (10) & (11) & $(12)$ \\
\hline \multicolumn{13}{|l|}{ Panel A: CZ-level demographics } \\
\hline Black $(\%)$ & $\begin{array}{c}20.61 \\
(5.92)\end{array}$ & $\begin{array}{c}11.05 \\
(3.24)\end{array}$ & $\begin{array}{c}-9.56 \\
(4.22)\end{array}$ & 0.54 & $\begin{array}{l}14.97 \\
(6.04)\end{array}$ & $\begin{array}{c}11.81 \\
(4.19)\end{array}$ & $\begin{array}{c}-3.17 \\
(4.81)\end{array}$ & 0.79 & $\begin{array}{c}23.37 \\
(6.8)\end{array}$ & $\begin{array}{r}9.67 \\
(3.7)\end{array}$ & $\begin{array}{r}-13.69 \\
(5.05)\end{array}$ & 0.41 \\
\hline Greater than high school education (\%) & $\begin{array}{r}-27.87 \\
(3.25)\end{array}$ & $\begin{array}{r}-15.52 \\
(1.94)\end{array}$ & $\begin{array}{c}12.36 \\
(2.78)\end{array}$ & 0.56 & $\begin{array}{r}-22.09 \\
(3.63)\end{array}$ & $\begin{array}{c}-11.25 \\
(2.73)\end{array}$ & $\begin{array}{c}10.84 \\
(3.69)\end{array}$ & 0.51 & $\begin{array}{c}-34.65 \\
(4.46)\end{array}$ & $\begin{array}{r}-20.34 \\
(2.9)\end{array}$ & $\begin{array}{l}14.31 \\
(3.62)\end{array}$ & 0.59 \\
\hline Poverty rate $(\%)$ & $\begin{array}{l}23.2 \\
(4.96)\end{array}$ & $\begin{array}{c}17.37 \\
(3.12)\end{array}$ & $\begin{array}{c}-5.84 \\
(3.24)\end{array}$ & 0.75 & $\begin{array}{l}22.88 \\
(4.81)\end{array}$ & $\begin{array}{l}13.75 \\
(3.5)\end{array}$ & $\begin{array}{c}-9.12 \\
(3.97)\end{array}$ & 0.6 & $\begin{array}{c}24.95 \\
(6.89)\end{array}$ & $\begin{array}{c}22.23 \\
(6.32)\end{array}$ & $\begin{array}{c}-2.71 \\
(4.05)\end{array}$ & 0.89 \\
\hline Income per capita & $\begin{array}{c}-26.21 \\
(3.82)\end{array}$ & $\begin{array}{r}-14.44 \\
(2.11)\end{array}$ & $\begin{array}{l}11.76 \\
(2.84)\end{array}$ & 0.55 & $\begin{array}{c}-23.25 \\
(3.84)\end{array}$ & $\begin{array}{c}-9.97 \\
(2.72)\end{array}$ & $\begin{array}{l}13.27 \\
(3.4)\end{array}$ & 0.43 & $\begin{array}{r}-29.58 \\
(4.8)\end{array}$ & $\begin{array}{c}-19.57 \\
(3.35)\end{array}$ & $\begin{array}{l}10.01 \\
(3.62)\end{array}$ & 0.66 \\
\hline Median house value & $\begin{array}{r}-25.51 \\
(4.03)\end{array}$ & $\begin{array}{r}-12.99 \\
(2.75)\end{array}$ & $\begin{array}{c}12.52 \\
(2.41)\end{array}$ & 0.51 & $\begin{array}{r}-18.26 \\
(5.66)\end{array}$ & $\begin{array}{c}-7.26 \\
(4.02)\end{array}$ & $\begin{array}{l}11 \\
(3.92)\end{array}$ & 0.4 & $\begin{array}{r}-32.62 \\
(4.55)\end{array}$ & $\begin{array}{r}-19 \\
(2.99)\end{array}$ & $\begin{array}{c}13.62 \\
(3.06)\end{array}$ & 0.58 \\
\hline Physical disability $(\%)$ & $\begin{array}{c}25.28 \\
(3.96)\end{array}$ & $\begin{array}{l}11.19 \\
(2.72)\end{array}$ & $\begin{array}{r}-14.1 \\
\quad(2.81)\end{array}$ & 0.44 & $\begin{array}{l}19.37 \\
(4.62)\end{array}$ & $\begin{array}{c}4.95 \\
(4.09)\end{array}$ & $\begin{array}{c}-14.41 \\
(3.61)\end{array}$ & 0.26 & $\begin{array}{l}30.13 \\
(4.73)\end{array}$ & $\begin{array}{l}16.77 \\
(2.59)\end{array}$ & $\begin{array}{r}-13.36 \\
(3.9)\end{array}$ & 0.56 \\
\hline \multicolumn{13}{|c|}{ Panel B: CZ-level healthcare market characteristics } \\
\hline For-profit hospitals (\%) & $\begin{array}{l}31.02 \\
(3.99)\end{array}$ & $\begin{array}{l}17.17 \\
(2.73)\end{array}$ & $\begin{array}{r}-13.85 \\
(3.63)\end{array}$ & 0.55 & $\begin{array}{c}29.12 \\
(5.09)\end{array}$ & $\begin{array}{l}17.13 \\
(3.34)\end{array}$ & $\begin{array}{r}-11.99 \\
(5.15)\end{array}$ & 0.59 & $\begin{array}{c}34.06 \\
(6.45)\end{array}$ & $\begin{array}{c}20.22 \\
(7.16)\end{array}$ & $\begin{array}{c}-13.84 \\
(4.75)\end{array}$ & 0.59 \\
\hline Teaching hospitals (\%) & $\begin{array}{r}-19.63 \\
(4.67)\end{array}$ & $\begin{array}{c}-6.9 \\
(3.47)\end{array}$ & $\begin{array}{l}12.72 \\
(2.31)\end{array}$ & 0.35 & $\begin{array}{r}-14.62 \\
(5.8)\end{array}$ & $\begin{array}{c}0.28 \\
(5.01)\end{array}$ & $\begin{array}{l}14.9 \\
(2.89)\end{array}$ & -0.02 & $\begin{array}{r}-25.37 \\
(4.31)\end{array}$ & $\begin{array}{r}-14.63 \\
(2.69)\end{array}$ & $\begin{array}{l}10.74 \\
(2.71)\end{array}$ & 0.58 \\
\hline Hospital occupancy rate $(\%)$ & $\begin{array}{r}-16.38 \\
(3.45)\end{array}$ & $\begin{array}{c}-9.16 \\
(2.44)\end{array}$ & $\begin{array}{c}7.23 \\
(2.22)\end{array}$ & 0.56 & $\begin{array}{l}-14.81 \\
(4)\end{array}$ & $\begin{array}{c}-6.69 \\
(3.41)\end{array}$ & $\begin{array}{c}8.12 \\
(2.76)\end{array}$ & 0.45 & $\begin{array}{r}-20.43 \\
(4.31)\end{array}$ & $\begin{array}{r}-10.92 \\
(2.31)\end{array}$ & $\begin{array}{c}9.51 \\
(3.77)\end{array}$ & 0.53 \\
\hline Hospital beds per capita & $\begin{array}{c}3.47 \\
(2.58)\end{array}$ & $\begin{array}{c}3.11 \\
(1.81)\end{array}$ & $\begin{array}{c}-0.35 \\
(1.64)\end{array}$ & 0.9 & $\begin{array}{l}1.7 \\
(2.75)\end{array}$ & $\begin{array}{c}-0.15 \\
(1.73)\end{array}$ & $\begin{array}{c}-1.85 \\
(2.14)\end{array}$ & -0.09 & $\begin{array}{c}7.13 \\
(4.09)\end{array}$ & $\begin{array}{c}6.68 \\
(2.33)\end{array}$ & $\begin{array}{c}-0.45 \\
(3.36)\end{array}$ & 0.94 \\
\hline Cost of charity care per patient day (\$) & $\begin{array}{c}4.56 \\
(6.52)\end{array}$ & $\begin{array}{l}6.35 \\
(3.56)\end{array}$ & $\begin{array}{c}1.79 \\
(3.82)\end{array}$ & 1.39 & $\begin{array}{c}6.48 \\
(5.64)\end{array}$ & $\begin{array}{l}10.57 \\
(4.39)\end{array}$ & $\begin{array}{c}4.09 \\
(4.25)\end{array}$ & 1.63 & $\begin{array}{c}2.17 \\
(8.55)\end{array}$ & $\begin{array}{c}2.35 \\
(4.8)\end{array}$ & $\begin{array}{c}0.18 \\
(4.78)\end{array}$ & 1.08 \\
\hline Payment by charity care patients $(\$)$ & $\begin{array}{c}0.42 \\
(2.75)\end{array}$ & $\begin{array}{c}-0.64 \\
(1.67)\end{array}$ & $\begin{array}{c}-1.06 \\
(1.77)\end{array}$ & -1.53 & $\begin{array}{c}-1.19 \\
(2.53)\end{array}$ & $\begin{array}{c}-4.15 \\
(1.56)\end{array}$ & $\begin{array}{c}-2.96 \\
(1.91)\end{array}$ & 3.48 & $\begin{array}{l}2.51 \\
(4.7)\end{array}$ & $\begin{array}{l}2.34 \\
(2.87)\end{array}$ & $\begin{array}{c}-0.17 \\
(2.86)\end{array}$ & 0.93 \\
\hline Medicare spending per enrollee (\$) & $\begin{array}{c}22.65 \\
(4.43)\end{array}$ & $\begin{array}{c}16.13 \\
(2.58)\end{array}$ & $\begin{array}{c}-6.53 \\
(3.47)\end{array}$ & 0.71 & $\begin{array}{l}19.24 \\
(4.66)\end{array}$ & $\begin{array}{c}19.66 \\
(4.36)\end{array}$ & $\begin{array}{c}0.41 \\
(4.15)\end{array}$ & 1.02 & $\begin{array}{l}22.5 \\
(6.02)\end{array}$ & $\begin{array}{c}12.24 \\
(2.88)\end{array}$ & $\begin{array}{r}-10.26 \\
(4.79)\end{array}$ & 0.54 \\
\hline Has any coverage $(\%)$ & $\begin{array}{r}-36.63 \\
(3.69)\end{array}$ & $\begin{array}{r}-22.99 \\
(2.77)\end{array}$ & $\begin{array}{l}13.64 \\
(3.13)\end{array}$ & 0.63 & $\begin{array}{r}-32.07 \\
(4.26)\end{array}$ & $\begin{array}{c}-20.9 \\
(4.56)\end{array}$ & $\begin{array}{c}11.17 \\
(3.89)\end{array}$ & 0.65 & $\begin{array}{r}-43.61 \\
(6.68)\end{array}$ & $\begin{array}{r}-27.82 \\
(6.79)\end{array}$ & $\begin{array}{l}15.79 \\
(5.34)\end{array}$ & 0.64 \\
\hline Has Medicaid (\%) & $\begin{array}{r}-13.36 \\
(3.83) \\
\end{array}$ & $\begin{array}{c}-3.91 \\
(3.26) \\
\end{array}$ & $\begin{array}{c}9.46 \\
(2.43) \\
\end{array}$ & 0.29 & $\begin{array}{c}-6.89 \\
(5.04) \\
\end{array}$ & $\begin{array}{c}-0.24 \\
(5.12)\end{array}$ & $\begin{array}{r}6.65 \\
(3.59) \\
\end{array}$ & 0.03 & $\begin{array}{r}-19.41 \\
(4.3) \\
\end{array}$ & $\begin{array}{c}-7.87 \\
(2.75)\end{array}$ & $\begin{array}{l}11.54 \\
(3.55)\end{array}$ & 0.41 \\
\hline
\end{tabular}

Note: This table reports the coefficients in a bivariate OLS regression of our counterfactual estimates of collections debt at age 65, with and without Medicare, on CZ-level correlates, the change in the coefficient at age 65. Columns 1-4 use the full sample, 2008-2017. Columns 1 and 2 report the coefficients from bivariate OLS regressions of the counterfactual estimates of collections debt at age 65 without and with Medicare, respectively, on each CZ-level correlate. Column 3 contains the difference in the coefficients. Column 4 contains the value of the coefficient with Medicare divided by the value of the coefficient without Medicare. Columns 5-8 use the pre-ACA sample, 2008-2013. Columns 5 and 6 report the coefficients from bivariate OLS regressions of the counterfactual estimates of collections debt at age 65 without and with Medicare, respectively, on each CZ-level correlate. Column 7 contains the difference in the coefficients. Column 8 contains the value of the coefficient with Medicare divided by the value of the coefficient without Medicare. Columns 9-12 use the post-ACA sample, 2014-2017. Columns 9 and 10 report the coefficients from bivariate OLS regressions of the counterfactual estimates of collections debt at age 65 without and with Medicare, respectively, on each CZlevel correlate. Column 11 contains the difference in the coefficients. Column 14 contains the value of the coefficient with Medicare divided by the value of the coefficient without Medicare. See Section 2 for additional details on the outcomes and sample. Source: CZ-level health insurance rates are from the American Community Survey, $2008-2017$. The financial health outcomes are based on 137,340,577 person-year observations from the New York Fed Consumer Credit Panel / Equifax, 2008-2017. Healthcare market characteristics are from the Healthcare Cost Report Information System (HCRIS) and the Dartmouth Atlas. 


\section{Table A11: Location-specific estimates and forecasts for 50 largest CZs}

\begin{tabular}{|c|c|c|c|c|c|}
\hline \multirow[b]{3}{*}{ State } & \multirow[b]{3}{*}{$\mathrm{CZ}$} & \multicolumn{2}{|c|}{ Per capita } & \multicolumn{2}{|c|}{ Per newly-insured } \\
\hline & & $\gamma_{l}^{f}$ & RMSE & $\beta_{l}^{f}$ & RMSE \\
\hline & & (1) & (2) & (3) & (4) \\
\hline Arizona & Phoenix & -23 & 11 & -260 & 137 \\
\hline Arizona & Tucson & -26 & 12 & -368 & 122 \\
\hline California & Fresno & -15 & 13 & -235 & 155 \\
\hline California & Los Angeles & -24 & 11 & -264 & 133 \\
\hline California & Sacramento & -17 & 8 & -253 & 99 \\
\hline California & San Diego & -27 & 7 & -369 & 126 \\
\hline California & San Francisco & -8 & 10 & -171 & 136 \\
\hline California & San Jose & -14 & 12 & -220 & 161 \\
\hline Colorado & Denver & -25 & 6 & -389 & 81 \\
\hline Connecticut & Bridgeport & -15 & 3 & -270 & 59 \\
\hline District of Columbia & Washington DC & -20 & 10 & -503 & 149 \\
\hline Florida & Miami & -51 & 12 & -444 & 116 \\
\hline Florida & Orlando & -36 & 13 & -456 & 166 \\
\hline Florida & Port St. Lucie & -48 & 13 & -589 & 160 \\
\hline Florida & Tampa & -44 & 13 & -466 & 153 \\
\hline Georgia & Atlanta & -37 & 12 & -558 & 148 \\
\hline Illinois & Chicago & -16 & 9 & -316 & 127 \\
\hline Indiana & Indianapolis & -37 & 11 & -513 & 143 \\
\hline Kentucky & Louisville & -22 & 12 & -374 & 155 \\
\hline Louisiana & New Orleans & -42 & 13 & -609 & 169 \\
\hline Maryland & Baltimore & -20 & 12 & -564 & 165 \\
\hline Massachusetts & Boston & -13 & 8 & -360 & 165 \\
\hline Michigan & Detroit & -19 & 11 & -419 & 159 \\
\hline Michigan & Grand Rapids & -8 & 12 & -165 & 157 \\
\hline Minnesota & Minneapolis & -4 & 9 & -194 & 154 \\
\hline Missouri & Kansas City & -33 & 13 & -409 & 159 \\
\hline Missouri & St. Louis & -26 & 10 & -470 & 137 \\
\hline Nevada & Las Vegas & -46 & 12 & -484 & 144 \\
\hline New Hampshire & Manchester & -11 & 11 & -191 & 143 \\
\hline New Jersey & Newark & -17 & 7 & -251 & 89 \\
\hline New Jersey & Toms River & -14 & 10 & -281 & 142 \\
\hline New York & Buffalo & -14 & 3 & -444 & 59 \\
\hline New York & New York City & -11 & 6 & -254 & 100 \\
\hline North Carolina & Charlotte & -46 & 13 & -624 & 166 \\
\hline North Carolina & Raleigh & -48 & 11 & -761 & 131 \\
\hline Ohio & Cincinnati & -24 & 9 & -435 & 117 \\
\hline Ohio & Cleveland & -15 & 10 & -318 & 145 \\
\hline Ohio & Columbus & -36 & 6 & -726 & 58 \\
\hline Oregon & Portland & -10 & 5 & -161 & 76 \\
\hline Pennsylvania & Philadelphia & -17 & 6 & -345 & 78 \\
\hline Pennsylvania & Pittsburgh & -18 & 11 & -319 & 160 \\
\hline Rhode Island & Providence & -2 & 7 & -135 & 133 \\
\hline Tennessee & Nashville & -48 & 8 & -590 & 73 \\
\hline Texas & Austin & -37 & 13 & -372 & 161 \\
\hline Texas & Dallas & -44 & 13 & -493 & 155 \\
\hline Texas & Fort Worth & -45 & 12 & -510 & 108 \\
\hline Texas & Houston & -42 & 12 & -426 & 124 \\
\hline Texas & San Antonio & -35 & 13 & -307 & 162 \\
\hline Washington & Seattle & -24 & 10 & -376 & 150 \\
\hline Wisconsin & Milwaukee & -28 & 10 & -404 & 151 \\
\hline
\end{tabular}

Note: This table reports the mean square error (MSE)-minimizing forecasts of the reductions in collections debt per capita and the reduction in collections debt per newly-insured for the 50 most populous CZs based on their near-elderly population. We construct the MSE-minimizing forecasting by first running a Lasso regression to predict the CZ-level reductions in collections debt per capita (or per newly-insured). This generates a prediction for each CZ, which we call $\hat{\gamma}_{l}$. Following Chetty and Hendren (2018) we then combine the $\hat{\gamma}_{l}$ estimates with our estimates of $\gamma_{l}$ to construct the mean square error-minimizing forecast for each commuting zone, $\gamma_{l}^{f}$, which we present in Column 1. Column 2 presents the root-mean-square error (RMSE) which is calculated using methods from Chetty and Hendren (2018). Column 3 reports the mean square error-minimizing forecast of the reduction in collections debt per newly-insured associated with a (nearly) universal health insurance expansion, $\beta_{l}^{f}$. Column 4 presents the RMSE for $\beta_{l}^{f}$. Source: Consumer credit outcomes are based on 137,340,577 person-year observations from the New York Fed Consumer Credit Panel / Equifax, 2008-2017. CZ-level uninsurance rates are from the American Community Survey, 2008-2017. Healthcare market characteristics are from the Healthcare Cost Report Information System (HCRIS) and the Dartmouth Atlas. For details on the data see Section 2. 